\title{
Grounding Motivation for Behaviour Change
}

\author{
Esther K. Papies Esther.Papies@glasgow.ac.uk \\ Lawrence W. Barsalou Lawrence.Barsalou@glasgow.ac.uk \\ Maria Almudena Claassen MariaAlmudena.Claassen@glasgow.ac.uk \\ Tess Davis t.davis.3@ research.gla.ac.uk \\ Stephanie T. Farrar Stephanie.Farrar@glasgow.ac.uk \\ Elodie Gauthier Elodie Gauthier@glasgow.ac.uk \\ Amy Rodger 2125525R@student.gla.ac.uk \\ Betül Tatar b.tatar.1@ research.gla.ac.uk \\ Lara H. Wehbe 1.wehbe.1@ research.gla.ac.uk \\ Johanna Werner j.werner.1@research.gla.ac.uk
}

Corresponding author: Esther K. Papies, School of Psychology and Neuroscience, University of Glasgow, 62 Hillhead Street, Glasgow G12 8QB, United Kingdom.

This manuscript will appear in B. Gawronski (Ed.), Advances in Experimental Social Psychology (Vol. 65). Academic Press.

The preparation of this chapter was partially funded by ESRC Research Grant ES/R005419/1 and ESRC Research Grant ES/T011343/1 awarded to EKP, and by PhD funding of the Scottish Graduate School of Social Science awarded to TD and AR. We are grateful to members of the Healthy Cognition Lab for useful feedback and discussion. 


\begin{abstract}
Many of the key problems humans are facing today result from desires, habits, and social norms impeding behaviour change. Here, we apply a grounded cognition perspective to these phenomena, suggesting that simulating the consequences of one's actions plays a key role in them. We first describe the grounded cognition theory of desire and motivated behaviour, and present evidence on how consumption and reward simulations underlie people's representation of appetitive stimuli and guide motivated behaviour. Then, we discuss how the theory can be used to understand the effects of habits, social norms, and various self-regulation strategies. We suggest conceptualising behaviour change as overcoming the simulations of hedonic and social reward that favour existing habits and behaviours, and as updating situated representations of motivated behaviours in their social context. We discuss how this perspective can help us understand the challenges that people experience in initiating and repeating new behaviours, and in high-impact decision making in the face of the status quo. In order to move beyond the socially sanctioned, habitual behaviours that currently threaten human and planetary health, we must understand what motivates them, and how this motivation can be harnessed for the greater good.
\end{abstract}




\section{Introduction}

Many of the key problems humans are facing today are problems of behaviour change. More often than not, behaviour is the key challenge that needs to be addressed to safeguard or improve human and planetary health, and in fact, survival. The epidemics of non-communicable diseases like overweight, diabetes, and cardiovascular disease, for example, result from behaviours. Although the root cause of many such conditions can often be found in structural factors like deprivation and social inequality, behaviours play a causal role in their etiology, for example overconsumption of high-calorie foods and sedentary habits. Similarly, our current, existential crises of climate change and ecological breakdown result from behaviours. These are behaviours of industry decision makers, such as pursuing profit from extracting fossil fuels; behaviours of public office holders, for example failure to pursue or enact policy changes to decarbonize infrastructure; and behaviours of individual consumers, for example consuming meat, buying fast fashion, and driving fossil-fuel powered cars.

\subsection{The evidence-behaviour gap}

In most domains where behaviour change is the key problem, there is no lack of information on effective mitigation measures. Indeed, on a policy level, there is sufficient evidence that behaviours such as changing financial incentives for and availability of "undesirable" products is effective to reduce their consumption and prevent harmful effects (e.g., Marteau, 2017; Peterson et al., 1992; Scarborough et al., 2020). On the level of individual actors, there is sufficient evidence that behaviours such as, for example, consuming plant-based foods and active travel protect both individual and planetary health (e.g., Chapman et al., 2018; Clark et al., 2019; Springmann et al., 2018). Despite this clear evidence, however, changing our ways is hard, and it is harder than many people seem to expect. Clearly, much behaviour of individual citizens and policy makers is not directed at beneficial long-term outcomes in a "rational" or evidence-based way. 
To be sure, there is now clear recognition of the intention-behaviour gap in social and health psychological research (e.g., Marteau et al., 2012; Sheeran \& Webb, 2016). This reflects the finding that intentions are often not translated into action. In other words, scientists are aware that providing information and forming good intentions is not enough to change behaviour. Instead, motivational processes like short-term desires, habits, and social norms often interfere (e.g., Papies, 2017; Sheeran $\&$ Webb, 2016). However, public health policy is still often based on the assumption that "knowledge and information drive behaviour" and that "it's just about getting the message across" to citizens (Kelly \& Barker, 2016). Scientists themselves seem to commit the same fallacy with regard to communicating research findings to policy makers. Specifically, scientists (and citizens) often seem to operate on the assumption that informing policy makers of the evidence base will suffice to motivate them to implement the appropriate policies.

In contrast to the view that some decision makers are fully "rational" and act purely on the evidence provided to them, it's probably safe to assume that all decision makers are to some degree affected by motivational processes like desires, habits, and social norms, which may limit any direct effect of information on behaviour. This will apply to citizens and consumers who make, for example, food or transport decisions in their daily lives as private individuals. But it will equally apply to individuals in other roles who act as organisational decision makers in the public and private sector, as well as public office holders who decide on policies that then provide the context for citizens' and organisations' behaviours (see also Nielsen et al., 2021; Whitmarsh et al., 2021). In addition, it has been suggested that for some new policies, for example in the domain of renewable energy, the precise content and consequences of policies are often not fully clear to legislators at the time of enactment. This has been termed "the fog of enactment" and will leave even more room for nonconscious motivational processes among individual decision makers to affect outcomes (Stokes, 2020). 
As an example of how nonconscious motivational processes may play out, a policy maker considering an active travel policy for their local community may be influenced by their own travel habits and preferences, by the fear of a public backlash in response to proposed changes, and by the desire to receive social approval for their plans. Thus, the anticipation of potential immediate, personal effects of their proposals will play a role in this kind of decision. In a similar way, an office worker planning their workplace lunch may be influenced not only by what they know is a healthy and affordable choice, but also by their short-term desire for a rewarding meal, their dietary habits, and the anticipated responses of co-workers to their choices. Thus, rather than bringing a salad from home, they may end up buying a tasty yet unhealthy meat-based meal at a nearby café. In this way, processes such as short-term desires, habits, and social norms may affect outcomes. In particular, they can reduce the degree to which a course of action is directed towards attaining long-term beneficial outcomes in an evidence-based way, and this can occur among individuals making decisions across levels of society.

\subsection{Overview}

The goal of the research program described in this chapter is to improve our understanding of the origins and development of such motivational processes. While most of the empirical work described here focuses on eating and drinking (e.g., consuming alcohol, sugary drinks, water, meat, plant-based foods), we will also discuss how these mechanisms can help understand motivational processes in other domains of appetitive behaviour. We will focus especially on the psychological processes underlying desire, but we propose that the same underlying mechanisms play out in other motivated behaviours as well, especially in how habits and social norms influence behaviour.

While most of our research has focused on the behaviour of people in their roles as citizens or consumers, we will discuss how the same processes may play out for individuals in other roles, for example within organisations and in public office. Recent work has emphasised how individuals in such roles, especially in higher socioeconomic positions, have disproportionate impact on 
greenhouse gas emissions, both because of the emissions associated with their activities, and because of their potential to influence decisions to reduce emissions on a structural level (e.g., through influencing organisations, affecting policy, or changing personal investment decisions; Nielsen et al., 2021). At the same time, most research does not address individuals in such roles, but focuses on downstream consumer behaviours that have a less wide-reaching impact (Whitmarsh et al., 2021). Given that climate change from greenhouse gas emissions is the most existential problem our species has ever faced, we hope to contribute to an understanding of the cognitive processes involved in behaviour change in high-impact decisions.

In other words, after discussing research on the processes leading to desire for food and drink, we will address how the insights from this work can be expanded to the understanding of motivational processes relevant for behaviour change in three novel ways, namely 1) to domains of appetitive behaviour other than eating and drinking; 2) to understanding other motivated behaviours, for example related to habits or social norms; and 3) to behaviours of individuals in other social roles than citizens, e.g., policy makers, organisational decision makers, etc. In sum, we will address the role of grounded cognitive processes in regulating a variety of socially relevant behaviours, and their potential to support behaviour change in decision making across levels of society.

In brief, our theme here is that mentally simulating the consequences of one's actions plays a key role in desire and motivated behaviour. Specifically, simulations, or re-enactments, of socially, affectively, or physically rewarding outcomes, typically based on previous, similar experiences, can trigger desire and motivated behaviour to obtain that outcome. As examples, simulating the rewarding experience of enjoying a rich and savoury food, or of gaining explicit approval from people who one values, can motivate goal-directed behaviour such as choosing a lasagne in a restaurant, or purchasing a new item of clothing.

Critically, we suggest that reward simulations play a key role not only in regulating everyday behaviours, but also in behaviour change, both when this involves single decisions, and when it 
involves repeatedly initiating new behaviours and forming new habits. Specifically, and as we will address in more detail in the final section of this chapter, we propose that reward simulations can motivate or prevent a one-off behaviour, which is often important in policy decisions. They can motivate initiating new behaviours, which lend themselves to habit formation. They can support repeating a behaviour, which is key for habit maintenance. Conversely, they can prevent engaging in a novel behaviour if it is not sufficiently more appealing than a previous, alternative behaviour. Thus, simulations of the effects of one's behaviour can play important roles in motivated behaviour and behaviour change, with potentially wide-ranging effects on social processes. In this chapter, we will outline a theory of the mechanisms and functions of such simulations in motivated behaviour, describe the findings and implications of a research program testing this theory, and discuss its potential for understanding and changing behaviour in other, socially important domains.

\section{The grounded cognition theory of desire and motivated behaviour}

The grounded cognition theory of desire and motivated behaviour was developed to explain the emergence of desire for appetitive stimuli, originally in the domains of eating and drinking. In brief, the theory proposes that every episode of appetitive behaviour stores or updates a multimodal memory representation of the experience, which can later be activated in relevant situations. Through simulations, for example of possible actions and outcomes, such representations then created desire and guide motivated behaviour (see Figure 1 for an overview of core assumptions).

\subsection{Situated conceptualisations}

We refer to the memory representations that are formed during consumption episodes as situated conceptualisations (Barsalou, 2003, 2009, 2016b, 2016a), and suggest that they integrate various streams of information that may be relevant in a given situation. In the case of eating or drinking behaviour, this could include information about sensory features (e.g., the visual appearance of a food or drink, its taste, texture, temperature) and motor behaviour (e.g., picking up a food or a drinks container, using a fork or spoon, chewing). Situated conceptualisations can also include 
external context features (e.g., location, other people present, time of day, other foods or drinks present), as well as internal context features (e.g., bodily, cognitive, and affective states including hunger, cravings, happiness). In addition, situated conceptualisations can include the immediate consequences of consumption (e.g., feeling refreshed, hedonic enjoyment, reward, or satiation); immediate affective experiences (e.g., feeling happy, guilty, socially connected), as well as thoughts of longer-term goals (e.g., health, sustainability).

Imagine, for example, eating a burger in a country pub after a long autumn walk with a group of friends. You might encode the look, feel, taste, and texture of the burger as you pick it up and eat it; but you might also encode a variety of other aspects of the situation, for example the chatter of people, clatter of dishes, and other sounds in the pub; the features of the physical space around you; the look of the other food and drinks on the table and your friends around it; as well as the feelings of physical exhaustion, social connectedness, and pleasure of warming up inside after a long day spent in nature.

We suggest that the situated conceptualisations that we hold for consuming a particular food or drink are not accurate records of any one particular event, but rather statistical, dynamic assemblies of features accumulated over a number of similar experiences (Barsalou, 2016a, 2016b). When representations of several similar consumption episodes have been encoded, they might form a category of situated conceptualisations that share specific features, and can inform later action in a dynamic and adaptive way (Papies et al., 2017). As we have proposed previously (e.g., Papies et al., 2017), we suggest that situated conceptualisations can be learned or updated through observing experiences of others, as well as through one's own direct experiences. We will return to this idea, and to its implications for behaviour change, later in this chapter.

In a given situation, an internal or external cue or combination of cues will lead to the activation of the best matching existing situated conceptualisation, to interpret the situation and guide goal-directed behaviour. In other words, when an aspect of a previously formed memory pattern is 
encountered later (e.g., seeing a burger on a plate; hearing about a country walk), this can activate the associated situated conceptualisation (Barsalou, 2009), which can then then inform and guide behaviour through simulations of possible actions and outcomes.

\subsection{Simulations}

Situated conceptualisations can trigger simulations of other, non-present elements, including possible actions and outcomes, which can be experienced as expectancies or predictions if they reach conscious awareness. Such simulations can be useful for preparing specific, goal-directed motor behaviours (see Tucker \& Ellis, 1998). Seeing a burger on a plate, for example, can activate the motor action of picking it up with one's hands, whereas seeing soup in a bowl can activate the motor action of picking up a spoon to eat it. Importantly, simulations can also create desire and other motivated behaviours. To continue with the example above, seeing a burger can also activate a simulation of what it would feel like in one's hands, what biting into it would feel like, and what its taste, temperature, and mouthfeel may be like - based on previous, similar experiences. In other words, on seeing a burger, one can infer what it would be like to eat this in the moment, and whether this would be rewarding, given previous experiences with similar internal and external features. This can inform one's desire to consume the object, and for example, one's plans to cook food at home, or one's menu choices in a restaurant.

Simulations can be understood as modality-specific re-enactments of previously encoded perceptual information. They are not exact replays of previously encoded perceptual information, but are shaped by what is salient during encoding and retrieval. In line with the grounded cognition account more generally, we assume that during any consumption episode, modality-specific activity is stored in relevant neural systems used to process perception (Barsalou, 1999, 2008). When consuming a food or drink, memories of its taste, texture, the consumption context, and the experienced reward, are stored in the somatosensory, gustatory, visual, and motivational systems of the brain, forming into the situated conceptualizations described above. The brain can later re-enact 
these modality-specific patterns of activation. As a result, for example viewing an image of an attractive food can lead to modality-specific activations in gustatory and reward areas in the brain (e.g., Simmons et al., 2005), re-enacting the processing that happened when a similar food was consumed previously; or viewing an image of a cup can lead to activations in motor areas in the brain, again re-enacting the processing that happened when a similar item was picked up before (e.g., Tucker \& Ellis, 1998).

In this way, we propose that simulations are the mechanism through which situated conceptualisations produce reward predictions and desire. Processing part of a consumption-related situated conceptualisation can lead to the simulation of a rewarding consumption experience, using the same brain areas that were involved in processing reward previously during actual consumption. If a cue leads to a reward simulation in this way, it can create desire to consume, and drive motivated behaviour.

Our emphasis on simulations of outcomes or consequences of one's behaviour could be argued to resemble expected utility theory (e.g., P. A. Samuelson, 1952). Indeed, the two theories are compatible in that simulations could be argued to inform both the value or utility assigned to an outcome, as well as its perceived probability. In other words, the ease with which one can imagine an outcome occurring, and the hedonic or social reward that this outcome would produce, can shape what economists would refer to as expected utility. Critically, what we propose here goes well beyond expected utility theory in that we argue not only that simulations play a key role in determining the reward value of potential outcomes and in motivating behaviour, but that these simulations are best understood as grounded and situated cognitive processes. Thus, they are shaped by both past experiences, and by features of the present situation, as represented in the situated conceptualisations described above. In addition, most behaviours will trigger simulations of numerous related outcome features (e.g., the taste and texture of a food, its carbon footprint, its health implications, the social approval of consuming it), whose weighing and integration into one 
"utility" value will again be influenced by past learning and by current states (see also P. A. Samuelson, 1952). As a result, many different features can dynamically affect the simulations that determine preferences, including language (e.g., how a food is described), internal states (e.g., how hungry one feels), salient goals (e.g., dieting or indulgence goals), other people present (e.g., vegan friends or meat-loving colleagues), to name but a few, and this can differ between people and situations. The grounded cognition perspective presented here aims to provide a cognitively and neuroscientifically supported framework to establish and examine core features of these processes, despite their variability.

In sum, we argue that simulations arising from situated conceptualisations that were stored during previous consumption episodes can help to navigate the environment and support goaldirected behaviour. Again, we propose that such reward simulations could shape appetitive behaviours not only with regard to food and drink, but in other domains as well, and that they play a role in other kinds of motivated behaviour, including planning, habits, social norms, and selfregulation strategies.

\section{Empirical support for the role of simulations in desire}

Significant research now supports the role of simulations in desire and motivated behaviour. Here, we will review research on this topic from the domains of eating and drinking, focusing therefore on simulations of consumption and reward and their role in appetitive behaviour. First, we will discuss studies suggesting that consumption and reward simulations are activated when people process appetitive stimuli, suggesting that they form part of the cognitive representations of such stimuli, shaped by previous consumption behaviours. We will discuss how these simulations affect desire and behaviour, based on recent research in the domain of drinks. Then, we will turn specifically to the domain of meat-based vs. plant-based foods to illustrate how cognitive representations of foods reflect eating patterns and possibly eating identities, and how they inform the public discourse around sustainable diets. Then, we will discuss research showing how 
simulations are reflected in salivation to food cues, how situations affect desire through consumption simulations, and how simulations are consciously experienced.

\subsection{Establishing consumption and reward features and their motivational implications}

A number of studies suggest that when people cognitively process appetitive stimuli, they simulate consuming them. Studies in cognitive science show that when participants are asked to come up with category names for different foods, they often list categories that reflect eating experiences and specific settings, such as "foods you eat with a spoon", or "appetizers" (Blake et al., 2007; Ross \& Murphy, 1999). Thus, in addition to taxonomic categories (e.g., "fruits", "breads") people seem to draw on direct experiences of interacting with the foods, rather than on more distal information, such as "animal-based foods", "foods containing corn" or "colourful foods". Research where people describe foods, or list thematic relations between foods, also suggests that people think about foods in terms of consuming them in specific situations (e.g., "with friends", "party", “summer"; Jouravlev \& McRae, 2016; Keller \& van der Horst, 2013). Similarly, using a feature listing paradigm where participants list what is "typically true" of a food item, they list features describing eating experiences, such as "juicy” or "eaten with ice cream" (McRae et al., 2005). Although much of this research is not focused on food specifically, it does suggest that food, like other concepts is represented cognitively through simulations of previous interactions.

Building on these initial findings using the feature listing task, recent research in our lab has used this task to test the role of consumption and reward features for a variety of food and drink stimuli. In a feature listing task (also referred to as "property generation"), participants are usually asked to list features or properties that are "typically true" of an object, and research has shown that this leads to situated simulations, similar to deliberate imagery, and richer than mere linguistic word associations (Wu \& Barsalou, 2009). In our research, we have used these instructions in some studies, but in other studies, we have asked participants how they would simply "describe the object right now". Those adapted instructions might make the task more accessible to a variety of 
populations, and might bring the focus more on currently active representations. In an initial study (Papies, 2013), participants were asked to list features that are "typically true" of four temping (i.e., highly attractive yet unhealthy foods, such as chips, cookies) and four neutral (i.e., less attractive, healthier foods such as rice, apple). Results showed that the tempting foods were much more likely to be described with features reflecting eating simulations than the neutral foods. As in the category generation studies described above (e.g., Ross \& Murphy, 1999), participants drew on experiences of interacting with the foods when describing attractive foods, while less attractive foods were described with reference to more distal information. Specifically, participants listed more sensory features (e.g., taste, texture, temperature), hedonic features (e.g., enjoyment, reward), and eating situations (e.g., time, physical setting) for tempting than for neutral foods (53\% of features listed for temping food, vs. $26 \%$ of features listed for neutral food). Neutral foods, in contrast, were more heavily described with visual features (45\% of features listed), as well as ingredients, preparation, and category information. In other words, when describing what is "typically true" of foods, participants described experiences of eating the tempting foods, and the visual appearance of neutral foods.

We have since updated and refined the coding procedure for coding feature listing data (Papies, Tatar, et al., 2020), and developed an application in the programming language $R$ (R Core Team, 2018) to facilitate feature coding (Johannes, 2020). The hierarchical feature coding scheme requires any feature produced by a participant to first be categorised as a feature experienced predominantly in a consumption situation, in a non-consumption situation, or a feature that is situation-independent. Within the consumption situation category, a feature is then further assigned to subcategories of sensory and action features (taste and flavour; texture; temperature; smell; auditory; action), contextual features (internal, such as bodily, cognitive, or emotional context of eating; or external, such as physical, time, or social setting), or features referring to the immediate positive and negative consequences of consumption (such as bodily, cognitive, emotional, hedonic, 
or social consequences). Within the non-consumption situation category, a feature can be categorised as referring to origins and production, package, purchase, preparation and storage, or the cultural embeddedness of a food or drink. Finally, situation-independent features comprise ingredients and content features, visual features, long-term health consequences, general evaluations, category and linguistic information, and other uses and facts of a food or drink. In total, the coding scheme consists of 46 categories at the lowest level, to which a feature can be assigned. With the use of this manual, a tremendous variety of food and drink features can be categorised systematically and reliably. Potentially, this scheme could be adapted for the use in other domains of appetitive behaviour as well, allowing researchers to establish representations of a variety of appetitive objects.

When using the feature listing task and the detailed coding scheme (Papies, Tatar, et al., 2020) in the domain of drinks, we found similar patterns as in the domain of foods (Keesman et al., 2018). Here, when participants ( $\mathrm{N}=110$ in the laboratory; $\mathrm{N}=56$ in a bar) listed features for various alcoholic and non-alcoholic drinks, they described these heavily in terms of consumption, especially the alcoholic drinks that they usually consumed, and sugary drinks. The alcoholic drinks that they most frequently consumed were also more heavily described in terms of social drinking situations than any other drink. Again, these findings suggest that when listing "typical" features, participants simulated consuming these drinks in specific situations. In addition, representing drinks in terms of social drinking situations was associated with a variety of measures of intrusive alcohol thoughts, alcohol cravings, and alcohol choices in a laboratory setting. In other words, participants who think about alcoholic drinks in terms of social drinking are more likely to have strong, possibly problematic desires for it.

A recent set of experiments (Papies et al., 2021) extended these findings to the domain of sugar-sweetened beverages and found again that attractive drinks (i.e., sugar-sweetened beverages) were more described in terms of consumption and reward than neutral drinks (i.e., bottled and tap water). In three experiments (total $\mathrm{N}=457$ ), this pattern was found when listing "typical" features 
or "simply describing" drinks, and when doing so in response to drink words, drink images, or actual drinks. In addition, consumption and reward features were consistently associated with consumption frequency, such that stronger consumption habits predicted listing more consumption and reward features. Although this pattern was descriptively more pronounced for the sugary drinks than for water, it was observed across drinks. In other words, when participants consumed a drink more frequently, they were more likely to think about it in terms of what it tastes and feels like, and how enjoyable it is (see Figure 2).

The experiments also demonstrated the richness and variability of participants' representations of appetitive objects. While participants were instructed to list at least five features per drink - and complied with this instruction on average - they produced hundreds of unique features for each drink. Indeed, the features pointed to rich, highly variable and detailed individual consumption experiences underlying participants' representations (e.g., "sweet”, "sticky", "tangy”, “on a hot day", “at the gym”, "satisfying”, “nice”, "awake”, “guilt”, “energy”). These findings suggest that participants simulated drinking and enjoying the drinks when asked to describe them or list their typical features. In other words, when thinking about appetitive stimuli, people re-enact some aspects of previous consumption situations that they have experienced, for example salient sensory, hedonic, or contextual features, and some of these are captured in the feature listing task used to access cognitive representations of appetitive stimuli.

Critically, consumption and reward features reliably predicted desire, and they predicted intake in the laboratory (see Figure 3). In two online experiments, participants who listed more consumption and reward features for a drink reported higher desire for it. This pattern was also found when desire was measured first, before the feature listing task that assessed consumption and reward features - albeit the association was then weaker. To assess intake, after the feature listing task, participants were presented with two sugar-sweetened beverages and two types of water in a square, so that no particular order of consumption was implied. For an alleged taste test, they 
sampled some of each drink, and they were told that they could consume as much of it as they wished. As predicted, listing consumption and reward features for a drink was associated with drinking more of it, and again this held for both sugary drinks and water, and it was also the case when controlling for typical consumption frequency. Thus, thinking about drinks in terms of consumption and reward is not only the by-product of consumption habits, but also has a unique effect on behaviour in addition to those habits.

When examining the representations of sugar-sweetened beverages and water, we had assumed that these would be shaped by thirst. Specifically, because the grounded cognition theory of desire and motivated behaviour posits that cognitive representations underlie the simulations that support effective goal-directed action, we predicted that thirstier participants would report stronger consumption and reward simulations, and that these would lead them to consume more of the drinks. In other words, being in a state of thirst would activate a representation of consuming a drink in a similarly thirsty state previously, where the drink may have been particularly rewarding (Papies et al., 2015). We did not find reliable correlational effects of thirst in two studies. Therefore, we manipulated thirst in the laboratory experiment, where we also offered participants the drinks for ad libitum consumption after feature listing.

Much to our surprise, thirsty participants did not drink more than non-thirsty participants. Specifically, participants who had not consumed any drink for more than two hours drank a mere 13 $\mathrm{ml}$ more than participants who had just consumed 0.51 of a cold beverage. In line with this finding, but contrary to our hypotheses, thirsty participants also did not differ in their feature listing patterns from non-thirsty participants. Notably, we had adapted the feature listing instructions to allow an effect of the momentary physical state to emerge, asking participants how they would describe each drink "right now", as compared to asking them to listing "typical" features. In addition, the drinks were positioned right in front of participants, and participants knew that they would sample them later. While this was designed to maximise the degree to which features would reflect action 
relevance, and thus the consumption and reward simulations presumably enhanced by thirst, it may have done so for all participants, overriding thirst effects. Indeed, the proportion of consumption and reward features was higher in this "live" experiment compared to computer-based studies with drink words or pictures. Since consumption and reward features did predict desire and intake, it seems that thinking about the drinks in terms of drinking and enjoying them affected motivated behaviour more than the physiological state of thirst. In other words, the effects of consumption and reward simulations seemed to fully override the effects of interoceptive cues of thirst.

It is possible that participants representations of drinks are not more rewarding when thirsty because most drinks are not consumed in response to thirst, and are not experienced as more rewarding when thirsty. In other words, participants' learning histories with non-alcoholic drinks do not include increased reward when thirsty. Indeed, this would be entirely consistent with our finding in the laboratory, where thirst did not affect intake. Rather than drinking to quench their thirst, participants may drink because they anticipate pleasure, perhaps from a drink's sensory features, or other rewarding outcomes, such as relaxation (see also Rodger et al., 2021). This is also in line with recent findings from a large-scale interview study with UK participants $(\mathrm{N}=60)$, where we found that participants regularly ignore, avoid, or suppress thirst cues (Rodger et al., 2021). However, it is also possible that the feature listing method is not sensitive enough to detect small changes in cognitive representations that could be induced by slight fluid deprivation. Finally, it is entirely possible that physiological states do not meaningfully affect cognitive representations of appetitive objects. This would be inconsistent with assumptions of the grounded cognition theory of desire that cognitive representations support simulations in the service of goal-directed action. Future research should continue to examine this question, including with tasks other than feature listing, and with stronger manipulations.

It is notable that health-related features are not salient in participants' representations of food and drink. In Papies (2013), 8\% of features listed for tempting foods (chips, cookies) referred to 
negative long-term health consequences (e.g., "makes you fat", "unhealthy"), and 7\% of features listed for neutral foods (e.g., rice, apple) referred to positive long-term health consequences (e.g., "healthy", "nutritious"). Similar percentage of health features were found in feature listing for nonalcoholic drinks (Papies et al., 2021). Here, across three experiments, the mentions of positive health features for sugar-sweetened beverages and of negative health features for water were negligible, which is not very surprising. However, unexpectedly, these figures were not much higher for drinks with much more salient health implications. For sugar-sweetened beverages, negative health features accounted for only 1-9\% of features across studies, and for water, positive health features accounted for 5-9\% of features. For frequently consumed alcoholic drinks (Keesman et al., 2018), only $1 \%$ of features were related to long-term health consequences. Especially for products so clearly unhealthy as chips, cola, and alcohol, the low salience of negative health consequence is striking. In contrast, the percentages of sensory features (e.g., taste, texture, temperature) for the attractive stimuli was typically around 30\%, and overall consumption and reward features (all sensory and action features, context features, immediate positive consequence features) averaged around 45-49\%. Health features did not predict intake of drinks (Papies et al., 2021). Consistent with our theory, this again suggests that people do not represent appetitive stimuli very much in terms of their long-term implications or other abstract or distal features, but rather in terms of the immediate and concrete experience of consuming them. This has important implications for behaviour change, which we will discuss in detail below.

In sum, the research on cognitive representations of food and drink stimuli discussed here shows that people represent them through rich, situated simulations of consuming and enjoying them, while health features are not salient. These rewarding simulations are more pronounced for more frequently consumed stimuli, and they in turn predict motivated behaviour.

\subsection{A causal role for cognitive representations in desire?}


In a recent experiment (Farrar et al., 2021), we manipulated participants' focus on different aspects of their food representations, while completing the feature listing task. This was designed to provide a more direct test of the causal role of cognitive representations of appetitive stimuli in desire. We instructed participants $(\mathrm{N}=1000)$ in a feature listing task to only list either health features, sensory features, hedonic features, or context features. We then compared their feature listing protocols and their desire for the foods with a control condition, where participants received a feature listing task without further instructions.

In line with the manipulation and our expectations, the sensory, hedonic, and context instructions increased consumption and reward features compared to the control, whereas the health instructions reduced consumption and reward features. While there was no main effect of the instructions on overall desire, we found the hypothesised indirect effect, such that the sensory, hedonic, and context focus conditions increased desire via consumption and reward simulations, whereas the health focus condition decreased desire via decreasing consumption and reward simulations. In these mediation analyses, it is possible that the direct effect on desire is weaker than the indirect effect (i.e., the effect of condition on consumption and reward features, and the association of consumption and reward features with desire), or that the dependent variable desire has high measurement error, leaving the experiment underpowered to detect a main effect (see Rucker et al., 2011). These possibilities should be examined in future research. Given the findings so far, it seems that increasing the salience of different aspects of representations through instructions can affect desire, mediated by increased salience of consumption and reward features. Thus, cognitive representations may indeed play a causal role in desire.

These findings are in line with recent experiments showing that focusing participants on certain features of foods changed their food preferences one day later (Dutriaux, Papies, et al., 2021). Here, participants were exposed to a number of foods and either a list of health-related features, or a list of hedonic features. For each food, they were instructed to indicate which of the given features 
applied to it. The next day, the same participants, plus an additional group of new "control" participants, were asked to indicate how much they would like to eat each food for a given meal. Results showed that participants who had focused on hedonic features made more hedonic choices one day later. Focusing on health-related features only affected the choices of participants with higher body weight, presumably because it engaged dietary restraint goals.

This research suggests that focusing attention on certain features of one's cognitive representations of foods can affect the representations activated during later food choices, and thus affect behaviour. This is in line with other recent research, which has shown that actively imagining the process of eating a food (which likely increases the salience of a food's taste and texture) increases preferences for "vice" foods over "virtue" foods, compared to imagining the outcomes of eating (which likely increases the salience of negative physical consequences; Muñoz-Vilches et al., 2019, 2020; Xie et al., 2016).

These findings are further consistent with lab and field experiments by Turnwald and colleagues (Turnwald, Boles, et al., 2017; Turnwald et al., 2019; Turnwald \& Crum, 2019), who have shown that food labels that emphasise the sensory and rewarding features of healthy foods can raise taste expectations of vegetable dishes - which are otherwise perceived as low in appeal - and therefore lead to increased consumption and liking. We suggest that these taste expectations are implemented as simulations of specific taste and reward experiences, based on similar previous experiences, which increase desire. Focus on health features, on the other hand, decreases the perceived appeal of the vegetable dishes. In contrast to the feature listing, endorsement, and imagery experiments described above (e.g., Dutriaux, Papies, et al., 2021; Farrar et al., 2021; Muñoz-Vilches et al., 2019) where participants drew on their own situated representations of eating the foods, participants here received "new" information about the presented foods (e.g., 'Sesame Garlic Roasted Broccoli with Creamy Tahini Sauce' vs. 'Smart Choice Broccoli'; Turnwald et al., 2019). However, both sets of findings show that representations that emphasises the sensory, hedonic, and 
context features typically forming central parts of rewarding eating experiences contribute to desire for a food, and we suggest that this is driven by consumption and reward simulations.

The research discussed in this section has shown that idiosyncratic aspects of previous consumption and reward experiences form a key part of people's rich and varied cognitive representations of appetitive stimuli. Frequently consumed and highly attractive stimuli are represented in terms of consuming and enjoying them. Consumption and reward features within cognitive representations predict desire and intake, more so than physiological needs. Finally, research manipulating the salience of different parts of cognitive representations points to a causal role of representations in motivated behaviour.

These findings are consistent with a body of research in the marketing literature (for a more detailed review, see Papies et al., 2017). This has shown, for example, that vividly imagining the taste, smell, and mouthfeel of a food increases expectations of enjoying it (e.g., Cornil \& Chandon, 2016; see also Larson et al., 2014). Similarly, spontaneous simulations of a food's sensory features can increase motivation to consume it, for example when such simulations are triggered by images that afford motor actions of eating, or by slogans the refer to several sensory modalities (e.g., Elder \& Krishna, 2010, 2012; Krishna et al., 2014).

Understanding the content of food and drink representations, and how situated simulations based on these representations affect motivated behaviour, may be useful for facilitating effective behaviour change. We will now turn to a particularly timely application of this research, namely the representations of foods in the context of sustainable eating behaviour.

\subsection{Representations of plant-based foods}

Given the urgent need to eliminate greenhouse gas emissions that cause global warming, much attention within food research has turned to the question of how a reduction in meat consumption can be achieved. Food systems are responsible for about $34 \%$ of global greenhouse gas emissions, and a particularly high proportion of this comes from the production of red meat, 
especially beef (Crippa et al., 2021; Poore \& Nemecek, 2018). In fact, emissions from the food sector alone will likely result in a rise of global temperatures beyond the 1.5 degree Paris Agreement target between the years 2053 and 2061 (Clark et al., 2020). Food groups that are associated with lower environmental impacts (such as vegetables, legumes and whole grains) also tend to improve adult health (Clark et al., 2019), suggesting that there are multiple benefits for shifting towards sustainable diets. Therefore, reducing the meat and especially beef consumption of mainstream consumers is of critical importance for limiting global warming, with further co-benefits for human health.

One of the key barriers to mainstream consumers reducing their meat consumption is liking meat-based foods, and expecting not to enjoy eating meat-free or plant-based foods (e.g., Bryant, 2019; Graça et al., 2019; Piazza et al., 2015; Wehbe et al., 2021). Indeed, a recent feature listing experiment including omnivores (i.e., people who consume meat) and vegans (i.e., people who don't consume any animal products like meat or dairy) showed that these groups represent foods in very different ways (Davis \& Papies, 2021b), pointing to different simulations that motivate behaviour.

In this feature listing work, participants were asked to describe a set of foods in both a meatbased and a plant-based version (e.g., beef burger; falafel burger), without this distinction being made explicit. Then, they rated how attractive they found each food. Results showed that each group described "their" foods more in terms of consumption and reward features, such as taste, texture, eating context, and pleasure, than "the other" food, which was described more in terms of situation-independent features, such as ingredients, health, and food category. Thus, as we had seen for drinks (Papies et al., 2021), participants described items that they consumed more frequently more in terms of eating and enjoying them. Across foods and groups, the use of consumption and reward features was associated with higher attractiveness ratings, again similar to the patterns seen for drinks. Thus, omnivores represented meat-based foods in terms of eating and enjoying them and vegan foods in terms of their ingredients or health features; the reverse pattern was found for vegans. 
A striking finding in feature listing responses was the high use of identity and socio-political context words. Overall, vegan participants used a higher proportion of situation-independent features than consumption simulation features, whereas omnivores used similar proportions of words from these categories across foods. This may suggest that the dietary pattern of avoiding animalbased foods is associated with a different way of representing food - possibly focusing relatively more on the distal implications of eating a food than on the immediate eating experience. To better understand this, we examined the content of the situation-independent category more closely. Vegan participants especially had listed a high number of features related to the socio-political context of eating meat. To capture these features, we created a new category for "socio-political context features". These include words like "animal agriculture", "unethical” and "planet destroying”, but also emotive language and graphic imagery of the animal's death, such as "cruel", "horrifying", "baby lamb", "terror", "slaughterhouse", and the like. In addition, when describing plant-based foods, identity-focused features such as "vegan revolution", "for vegans" and "vegan only" were used by both omnivore and vegan participants. These findings show the strong emotive and moral responses of vegans to meat-foods, but also the central role of the vegan identity in their food representations.

The strong role of vegan identity was also apparent when we analysed the way that plantbased, vegetarian, and meat-based foods were presented on Instagram. Here, in two observational social media studies (Davis \& Papies, 2021a), we coded the hashtags of several thousand Instagram posts with the same manual used to code feature lists in experiments. We added separate "sociopolitical context" and "identity" categories, and a further "social media language" category. For a typical food post, on average 14 hashtags were coded, for example "dinner", "veganfood", "homemade", "foodie", "steak", "bbq", or "yummy". We found that the proportion of consumption simulation words was higher in posts about meat-based foods than in posts about plant-based foods, and that in turn the proportion of situation-independent words was higher in posts about plant-based 
foods than meat-based foods (see Figure 4). Again, plant-based foods were tagged with a high proportion of identity words, such as "vegancommunity", with health-related words such as "healthy", and socio-political context words, such as "climate". Thus, consistent with the feature listing by vegans and omnivores described above, meat-foods were more likely to be tagged with reference to an enjoyable eating experience, whereas plant-based foods were more likely to be tagged with references to more distal implications of food, such as health, sustainability, and social identity.

These hashtags about plant-based foods likely serve a social signalling and community building function for vegans on social media (Costa et al., 2019; Kaakinen et al., 2020). However, despite the urgent need for a mainstream shift toward plant-based foods, they probably don't serve to make plant-based foods more attractive to mainstream consumers, but rather may contribute to polarisation of dietary patterns and identities (e.g., Buddle et al., 2018; De Groeve et al., 2019; Van Bavel \& Pereira, 2018).

Notably, the same pattern of meat-based foods being presented in a more enticing manner was found in the packaging descriptions of ready-meals in UK supermarkets (Papies, Johannes, et al., 2020). Here, we used the feature listing coding manual to analyse the words used in the descriptions of 240 meat-based, vegetarian, and plant-based ready meals from four UK supermarkets. Again, the meat-based foods had more consumption and reward language, mentioning taste, texture, and enjoyment, while the meat-free foods had more situation-independent language, mentioning ingredients, visual features, and categories. This finding is consistent with work by Turnwald and colleagues, who showed that descriptions of healthier foods on restaurant menus were described as less appealing and with more health-related language, compared to standard restaurant dishes (Turnwald, Jurafsky, et al., 2017).

Do these differences in language matter? Based on the grounded cognition theory of desire, we would argue that they do, because consumption and reward simulations can be triggered by 
language, and can contribute to desire. Testing this hypothesis in the domain of plant-based foods and among people who consume meat, we hypothesised that presenting plant-based foods with descriptions that incorporate consumption and reward-related words would increase their appeal (Papies, Johannes, et al., 2020). While a first experiment incorporating either sensory or context words showed no effect on appeal $(\mathrm{N}=170)$, the findings of a second experiment $(\mathrm{N}=166)$ with "stronger" labels were consistent with this hypothesis.

For both 20 plant-based and 20 meat-based foods, we constructed labels that included sensory, context, and hedonic features (e.g., "Pub-favourite burger with soft soy, crispy cabbage, aromatic rice, and deliciously sweet beetroot"), and control labels that included ingredients, categories, and visual features (e.g., "Burger patty with rice based on soya protein, cabbage, and small beetroot pieces"). We then asked participants to indicate how attractive each meal sounded to them, and to report their eating simulations ("When I read this label, I imagine what the food would taste and feel like"). As predicted, while meat-based foods were rated as higher on attractiveness and simulations than plant-based foods, simulation-based labels increased both attractiveness and eating simulations, for both kinds of food. The effect of the labels on attractiveness was mediated by eating simulations. Importantly, while a higher meat eating frequency was negatively associated with the rated attractiveness of plant-based foods, this relationship was attenuated by consumption and reward labels. In other words, presenting the plant-based foods with appealing language increased their appeal especially among more habitual meat eaters.

Together, these findings on the representations of meat-based and plant-based foods are consistent with findings in other domains, showing that liked foods are more heavily represented through eating simulations, and that eating simulations in turn make foods more attractive. These findings further show that depending on one's eating goals and identities, other food-related information (e.g., socio-political context, social identity) can dominate cognitive representations of food stimuli above consumption and reward features. In addition, these patterns of appealing and 
polarising language are reflected in food communication on packages and social media, and thus in the public discourse around food.

The polarisation of food choices, and the often challenging role of social identity in dietary change, is also reported by mainstream consumers who are attempting to reduce their meat and dairy consumption. We found clear evidence on this in a recent qualitative survey (Wehbe et al., 2021) among meat and dairy reducers in the UK $(\mathrm{N}=80)$, who reported on the various social challenges they encounter in their daily lives when trying to make more sustainable food choices. These participants described how they frequently had to explain or justify their choices. They also struggled to find a helpful dietary identity to support their efforts or signpost their meat reduction to others (e.g., "flexitarian", "vegetarian”, "pescatarian”, etc). Given the urgent need to shift towards more plant-based foods to ensure that the planet remains habitable for our species, this public discourse is important to understand and potentially shift. Ideally, this discourse should avoid polarisation while establishing appealing and inclusive narratives around plant-based foods, especially for mainstream consumers.

Given the evidence we have seen for consumption and reward simulations increasing desire, appealing narratives for plant-based foods should focus on what it feels like to eat and enjoy the foods, in other words, on creating and triggering rewarding simulations of eating them.

\subsection{Physiological effects of simulations}

As we have seen so far, substantial research now supports a bi-directional relationship between consumption and reward simulations, and desire for food and drink. More attractive foods and drinks are more likely to trigger consumption and reward simulations, and these simulations in turn are associated with increases in desire and motivated behaviour. Research assessing salivation to food cues as an implicit measure of desire provides a good illustration of both relationships. Specifically, our research guided by the grounded cognition theory of desire shows that simulations 
and salivation are stronger for attractive foods, and that simulations in turn increase desire, especially for attractive food (Keesman et al., 2016).

Salivation to food cues has often been examined as a physiological marker of the anticipation of eating (e.g., Christensen \& Navazesh, 1984; Nederkoorn et al., 2000). Research has shown, for example, that the exposure to highly liked foods trigger more salivation than exposure to less liked foods (Rogers \& Hill, 1989), that chronic dieters salivate less than non-dieters (Nederkoorn \& Jansen, 2002), and that hunger can increase salivary responses to foods (Wooley \& Wooley, 1973) in other words, salivation is more pronounced when foods are more action relevant to the perceiver. In sum, salivation in response to food cues can be interpreted as a physiological measure of the motivation to eat, or of food desire. This response happens quickly and without conscious intention and effort, so could be described as happening automatically (Moors \& De Houwer, 2006).

While previous research has established that food cues trigger salivation, accounts of mechanisms typically rely on learned associations, e.g., conditioning, suggesting that salivation occurs automatically because of the anticipation of eating. We propose that the anticipation of eating is implemented as a simulation of previous eating experiences, and is therefore more pronounced for attractive compared to neutral food. To test this idea experimentally (Keesman et al., 2016), 60 participants were instructed to look at a neutral, an attractive, and a very sour food for one minute. Half of the participants were instructed to actively imagine, or simulate, eating the food, and the other half to simply look at it. Then, we measured eating simulations (e.g., "It was as if I could really taste the object", "It was as if I could really feel the texture of the object in my mouth") and desire ("I would have liked to eat ...").

In line with feature listing findings, participants reported stronger consumption simulations and desire for the attractive compared to the neutral food, even when instructed to simply look at the foods. Crucially, participants salivated more when instructed to simulate eating the food, and 
especially when the food was attractive, suggesting increased anticipation of eating (see Figure. 5) ${ }^{1}$. Thus, eating simulations increase desire, as reflected in increased salivation, particularly when the food is attractive. Together, this work provides converging physiological evidence for the role of simulations in desire, showing that consumption simulations are stronger for attractive foods, and that they in turn increase the motivation to eat.

\subsection{Situation effects on simulations and desire}

Much of the research on cognitive representations of appetitive stimuli described above has referenced contextual features of consumption. Specifically, participants often mention eating situations in feature listing and categorisation tasks (e.g., "with friends", "summer"), social media users mention eating situations when tagging posts about food (e.g., "brunch", "birthday"), and ready-meal packages contain references to eating situations (e.g., "perfect for sharing", "family"). Indeed, this likely reflects the fact that eating occurs in an infinite number of rich, multidimensional situations, which may affect people's eating experiences, and which feel worth communicating about. In other words, information about the consumption context forms part of people's situated conceptualisations of appetitive stimuli. This is consistent with the situated cognition perspective more generally, and has been shown for stimuli in other domains as well (e.g., Santos et al., 2011; Wu \& Barsalou, 2009).

An implication of the situated cognition perspective for the representations of appetitive stimuli is that situational or context cues could trigger desire for food. Indeed, previous research suggests a strong role for context cues in appetitive behaviour, for example in conditioning (e.g., Bouton, 1994; van den Akker et al., 2013), in the neuroscience of reward learning (Berridge et al., 2009), and in eating habits (Riet et al., 2011). This would also fit anecdotal evidence, where people report stronger cravings in situations in which they have previously consumed a liked food or drink.

${ }^{1}$ For sour food, increased salivation is consistent with saliva's function to protect teeth and digestive system from increased acidity (Watanabe \& Dawes, 1988). 
However, do situational cues affect desire even when one is not currently immersed in a situation? And do consumption simulations play a role in these effects, such that situational cues contribute to simulations of eating and enjoying a food or drink?

A recent set of experiments was designed to directly examine these questions, and tested whether situational information affects desire for appetitive stimuli through eating simulations (Papies et al., 2022). In a series of experiments, participants were shown food stimuli either in a congruent background (e.g., a bowl of tomato soup on a dinner table; cucumber slices in the kitchen), in an incongruent background (e.g., a bowl of tomato soup in a cinema; a bowl of cucumber slices in a bar), or with no background (e.g., a bowl of tomato soup in front of a white background; a bowl of cucumber slices in front of a white background). They looked at the image for one minute and were instructed to fully immerse themselves in the situation shown, but there was no mention of food or eating. Then, we measured self-reported eating simulations (e.g., "It was as if I could taste the soup.", "It was as if I could feel the texture of the soup in my mouth.”, “, I imagined how eating the soup would make me feel."), expected liking of the soup, and desire to eat the soup. In one experiment, we also measured salivation, and in two experiments, participants tasted the soup afterwards, and we measured actual liking of the soup.

Across experiments, the congruent situations led to stronger eating simulations, even when controlling for feelings of hunger. This suggests that the food cues together with the cues of an appropriate consumption situation were more likely to trigger a re-enactment of the eating experience than the food cue alone or in an incongruent situation. In other words, when a context does not match with a context in which we have encoded consuming a food previously, it is less likely to lead to a strong re-experience. As in previous research, eating simulations were stronger for attractive, high-calorie foods (e.g., cookies) than for neutral, healthier foods (e.g., cucumber slices); however, the effect of situational congruence was the same for both kinds of foods. Thus, even healthy foods "benefited" from being shown in eating congruent situations. Together, these findings 
again show that foods are not processed in isolation, but in relation to the background situation which is consistent with the grounded cognition account preparing for situated goal-directed action.

Congruent situations also increased desire for the foods, and expected liking, and these effects were mediated by eating simulations. Salivation in response to the images was also stronger if the food was presented in a congruent compared to an incongruent eating situation. Unexpectedly, the effects on actual liking were much weaker. Only in the experiment where the food was tasted right after viewing the image did we find an indirect effect of congruence on liking through eating simulations and expected liking.

Overall, these experiments provide strong evidence that by increasing eating simulations, background situations affect desire and expected enjoyment of food, even when the perceiver is not physically present in the displayed situation. Thus, situational cues can activate memories, or situated conceptualisations, of previous similar eating experiences, which enhance the eating simulations triggered by the foods alone, and lead to stronger expectations of reward.

These findings suggest again that desire for food is not a simple association or conditioned response, as it is modulated by a match with background information, and mediated by simulations of what it would feel like to eat the food. The findings also have important implications for research with food and drink images. In most experiments, great care is taken to standardise the way foods are presented in images, for example on a white plate in front of a neutral background - even though many of the foods might not typically be encountered on a white plate (e.g., M\&M's), and food is hardly ever encountered in a "neutral" background. Thus, such unsituated stimuli do not reflect how participants mentally represent foods, or how they encounter foods in daily life. As a result, potentially important processes that contribute to food desires are "controlled away" when unsituated stimuli are used, which may limit both the internal and ecological validity of the research using them.

This research has at least two clear implications for behaviour change. First, it shows how situations can lead to desires and potential self-control conflicts, for example when the desires for 
unhealthy or unsustainable foods or drinks are triggered or enhanced by environmental cues. Thus, this supports the behaviour change strategy of changing the environment, so that environmental cues are less likely to trigger "undesirable" motivational processes and behaviours (e.g., Best \& Papies, 2017; Hollands et al., 2017; Marteau et al., 2012; Papies, 2017). Such interventions, for example, could take the form of removing alcohol advertisements and drinking paraphernalia from public spaces. Alcohol consumption could only be allowed in fewer places (i.e., not in public parks, cinemas, sports venues) to prevent situated conceptualisations of alcohol forming for many external contexts.

Second, this work provides further support for the potential of context-based interventions to improve the appeal of "desirable" motivational processes and behaviour. It suggests, for example, that it is important to create cognitive representations of consuming healthy foods and drinks in a variety of appealing situations, so that situational cues from those situations can later enhance consumption simulations and lead to healthy desires. Although the majority of people's situated representations of food and drink may come from their own experiences, advertisements of food and drinks, social media content about food, and observing others' consumption, are part of social food culture as well. These platforms could be used proactively to help people lay down situated memories of consuming and enjoying foods and drinks that don't harm people's wellbeing or threaten planetary health. In other words, successful behaviour change needs to overcome the rewarding simulations that often favour unhealthy foods, and update situated representations of healthy and sustainable foods to trigger rewarding simulations of consuming them in appealing contexts.

\subsection{Neuroimaging findings on simulation and desire}

Neuroimaging findings provide further support for the hypothesis that food and drink objects are represented through simulations of consuming and enjoying them. When people are exposed to food or drink cues, such as food images or food words, in an fMRI scanner, this triggers activity in 
primary gustatory areas of the brain as well as reward areas - similar to the activations typically seen when people actually consume food or drink (Chen et al., 2016; Simmons et al., 2005; van der Laan et al., 2011). This suggests that when processing these cues, the brain re-enacts experiences of consuming the food or drink in the relevant modalities, simulating previous sensory and reward experiences. In other words, the brain responds as if one were actually eating, tasting, and enjoying the food or drink. Providing evidence of the specificity of these re-enactments, one experiment showed that reading odour-specific words like "garlic" or "cinnamon" activates olfactory brain areas - presumably because experiences with garlic or cinnamon typically involved salient olfactory processing, which is then re-enacted upon later reading the linguistic labels (González et al., 2006).

In line with the behavioural studies described above, activations in sensory and reward areas are stronger when the appetitive stimulus is more attractive or has more motivational relevance, such as when it is higher in calories, when the perceiver is hungry, or in perceivers who are (at risk of) overweight (e.g., Killgore et al., 2003; Siep et al., 2009; Stice et al., 2009, 2011), or in the domain of alcohol, among problematic drinkers (e.g., Myrick et al., 2004; Schacht et al., 2011).

Integrating these neuroimaging findings for the domain of food, we proposed a "core eating network" that underlies both the experience of eating itself, as well as responses to food cues, such as food words or images (Chen et al., 2016). This proposed network consists of a "ventral reward pathway" that represents responses to food stimuli that underlie the desire to eat, as well as a "dorsal control pathway", that underlies the control of cognitive and behavioural responses to foods. The differential activation of these two pathways can explain the different patterns of brain activation in response to food cues, for example stronger activations in the reward pathway in hungry participants or towards high-calorie foods, and stronger activations in the control pathway in those who have salient dieting goals (see Chen et al., 2016, for a review). Consistent with this interpretation of neural activity, activations in areas of the ventral reward pathway also predicted behavioural outcomes with regard to food, for example increased food desire, snack intake in the laboratory, and 
giving in to food temptations in daily life (Lawrence et al., 2012; Lopez et al., 2014; Wang et al., 2004). In addition, greater orbitofrontal cortex activation in response to attractive food cues predicted BMI increases one year later in adolescent girls (Yokum et al., 2011), and greater reward pathway activations to high-calorie vs. control pictures among individuals with obesity were associated with being less successful at weight loss in the following 12 weeks.

Together, the findings reviewed in this section provide convergent neural evidence for the role of simulations, or re-enactments of previous neural states, in appetitive behaviour. They further elucidate the neural pathways that may underlie the consumption and reward features reflected in people's cognitive representations of appetitive stimuli, as described above, and which predict motivated behaviour. Next, we will address evidence suggesting that these consumption and reward simulations can also be experienced consciously.

\subsection{Conscious experience of eating simulations}

The research discussed so far has demonstrated the role of consumption and reward simulations in motivated behaviour using a variety of measures. Many of our experiments used feature listing to detect features that suggest that the participant simulated a consumption experience (Davis \& Papies, 2021b; Keesman et al., 2018; Papies, 2013; Papies et al., 2021). Based on the findings reviewed so far, feature listing can be considered an indirect measure of consumption simulations, because it does not assess simulations directly, but can still be argued to reflect simulations. Specifically, simulating a consumption experience would be the most parsimonious process explanation for the idiosyncratic, situated consumption features produced (see also Wu \& Barsalou, 2009). In addition, the task can also be considered an implicit measure of simulations in the sense that the production of consumption-related features is quick and effortless in relation to the production of other features, requires no specific intention, and possibly happens outside of conscious awareness (De Houwer et al., 2009). 
In some of the other experiments reviewed above, we have used self-report rating scales to assess participants' eating or drinking simulations (Keesman et al., 2016; Papies et al., 2022; Papies, Johannes, et al., 2020). Here, participants indicate on a scale to what degree for example seeing a food or reading a food label makes them think about eating it, or makes them imagine specific aspects of the food, such as its taste or mouthfeel. Together, using these measures of consumption and reward simulations, the research so far suggests that simulations can happen quickly and effortlessly outside of conscious awareness (e.g., as assessed in feature listing), but that they can also be accessed introspectively by participants through directed questions (e.g., as assessed with rating scales).

Recent research suggests that consumption and reward simulations can also come into conscious awareness without participants intentionally directing their attention towards them, and that these intrusive simulations can affect participants' motivation and behaviour. In our qualitative survey of meat and dairy reducers (Wehbe et al., 2021), participants reported how exposure to food cues or thoughts about sensory features of foods would trigger cravings and desire for foods that they were trying to avoid (e.g., "The smell of bacon would, even years after abstaining... the smell of it frying would make my mouth water and stomach growl."; "I often craved the taste of cheese on toast.", or "On a day-to-day basis it hasn't felt too hard but walking past a restaurant and smelling a steak still makes me feel like I'd like to eat meat.").

Vivid experiences of simulating eating were also reported by participants in a recent qualitative interview study (Tatar et al., 2021). Participants were interviewed after viewing a number of food images, and again after learning to apply a mindfulness-based technique to their experiences. After viewing images of five highly attractive foods (e.g., brownie, burger) for 10 seconds each, with instructions to view the foods like they normally would and to follow up on any thoughts, feelings, or physical sensations that they may have, participants were asked to describe their experiences. 
Thematic analyses showed that all participants evidenced the experience of consumption and reward simulations, such that re-experiences of eating and enjoying foods arose automatically. Participants referred to how easy it was to imagine the taste and the texture of foods, and mentioned situations for eating them (e.g., "I had the image of like being eating a burger at a, a place and enjoying it"). In addition, some participants reported that the content and intensity of their simulations varied with other factors, for example their personal food preferences, or their current state ("I first thought the, the carrot cake was quite fluffy but maybe a bit too sweet for ... to, to have just now"). Thus, participants clearly processed the food images with regard to their action relevance. In other words, they described whether they would like to eat the food or not (i.e., their desire), as a function of their thoughts on expected taste and texture (i.e., their eating simulations) although no such instructions were given.

Some participants also indicated that merely viewing food images on screen, rather than live objects, reduced their simulations somewhat, because it was clear that these foods were not available for consumption- and therefore, less action relevant. These reports are consistent with the findings that more consumption and reward features were listed in response to drinks placed in front of participants compared to drink words or images shown on screen (Papies et al., 2021). Clearly, these findings are also consistent with the grounded cognition perspective that simulations prepare individuals for situated goal-directed action - which may cause simulations to be less likely and less vivid when the stimuli shown are not actionable.

These experiences suggest that when prompted to describe their responses, participants report vivid mental imagery of eating. Mental imagery is at the core of the elaborated intrusion theory of desire (Kavanagh et al., 2005). This theory suggests that conscious and elaborate mental imagery, often in response to spontaneous intrusive thoughts about appetitive cues, plays a causal role in desire. This emphasis on conscious experiences is a crucial difference from the grounded cognition theory of desire, which argues that while consumption and reward simulations can become 
conscious, they can also occur nonconsciously and affect behaviour without ever reaching conscious awareness and without taxing working memory (Papies \& Barsalou, 2015). In fact, we assume that the simulations that underlie desire and motivated behaviour are a much more general mechanism supporting goal-directed behaviour across a variety of actions and situations, and therefore occur relatively automatically in the sense of low effort and awareness. Thus, our grounded cognition account of motivated behaviour extends beyond desire, and can explain other important phenomena of behavioural regulation such as habits, social norms, and effects of various self-regulation strategies. We will discuss this in more detail in the next section. Finally, in contrast to the elaborated intrusion theory of desire, our more general account focuses not only on sensory mental imagery, but on simulations of a variety of features of experience, including internal states, goals, motor behaviour, emotions, and so forth. In sum, while the theories share the core assumption that representations of consumption experiences fuel desire, the reach and the mechanisms of the accounts differ significantly.

\subsection{The role of simulations in appetitive desires in domains other than eating and drinking}

So far, we have described research on the role of grounded cognitive processes in the domains of eating and drinking. It is likely, however, that similar processes of sensory-specific reenactments of previous experiences will guide motivated and situated, goal-directed action in other domains of appetitive behaviours as well. In the domain of smoking, research has shown that among smokers, immersing oneself in vivid and multimodal descriptions of smoking urge situations can lead to strong urges to smoke, along with physiological indicators of craving (e.g., increased heart rate; Tiffany \& Hakenewerth, 1991). Vivid mental imagery of waterpipe tobacco smoking can increase desire to smoke, driven by the positive valence of the simulated experiences (Lipkus et al., 2021). Consistent with these behavioural findings, neuro-imaging research has shown systematic activations in reward-relevant areas of the brain (amygdala, orbitofrontal cortex, ventral striatum) in 
response to smoking cues (Tang et al., 2012), other drug cues (e.g., Volkow et al., 2012, 2013), and money cues (Simon et al., 2015). This has lead researchers to suggest neurobiological overlapping in the valuation systems underlying many day-to-day behaviours, including those associated with the (over)consumption of food and addictive substances (Levy \& Glimcher, 2012; Volkow et al., 2012).

In the domain of media use, similar processes may affect the desire to engage with social media. The phenomenon of telepresence (Steuer, 1992), which captures the sensation of experiencing events presented through digital technology as if they were happening live, can provide hedonic value to users (Rodríguez-Ardura \& Martínez-López, 2014). The feeling of 'being there' when browsing through posts on social media can enact mental imagery of situating oneself in a reconstructed reality, which intensifies the enjoyment of this online engagement and the desire for continued use (Jung, 2011). Therefore, this sense of 'being' in a virtual environment from the perception of external stimuli on digital media can be seen as analogous to the cognitive processes underlying the role of memory and desire involved within other consumption behaviours.

Finally, in the domain of sexual relationships, situated conceptualisations and simulations may underlie the effects of sexual fantasising on desire. Fantasising about having sex with one's partner reflects one's previous interactions with one's partner (Birnbaum et al., 2011), consistent with these being stored as multimodal situated conceptualisations. Retrieving such fantasies, possibly as simulations or vivid imagery, in turn increase desire and behaviours that benefit the relationship (Birnbaum et al., 2019). Like in the domains of food and drink, this suggests that rewarding simulations reflect previous experiences, and in turn motivate goal-directed behaviour.

Future research could establish the content and modalities of situated conceptualisations of desire stimuli in these domains, and examine the ways in which these are learned, especially in the case of problematic behaviours. For example, what is the role of media and culturally shared imagery on situated conceptualisations of smoking or sexual interactions? What is the role of 
modality-specific embodied processes in these different domains? Addressing such questions across domains could help elucidate general cognitive mechanisms underlying motivated behaviour.

\subsection{Summary and future research}

The research discussed in this section shows that cognitive representations of appetitive stimuli reflect consumption and reward simulations, learned from previous experiences. These consumption and reward simulations are stronger for liked or habitual foods and drinks, and they in turn increase liking and desire. Indeed, experimental studies manipulating the consumption and reward simulations suggest that they may have a causal role in desire. External cues, including cues of relevant situations, can trigger consumption and reward simulations and desire, which manifest also in neural and physiological responses (i.e., activation in gustatory and reward areas in the brain; salivation). While most of the work discussed here focuses on food and drink representations, research on other domains of appetitive behaviour points to similar processes.

Important questions for future research include the role of physiological states in consumption and reward simulations. Do current states systematically affect the simulations triggered by appetitive cues? Related, future research could also explore links with research on motivated perception, where Goal-Promoting Perception Theory (Cole \& Balcetis, 2021) suggests that visual perception is often biased in ways that supports effective goal-pursuit, for example through selective attention, biases in size perception of goal-relevant stimuli, etc. Studies bringing these two theories together could assess whether consumption and reward simulations play a mechanistic role in driving motivated perception, such that objects related to more rewarding simulated outcomes attract more attention and are prioritized during processing as a result of simulations (see Cole \& Balcetis, 2021). In addition, do action and outcome simulations bias perceptual processes such that they facilitate effective goal pursuit, based on situated conceptualisations of previous, successful goal pursuit? And does motivated perception in turn facilitate further consumption and reward simulations, in the case of attractive food or drink? 
Research might also examine how, when, and why some simulations reach conscious awareness (Kavanagh et al., 2005) while others do not. Does conscious awareness make consumption and reward simulations easier or more difficult to regulate, and which individual differences may play a role here? Finally, research could address how the reward of long-term investment goals is simulated, or re-enacted. How do individuals with different levels of motivation represent long-term goals, such as being healthy, or preserving human life on Earth? How can such reward simulations be activated and recruited most effectively to support the successful pursuit of long-term goals?

\section{A grounded cognition perspective on other motivated behaviours}

In this section, we will discuss how the core components of the grounded cognition theory of desire may play a role in other motivated behaviours as well. Specifically, we will address outcome expectancies, habits, planning, norms, and self-regulation techniques including mindfulness.

\subsection{Outcome expectancies as consumption and reward simulations}

We suggest that expectancies in the domain of eating and drinking can be understood as consumption and reward simulations within situated conceptualisations, learned and updated in previous experiences. Expectancies are an important construct in research on alcohol consumption, but have also been used to explain other experiences and behaviours, for example the effects of food and drink labels on liking. We will discuss these domains in turn.

Substantial research in the domain of alcohol suggests that people represent alcoholic drinks in terms of outcomes of consuming them, so-called outcome expectancies. This suggests that experiences of alcohol outcomes form part of people's situated conceptualisations of drinking alcohol. Specifically, people think about alcohol in terms of positive physical and social effects of drinking, such as feeling more romantic, finding it easier to talk to people, decreased tension and worry, and increased confidence and perceptions of power (Brown et al., 1987). In other words, people simulate these outcomes when they think about alcohol. In addition to direct self-report 
questionnaires, a variety of tasks have been developed to assess these expectancies or their underlying memory associations indirectly. Using such tasks, it has been shown, for example, that the likelihood of listing "drinking alcohol" as a behaviour that can lead to the outcome "relaxation" is associated with both past and prospective drinking behaviour (Stacy, 1997; Stacy et al., 1994). Expectancies such as feeling "good" from drinking alcohol have even been found in children and adolescents (Dunn \& Goldman, 2000). In addition, both explicitly and implicitly measured alcohol outcome expectancies are related to the quantity of intake (Jajodia \& Earleywine, 2003; Jones et al., 2001; Reich et al., 2010).

These findings are highly consistent with the findings on the role of consumption and reward simulations in eating and drinking described above, which showed that the degree to which people represent an appetitive stimulus through simulations of consuming and enjoying it predicts desire and intake. We suggest that alcohol expectancies are implemented cognitively as simulations, or reenactments, of consumption outcomes encoded during previous consumption experiences. The degree to which people represent alcohol through such simulations of positive outcomes predicts their motivation to consume.

Related research has shown that cueing outcome expectancies from drinking (e.g., using words such as "sexy" or "confident"), as well as situational cues typically associated with drinking (e.g., a bar environment), can increase the motivation to drink (Field et al., 2008; Stein et al., 2000). Further, it is not only positive outcome expectancies that can be cued in this way: priming with alcohol words can impair cognitive performance and lead to aggressive thoughts (Bartholow \& Heinz, 2006; Fillmore et al., 1998). Indeed, much research on the so-called alcohol placebo effect has demonstrated that the expectancy of drinking alcohol can lead to the experience of a variety of alcohol effects, including changes in motor behaviour and reduced anxiety (see Mckay \& Schare, 1999 for a meta-analysis). Thus, activating part of the situated conceptualisation of drinking can 
lead to simulations of drinking outcomes, including cognitive, affective, and physiological effects. These simulations are experienced as expectancies and measured as such in research.

We suggest that the effects of food and drink labels can similarly be understood as outcome expectancies. Tasting a savoury liquid labelled as "rich and delicious" has been shown to trigger increased activation in reward areas in the brain, compared to the same stimulus labelled as "boiled vegetable water" (Grabenhorst et al., 2008). The same has been shown for tasting a wine with a more expensive-looking compared to a cheaper-looking label (Plassmann et al., 2008). Tasting a milkshake labelled as "indulgent" rather than "sensible" has been shown to trigger hormonal satiety signals (Crum et al., 2011), and health labels suggesting lowered salt or fat content have been shown to lower participants' expected and actual liking of foods (e.g., Kahkonen \& Tuorila, 1998; Liem et al., 2012). These findings suggest that labels activate expectancies of what a food will taste and feel like, which are implemented as neural, physiological, and mental simulations, and which can be superimposed on actual sensory experiences.

Together, the findings discussed here are consistent with an interpretation of outcome expectancies as consumption and reward simulations within situated conceptualisations, which can be activated by external cues and affect bodily experiences as well as motivated behaviour.

\subsection{Habits as situated conceptualisations}

Habits are commonly conceptualised as learned, automatic responses to context cues that result from frequently performing the same behaviour in the same context (Gardner, 2015; Wood \& Rünger, 2016). Thus, habitual behaviour can occur when a contextual cue triggers an action, or the cognitive representation of an action, that has been performed repeatedly in that context, for example when the context of "having a work break in the afternoon" triggers the action of walking to the kitchen to prepare a cup of tea. We suggest that within a grounded cognition framework, habitual behaviours can be understood as goal-directed behaviours resulting from the same cognitive structures (i.e., situated conceptualisations) and processes (i.e., simulations) as other motivated 
behaviours. Specifically, frequently performing a behaviour in a given context forms a situated memory representation of the behaviour, the context it is occurring in, the outcomes experienced, and so forth - in other words, a situated conceptualisation, as described previously. When a similar situation is encountered again later, its features can be mapped onto a related situated representation in memory that supports simulating possible actions and their likely outcomes. As an example, perceiving a food image or a situation where one often eats a food can trigger simulations of the taste, mouthfeel, and enjoyment of eating it, leading to bodily preparations to eat (i.e., salivation), desire, and possibly motivated actions to obtain the food. Indeed, we have seen in some of the experiments describe above how this process operates (Papies et al., 2022).

Applying the same process of consumption and reward simulations motivating behaviour to the example of a potential habitual behaviour, imagine that on reaching afternoon break time in the office, one starts thinking about the taste, mouthfeel, and energising effects of a cup of tea, and then wanders off to the kitchen to prepare it. In this account, the behaviour is more likely to be performed to the degree that it is expected to lead to a rewarding outcome based on consumption and reward simulations. If the same behaviour is performed more frequently in response to specific situational cues, this may become more automatic, or quicker and easier. As a result, it may be experienced as "automatic" by those who perform it (Verplanken \& Orbell, 2003), and categorised as "habitual" by researchers. However, it could still be motivated by simulations of rewarding outcomes. In other words, reward would play a role not only in habit learning, such that repeating highly rewarding behaviours lead to stronger habits than less rewarding behaviours, but also in later habit performance, such that reward expectations plays a role in determining whether a behaviour is likely to be performed or not (see also de Wit \& Dickinson, 2009).

\subsubsection{A grounded cognition perspective on reward experiences in habits}

Indeed, the role of reward in habit performance is an important theoretical issue in the domain of habits. Some accounts of habitual behaviour suggest that once a habit is established, its 
performance is no longer contingent on reward (Wood \& Rünger, 2016), and that habits should be seen as separate from goal-dependent forms of automaticity (Wood \& Neal, 2007). From that perspective, context cues would trigger automatic behaviour independent of reward expectations; in the example above, one's work break triggering the preparation of a cup of tea would be independent of one's desire for tea. Other accounts suggest that most human behaviour is goal-directed, even if it is performed frequently and in relatively stable contexts, and therefore contingent on reward and sensitive to changes in reward occurring (Kruglanski \& Szumowska, 2020). This view of goaldirected habits would imply that preparing the cup of tea during one's break would be driven by the desire to drink tea. If the weather were too hot for tea, or a colleague dropped by with fresh coffee, one might not make tea after all, because the reward of preparing and drinking tea in those situations would not be sufficiently high.

We suggest that the grounded cognition approach can explain habitual behaviour quite naturally. Considering habits as situated conceptualisations would suggest that habitual behaviours rely on the same underlying cognitive mechanisms as for example, impulsive behaviours. From this perspective, a behavioural response is activated when a situational cue triggers a situated conceptualisation that has become well entrenched in memory. The resulting behaviour could be considered an impulse, or a habitual behaviour, but the common underlying mechanism would suggest that it leads in relatively effortless ways to behaviours that have previously produced rewarding outcomes. In other words, this framework proposes that even frequently performed or relatively automatic behaviours are still reward-driven.

\subsubsection{Reward experiences in daily-life habits}

In line with the grounded cognition perspective, some recent research from our laboratory suggests that reward expectations may play a key role in the performance of behaviour, even among those who appear to have strong habits. For example, a recent set of correlational studies on the predictors of 40 positive and 40 negative daily-life behaviours (e.g., eat healthy snacks, maintain 
contact with friends, take study breaks, brush teeth twice daily; drink soft drinks, use bad language in public, procrastinate, bite nails) speaks to this issue (Dutriaux, Clark, et al., 2021). Here, participants reported for each of the 80 behaviours how often they performed it, along with how much they performed it in consistent contexts, how much they performed it to feel good in the moment (i.e., immediate reward), how much they performed it for long term benefits (long-term reward), how conflicted they felt about it, and how automatic their performance of it was. While consistency and automaticity had the strongest predictive value, both immediate and, to a lesser degree, long-term reward predicted the reported frequency of people performing each of the behaviours. This suggests that people believe that the behaviours they perform will serve them well either in the short or long term, or possibly both. Most importantly, the habitualness of a behaviour increased strongly with how rewarding it was at both the group and individual levels of the multilevel regression analyses. Rather than habitualness being unrelated to reward, they were strongly related, suggesting that how habitual a behaviour becomes reflects how rewarding it is.

Similar findings have emerged in the domain of water drinking behaviour, where habits have emerged as a pivotal factor in healthy drinking (Rodger et al., 2021; Rodger \& Papies, 2021). Water drinking is a crucial health behaviour, because underhydration has been associated with physical and psychological health outcomes such as chronic kidney disease, metabolic disease (Perrier et al., 2021) and altered mood states (Pross et al., 2014). In addition, it is an excellent domain to study habits, since achieving and maintaining healthy hydration levels requires a high frequency of water drinking, making it susceptible to habit formation.

We conducted a large interview study $(\mathrm{N}=60)$ on water drinking motivation and behaviour in a UK sample (Rodger et al., 2021). We found that participants reported highly situated water drinking habits, such that external (e.g., water dispenser) or internal cues (e.g., thirst), other goals (e.g., socialising), and cognitive states (e.g., boredom) present during a situation affected whether participants drank water or not (see Table 2). For example, a person might report effortlessly 
drinking water from a water dispenser while they are working out at the gym, but also report not drinking water from a water dispenser while they are working at their desk, because this is perceived as effortful. The grounded cognition framework can explain these situated drinking habits such that the situated conceptualisation of drinking water at the gym, potentially activated by feeling thirsty and warm while exercising, could lead to simulations of quenching thirst and cooling down through water intake. Situated conceptualisations of drinking water at the office, however, might lead to simulations that do not lead to desire as drinking water lacks reward in terms of taste. Additionally, situated conceptualisations of drinking coffee or tea at the office might lead to simulations of feeling hedonic pleasure, energised or destressed, leading to more desire for these alternative options. This framework also explains why many of our study participants had low water intake: most participants' situated conceptualisations of water intake relied on contextual features, such as exercising, that happened infrequently during the day, and on internal cues, such as thirst, that can be ignored or suppressed.

Findings from both the interview study and a mixed-methods survey study $(\mathrm{N}=101)$ on water drinking motivations (Rodger \& Papies, 2021) also suggest that reward matters for both water drinking habit formation and maintenance (see Table 2). Reward or the lack of reward were frequently mentioned by high and low water drinkers, respectively, as a reason for their water drinking behaviour. Participants with low water intake associated water drinking with limited shortterm (e.g., taste) and long-term (e.g., health benefits) rewards, and associated other drinks with high short-term rewards. Participants with high water intake frequently mentioned water intake leading to short term rewards such as tangible wellbeing benefits (e.g., improved skin, increased alertness). Although these findings rely on participants retrospective and introspective reports that may be influenced by lay theories of behaviour, they provide a compelling picture of the diverse roles of reward in this domain. 
The grounded cognition framework emphasises the importance of spontaneous simulations of previously rewarding consumption experiences for desire and motivated behaviour. This can explain why participants who have more salient reward simulations for other drinks have low water intake, whereas participants who have salient reward simulations for water have a high water intake. Conventional habit theory, where a sole situated external cue triggers water drinking independent of reward, does not seem to provide a sufficient framework to understand the situated water drinking habits researched in our qualitative studies. Situated water drinking habits are better understood as resulting from situated conceptualisations that involve a variety of cues and contextual features, which result in simulations of the rewarding outcomes of drinking water.

In a recent longitudinal study on drinking behaviour, we examined how the consumption of sugary drinks and of water changed during a Covid-19 lockdown (Claassen, Lomann, et al., 2022). We had seen in our previous studies that participants reported drinking sugar-sweetened beverages especially in situations outside the home, such as when eating out, when traveling, or on a day trip. During national lockdown periods, however, cafes and restaurants, gyms, entertainment venues, and many workplaces were closed, and travel was restricted. As a result, these habitual situations for drinking sugar-sweetened beverages could no longer occur. Given that habitual behaviour is heavily influenced by recurring situations, we were interested to see how consumption patterns would be affected by these changes.

We contacted a sample of regular sugary drinks consumers in the UK twice $(\mathrm{N}=211$ at $\mathrm{T} 1$ and $\mathrm{N}=160$ at $\mathrm{T} 2$ ). First, we contacted them during a lockdown period, when they reported on their typical drinks consumption before the lockdown and during the lockdown. Then, we contacted them again after the lockdown period had ended and asked them to report on their current drinks consumption. We assessed how often participants consumed water and sugar-sweetened beverages in ten typical situations for drinking them (e.g., when waking up, with a meal, at a party), and how much of each they consumed in total on a typical day. We also used the self-report habit index 
(Verplanken \& Orbell, 2003) to assess perceived habit strength of drinking sugar-sweetened beverages and water, independent of specific situations (e.g., "Drinking soft drinks is something I do automatically”; “...that belongs to my daily routine”, “... that I do without thinking”).

Results of this longitudinal study showed that as predicted, the frequency of consuming both sugary drinks and water across situations was reduced during the lockdown compared to before. Consumption amount, however, did not reduce. Further analyses showed that while the amount of water consumed stayed the same, participants increased their intake of sugary drinks, especially when they had strong perceived consumption habits of sugary drinks as reported with the self-report habit index. This may be surprising from a perspective of habits as purely automatic behaviours triggered by contextual cues. From that perspective, the lockdown period and its elimination of many social drinking situations should have strongly reduced sugary drinks intake. The observed pattern shows, however, that those with the strongest habits increased their overall consumption amount, even though the typical consumption situations had virtually disappeared. Indeed, the frequency of drinking sugary drinks in one single category strongly increased: "at home". This pattern did not occur for water. After lockdown had ended, behaviours returned closely to pre-lockdown levels.

These results on sugary drinks consumption suggest that for strongly habitual sugary drinks consumers, situations were less important than we had expected. Instead, it seems as if the reward of consuming sugary drinks motivated people to transfer their consumption habits, so that they built new routines of drinking at home when this was not possible outside the home. Although preliminary, these findings are consistent with the perspective that habits are flexible and efficient behaviours in the pursuit of reward.

In light of these findings, it is important to note that it is an unresolved issue how to most effectively define a situation, or context, in which a behaviour occurs. Is a situation defined most effectively by the physical space a behaviour occurs in, by the time of day, by affective or physiological states, or other features? Do these features or their combination differ between 
situations, individuals, and behaviours? Thus, it also remains a key challenge to establish the features of a situation that are most central to an individual's situated conceptualisation of a certain behaviour, and that may cue spontaneous simulations of that behaviour.

Research on habits and behaviour change tends to focus on external situations and sole external cues of behaviour, such as being at work, or seeing a water bottle on one's desk. However, based on the grounded cognition framework and findings from our previous research (Rodger et al., 2021), it seems important to define situations in which behaviours occur more extensively, such that they include a variety of external and internal features of a situation that could be relevant to the behaviour of interest. To do this effectively, researchers likely need to improve their understanding of the situations in which their specific behaviour of interest is performed, and how this differs between individuals. However, the most effective way to define a situation and which are its key features that determine simulations and behaviour is still an empirical question that needs to be addressed in future research.

Together, the results of the quantitative and qualitative studies on habitual behaviour discussed here are consistent with an interpretation of habits as situated conceptualisations of goaldirected behaviours performed frequently in similar situations. When a relevant situation is later encountered, these situated representations result in simulations of potentially rewarding outcomes, which can then motivate and guide behaviour in a highly efficient manner.

\subsection{The role of simulations in planning for behaviour change}

We propose that simulations also play an important role in the behaviour change technique of planning, and in the effects of planning on behaviour change. Planning, for example through if-then plans (i.e., implementation intentions) or other action planning techniques, is often designed to associate cues with actions, in the service of goal pursuit (e.g., Gollwitzer, 1999; Hommel et al., 2001; Sniehotta et al., 2005). Indeed, the act of planning a behaviour in response to a stimulus has been conceptualised as a mental simulation, such that the planner mentally enacts the desired 
behaviour in response to the critical cue, thus creating a memory association between cue and behaviour. This simulation is then partly re-activated when the stimulus is encountered again later, which facilitates the performance of the planned action (Martiny-Huenger et al., 2017). This is consistent with research on the role of motor simulations in action control and mental practice (e.g., Driskell et al., 1994; Eschen et al., 2007; Jeannerod, 1995, 2001). In complex and multidimensional situations of daily life, such simulations likely not only include a single visual cue, as would be the case in laboratory experiments, but other elements of the situation as well - and the degree to which this is the case may increase the effectiveness of this planning technique (see also Stawarz et al., 2020).

From this perspective, action planning can be conceptualised as forming situated conceptualisations of planned behaviours, not through repeat performance, but through effortful and vivid imagery of oneself performing the planned behaviour in the specified situation (see Papies, 2017). In line with this account, planning through implementation intentions has been shown to be more effective when it is supported by vivid mental imagery (e.g., Knäuper et al., 2009; Papies et al., 2009). Possibly, this is the case because more relevant cues are simulated during the planning or encoding phase, such that the planned behaviour is more likely to be activated by any of these cues in the performance phase. Alternatively or in addition, it is also possible that vivid mental imagery improves planning because it facilitates choosing more suitable situations for the planned behaviour (Adriaanse et al., 2010). This account of using mental imagery to form new situated conceptualisations might also explain the ironic effects of implementation intentions not to perform a specific behaviour (Adriaanse et al., 2011). These have been found to lead to cognitive and behavioural "rebound" effects of these behaviours becoming more salient and more frequent as a result of planning not to do them. Possibly, this happens because it is difficult to form a strong situated representation of oneself not performing a behaviour. This attempt may also inadvertently trigger imagery of the unwanted behaviour, reinforcing the existing situated representation. In sum, 
forming situated conceptualisations through imagery seems to be key to the effects of planning on behaviour.

Anticipated reward emerges as another key dimension of planning for behaviour change. Consistent with the grounded cognition perspective on motivated behaviour outlined here, planning for behaviour change relies on being motivated to perform the planned behaviour. Indeed, implementation intentions and action planning are typically seen as self-regulation strategies to bridge the intention-behaviour gap (e.g., Gollwitzer \& Sheeran, 2006; Papies, 2017; Sheeran \& Webb, 2016), thus allowing people to follow through if they are motivated to perform a behaviour to begin with, but when they might nevertheless forget this in the moment, or get distracted from goal pursuit in other ways (Gollwitzer \& Sheeran, 2006). This is in line with the idea that situated conceptualisations are more likely to affect behaviour if the simulations predict the experience of reward, or of a desired outcome. Indeed, a recent mixed-methods study on using implementation intentions to increase water drinking suggested that implementation intentions in the absence of a reward expectation are not effective to instigate behaviour (Rodger et al., 2022). In other words, one might remember the planned behaviour after forming implementation intentions, but if one does not like performing it (i.e., does not like the taste of water) or does not value it enough (i.e., another activity is more rewarding in the moment), one is still unlikely to follow through and perform it.

Applying the grounded cognition perspective on motivated behaviour to planning, we suggest that simulations again play a key role: only if simulating the planned behaviour in response to the situational cue leads to the expectation of reward, is it likely to be performed. In sum, planning can be conceptualised quite naturally as forming new situated conceptualisations of a behaviour through intentional, vivid simulations or mental imagery, which will affect behaviour in the specified situation if the action simulation also leads to a simulation of reward.

\subsection{Grounded cognitive processes in social norms}


We suggest that the grounded cognition perspective on desire and motivated behaviour can also be applied to behaviour that is guided by social norms. Along with habits and expected liking, social norms are a crucial predictor of appetitive behaviours, as people choose foods, drinks, and intake amounts to align with what they perceived as socially appropriate (e.g., Best \& Papies, 2019; Higgs, 2015; Neighbors et al., 2007; Versluis \& Papies, 2016).

A classic distinction in social psychology is between injunctive or subjective norms, which refer to a person's understanding of what others expect of them, and descriptive norms, which refer to a person's representation of the norm-relevant behaviour of other people (Cialdini et al., 1991). In the domain of transport, for example, the injunctive norm might favour active travel, such as walking and biking; however, if a person perceives that most other people are driving, the descriptive norms favours driving, and they will be more likely to drive. Indeed, in situations where injunctive and descriptive norms collide, research has shown that descriptive norms tend to have a more powerful influence on behaviour (e.g., Keizer et al., 2008).

We suggest here that simulations of other people's responses to one's behaviour may underlie the effects of social norms on behaviour, both injunctive and descriptive. Specifically, simulations of one's actions and their outcomes in a social context may motivate behaviour through anticipated reward. In other words, social norms work through expectancies of approval or disapproval from others in response to one's behaviour, with these expectancies being implemented as simulations.

As an example, consider the meat - masculinity norm. Meat is considered an archetypal food for men (Sobal, 2005), such that sourcing and consuming it is viewed as a central and intrinsic symbol of masculinity. Men consume more meat than women, especially when they conform to traditional masculinity norms (Rosenfeld \& Tomiyama, 2021). From the perspective of the grounded cognition theory of desire and motivated behaviour, men might simulate responses from others to their food choices, such that they anticipate approval from others for eating meat (i.e., being perceived as strong and masculine in line with existing norms), and disapproval for not eating meat 
(i.e., being perceived as weak or feminine in line with existing norms). These potential outcomes of one's actions in a social context might motivate conforming to shared societal "food scripts" (Sobal, 2005). Indeed, vegetarians, who clearly do not conform to this norm, are rated as less masculine than omnivores (Ruby \& Heine, 2011). Considering these strict pressures on men to conform to high meat consumption, simulations of negative social outcomes due to deviating from eating meat may reinforce this normative behaviour.

Similarly, consider the example of littering norms. Most people have grown up with the rule that litter may not be thrown onto the ground. The anticipated or simulated disapproval that one may receive from others if one were to violate this norm motivates carrying one's litter to the nearest bin. However, in a situation where other people have clearly violated this norm, because there is litter on the ground, the more situated, descriptive norm may prevail, because simulations of disapproval from others for littering are less likely (Cialdini et al., 1990; Keizer et al., 2008). In other words, the grounded cognition perspective would suggest that in situations where the injunctive and the descriptive norm are inconsistent, the descriptive norm affects behaviour more because it signals likely social outcomes in a more situated and hence informative manner (i.e., in the given context), implemented as simulations of approval or disapproval from others in the specific situation. While this conceptualisation of responses to social norms is consistent with previous theorising in the context of the focus theory of normative conduct (Jacobson et al., 2011), the grounded cognition perspective adds the proposition that it is simulations of other people's responses that shape behaviour. Specifically, while previous theorising suggests that descriptive or injunctive norms will affect behaviour to the degree that each kind of information is salient, we suggest that a salient norm affects behaviour because it shapes how an actor in a given situation simulates other people's responses to normative and norm-breaking behaviours. A salient "no littering" sign may trigger simulations of disapproval if one were to litter, whereas salient litter on the ground may trigger simulations of indifference in others if one were to litter. 
Social norms may be learned as situated conceptualisations of behaviours that occur in a certain context (see also Aarts \& Dijksterhuis, 2003), encoded either through observing others, or through performing these behaviours oneself with positive social outcomes, such as smooth coordination with others, social approval, or a positive social identity (e.g., Brick et al., 2021; Hawkins et al., 2019; Higgs, 2015). From this perspective, again, the cognitive structures of social norms may not differ much from those underlying habits or desires, especially when the relevant behaviours are performed frequently. These situated conceptualisations allow individuals to simulate possible behaviours in a given situation and pursue a behaviour that is anticipated to result in positive social outcomes. The perception of norms may also make normative behaviours more appealing, for example through increasing liking of foods that are perceived as normative for one's ingroup (Hackel et al., 2018; Higgs, 2015). In addition, social norms also serve as a framework of expectations around the behaviours of others (Hawkins et al., 2019), which may also be implemented as simulations of their behaviour. Thus, with the common denominator of outcome and reward simulations within situated conceptualisations, it seems that the grounded cognition perspective can naturally accommodate the diverse phenomena of desires, habits, and socially normative behaviour in one integrative framework.

\subsection{Grounded cognitive processes in self-regulation strategies}

The constructs of situated conceptualisations and simulations guiding behaviour can also be useful in the study and application of self-regulation and behaviour change techniques. Here, we will focus on the role of situated conceptualisations and simulations in the effects of goal priming and mindfulness interventions. We will also draw links with related techniques, such as distancing.

\subsubsection{Goal priming from the grounded cognition perspective}

Exposure to reminders of goals has been shown to affect the behaviour of individuals who are motivated to pursue those goals. In the domain of health, this phenomenon is typically referred to as health goal priming (e.g., Buckland et al., 2018; Papies, 2016a, 2016b; Weingarten et al., 2016). 
Theoretical analyses of health goal priming have proposed that goal reminders affect cognition and behaviour of individuals because they affect which goals are salient in a given situation. In the context of eating behaviour, for example, a hedonic enjoyment goal may be salient in most eating situations. When exposed to a health goal prime (e.g., a low-calorie recipe with health-related words), a long-term investment goal may become more salient and may ultimately affect the food one chooses to eat, for example the goal of maintaining a healthy body weight or cardiovascular system (see also Stroebe et al., 2013).

From a grounded cognition perspective, however, a goal-related cue will not merely increase the cognitive accessibility of the goal itself (e.g., unsituated and amodal thoughts about being healthy), but may activate a situated conceptualisation of reaching the goal (e.g., what it looks and feels like to be fit and healthy, in a specific situation). This may lead to vivid and potentially rewarding simulations. In other words, rather than simulating the pleasure of a piece of cake, a health goal prime may trigger the simulation of the embodied experience of feeling fit and healthy, and thus reduce unhealthy eating behaviours in those who find this rewarding. Indeed, as part of rewarding representations of long-term goals, health goal primes may also activate representations of goal-directed behaviours, to the degree that one has successfully pursued such behaviours in the past (e.g., foods to eat in order to be fit and healthy; see also Papies \& Barsalou, 2015; Barsalou, 2016a). In sum, the grounded cognition perspective on goal priming suggests that goal primes change which situated conceptualisations are cued by a given situation, and thus which potentially motivating outcomes are simulated and pursued (for more extensive discussions, see Papies, 2016a, 2016b). This way, simulations of rewarding outcomes play a key role in the effects of goal primes on behaviour.

\subsubsection{Mindfulness interventions from the grounded cognition perspective}

We have suggested that simulations can similarly help in interpreting the findings of mindfulness-based approaches in interventions on eating and drinking behaviour. Numerous studies 
have shown that mindfulness interventions can improve the regulation of appetitive behaviours, for example by reducing food cravings (e.g., Alberts et al., 2012), preventing overeating on unhealthy foods (Jordan et al., 2014), reducing smoking behaviour in response to cigarette cravings (Elwafi et al., 2013), and reducing heavy drinking (Bowen et al., 2014; see also Chiesa \& Serretti, 2010 for a systematic review). Experimental research has focused particularly on the meta-cognitive component of mindfulness that is often referred to as decentering. This refers to the insight that one's thoughts, feelings, and experiences are passing mental states, rather than accurate reflections of any objective reality (see Bishop et al., 2004; Safran \& Segal, 1990). Thus, instead of getting deeply immersed in one's thoughts and experience them as very "real", decentering reflects the awareness that one's experiences are in essence mental events which will arise and dissipate, however compelling and intense they may appear. In other words, instead of getting deeply immersed in detailed, multimodal simulations of consuming and enjoying a food or drink, one learns to see these thoughts as mental simulations, which one does not need to act on.

In the domain of appetitive behaviour, researchers have studied the specific effects of decentering by manipulating decentering without other components of mindfulness interventions (e.g., attention regulation). Typically, participants in these experiments learn about decentering, and then practice applying this concept to appetitive stimuli, such as food or drinks objects or images. They are told, for example, to observe their thoughts and experiences in response to food pictures, and to consider these thoughts and experiences as transient mental events. Participants' responses to these stimuli are then compared to the responses of participants in a control condition, who were, for example, merely exposed to the stimuli, or were instructed to look at them in their normal way, without further processing instructions.

Applying decentering in this way has been shown to reduce reactivity to appetitive cues, which has been operationalised, for example, as approach impulses, salivation, cravings, food choices, and unhealthy snacking occasions (e.g., Jenkins \& Tapper, 2014; Keesman et al., 2017; 
Lacaille et al., 2014; Papies et al., 2012, 2015; Tatar et al., 2021; Westbrook et al., 2013). From the grounded cognition perspective, decentering instructions likely induce a metacognitive re-appraisal of one's simulations as "mere" mental events, which reduces their "subjective realism" (Papies et al., 2012) and their motivational effects.

Recent studies have suggested that even if a food cue is approached from a decentered perspective, consumption and reward simulations still occur. However, decentering seems to reduce the motivational power of these simulations, such that the link between simulations and behaviour becomes less automatic. Indeed, in a qualitative decentering study, participants reported feeling "less involved" and "less unempowered" with regards to the food, suggesting that their simulations were less likely to overwhelm them and automatically initiate cravings and appetitive behaviour, when applying decentering (Tatar et al., 2021). Similarly, in an experiment assessing mental imagery and salivation in response to an attractive or neutral food, we found that decentering did not reduce mental imagery (i.e., consumption and reward simulations), but did reduce salivation to the attractive food, again suggesting a weakened link between simulations and their motivational effects (Keesman et al., 2017). This is consistent with accounts of mindfulness leading to a "decoupling" of reward simulations and desire or behaviour in other domains (e.g., Elwafi et al., 2013; Hadash et al., 2016; Ostafin et al., 2012). How to best operationalise this "decoupling" and examine its underlying mechanisms is an important task for future research.

These findings are clearly related to research on psychological distancing as a self-regulation technique. Indeed, adopting a distanced perspective on distressing events by focusing how one may feel about a currently distressing event in the far future can alleviate distress (Bruehlman-Senecal \& Ayduk, 2015). This change is driven by increasing the awareness that one's distress is impermanent, or in other words, a passing, temporary state that will likely dissipate over time. While such temporal distancing falls somewhat short of the meta-cognitive insight that all thoughts and 
experiences are in essence passing mental events, it may be effective in the moment for the same reasons, namely because it conveys that negative affect, or strong desire, will fade.

Such distancing effects can also be achieved through language (Orvell et al., 2019), possibly because language can affect which situated conceptualisations are retrieved. Indeed, considering attractive foods from the immersed perspective of "what do I want?" may be more likely to activate situated conceptualisations of wanting and consuming attractive foods, based on one's previous experiences, compared to the distanced perspective of "[name], what do you want?". This way, more immersed language can lead to unhealthier choices (Furman et al., 2020), possibly because it triggers more consumption and reward simulations. This is in line more generally with findings that shifting toward more abstract, less vivid and concrete construals of a situation supports long-term goal pursuit (Fujita \& Carnevale, 2012). Future research could test the effects of distancing strategies on situated conceptualisations and simulations, and examine whether repeatedly processing an event or stimulus from a distanced perspective changes the way it is encoded in memory, thereby changing later simulations and affective and motivational responses.

Together, the research described here is consistent with the view that decentering and distancing interventions aimed at consumption and reward simulations can disrupt the strong link between these simulations and motivated behaviour.

\subsubsection{A grounded cognition perspective on regulating negative mental imagery}

The cognitive processes of simulations, and of learning and updating situated conceptualisations, may also underpin emotion processing (e.g., Lebois et al., 2020), and may be effective targets for self-regulation strategies to deal with negative affect. 'Mental imagery' refers to vivid perceptual experiencing of imagined stimuli and events in the absence of sensory input (Kosslyn et al., 2001; MacNamara, 2018). Research on the physiological responding that takes place during mental imagery suggests that emotional mental imagery elicits physiological reactivity with an 'as-if real' quality (Ji et al., 2016). For example, an EEG study of healthy individuals by 
MacNamara (2018) found that negative imagined scenes elicited an increased Late Positive Potential (LPP; a measure of emotion processing). In other words, imagery led to increased neural processing, even in the absence of visual cues.

It has been suggested that intrusive negative imagery may be a key risk and maintenance factor of emotional disorders. For instance, in a qualitative study, Patel and colleagues (2007) found that individuals with depression experienced intrusive images. Crucially, participants described these images as 'snapshots' of an intrusive memory that were coupled with a sense of 'nowness', and physical and emotional re-experiencing. Similarly, in a sample with comorbid anxiety and depression, those with generalised anxiety disorder (GAD) showed increased neural processing of negative imagery when controlling for depression (Bauer \& MacNamara, 2021). Together, the processes described here closely parallel the grounded cognitive processes of situated conceptualisations and simulations discussed above for the domains of appetitive behaviour. Specifically, the activation of situated conceptualisations, or detailed event memories, formed during past affective experiences may lead to vivid, consciously experienced simulations (i.e., mental imagery) of parts of those experiences, including strong affective, neural, and physiological responses that may lead to distress.

Again, this process may be a key mechanism in self-regulation strategies, including exposurebased therapies and mindfulness interventions. Exposure-based therapies entail systematic confrontation of subjectively distressing experiences in an objectively safe context. Exposure could be 'in vivo' (i.e., in real-life situations), imaginal, and even through virtual reality (Opriş et al., 2012; Rauch et al., 2012). There is strong evidence suggesting that exposure is effective for treating a range of disorders, including specific phobias, post-traumatic stress disorder, and generalised anxiety disorder (for an overview, see Ji et al., 2016). According to Foa and Kozak’s (1986) emotional processing theory, exposure-based therapies are effective because they first activate the 'fear structure', and then present alternative information. Here, 'fear structure' refers to the cognitive 
representation of emotional memories, akin to 'situated conceptualisations' in the grounded cognition theory. The ensuing presentation of alternative information disconfirms and replaces the unhelpful elements of the original memory, such as feared outcomes (e.g., loss of control, retraumatisation), thus updating situated conceptualisations. Over time, confrontation that does not lead to feared outcomes elicits a reduced emotional response (i.e., habituation), again suggesting that updated situated conceptualisations support more adaptive simulations and behaviours.

In mindfulness-based interventions, in contrast, it is not the content of situated conceptualisations that is changed, but rather the individual's relation to it. The meta-cognitive insight of decentering may target mental imagery by 'competing' for cognitive resources required to process mental imagery (Holmes \& Mathews, 2010). Alternatively, and as described above for appetitive stimuli, decentering may de-couple mental imagery from automatic negative affective responses (Paz et al., 2017). Adopting a decentred perspective may lead one to observe one's imagery as transient, however vivid and compelling it may be. Therefore, even if this imagery remains active in the mind, decentering may reduce the impact that imagery has on one's affective responses through a shift in perspective, and thus change how one views the content of one's situated conceptualisations (Keesman et al., 2020; Lebois et al., 2015). Over time, this may in turn update one's situated conceptualisations to trigger less negative affect, akin to exposure therapy (see Hölzel et al., 2011).

This perspective is largely consistent with a recent framework on the immediate and sustained effectiveness of different kinds of emotion regulation strategies more generally (Sheppes, 2020). Sheppes argues that emotion regulation strategies that focus on early attentional disengagement may provide immediate affective benefits at relatively low cognitive cost, while only strategies that effortfully engage with emotional information and modulate its meaning provide longer-term benefits (Sheppes, 2020). From a grounded cognition perspective, we would argue that emotion regulation strategies are often spontaneously or strategically employed when a situation 
activates a situated conceptualisation that triggers strong negative affect. Attentional disengagement, for example by deliberately activating competing situated conceptualisations (e.g., through focusing on other external or internal features of one's experience), can be adaptive insofar as it can prevent or temper simulations of negative outcomes or experiences that would cause immediate distress. This contrasts with effortful strategies of mentally engaging with the content of the situated conceptualisations that trigger negative affect, for example by applying a decentered perspective. Such an approach may reduce the vividness of the simulations and resulting negative affect both in the moment and when re-activated later, thus providing both short and longer term benefits if applied over a period of time. We should note that a decentered perspective can be applied to both the content of the situated conceptualisation, as well as to one's affective responses. Thus, a decentering approach can be applied instead of attentional disengagement to high intensity affective information, consequently allowing negative affect to be unlearned, similar to exposure therapy. In sum, from a grounded cognition perspective, an emotion regulation strategy will be effective to the degree that it updates a situated conceptualisation such that simulating its features triggers less negative affect.

Drawing parallels between extant literature in emotion processing and the grounded cognition perspective in this way may open up promising new research avenues, including in the context of self-regulation strategies.

\subsection{Summary and future research}

In this section, we have explored the roles of grounded cognitive processes in some key research topics related to self-regulation and behaviour change, including outcome expectancies, habits, planning, goal priming, mindfulness and related techniques, as well as in the situated measurement of motivated behaviour. Across these domains, it seems that understanding selfregulation and behaviour change from the grounded cognition perspective on desire is consistent with empirical findings and is helpful in at least two ways. 
First, the grounded cognition perspective is useful because it draws attention to the situated nature of cognitive processes supporting self-regulation and behaviour change. We have shown how representations of appetitive stimuli contain a multitude of detailed situational features that influence desire, with clear parallels in domains of negative affective experience. These rich and idiosyncratic situations not only affect desire and motivated action with regard to the appetitive stimulus, but they also form the context of any attempt at behaviour change. Thus, research on outcome expectancies, habits, social norms, implementation intentions, and mindfulness-based techniques needs to take into account the significant variability in both internal and external cues that can affect potentially problematic behaviour, and that simultaneously could provide opportunities for enacting behaviour change.

Laboratory-inspired traditions that identify a single cue, or a single anticipated outcome, even if this is tailored to individual participants, are unlikely to be able to capture the richness of situational cues potentially shaping simulations and behaviour. As a result, they are also unlikely to use such cues effectively to support behaviour change. A key question for future research is therefore how to measure how an individual perceives a situation comprehensively and which features matter most. How can we assess each person's situated conceptualisation of a behaviour, and how can we determine which situational features have the strongest influence on cognition and behaviour?

Situated conceptualisations and their influential features will likely vary strongly across both individuals and situations, and possibly also over time (see Barsalou, 2020; Dutriaux, Clark, et al., 2021). Clearly, this does not afford the clean and clear-cut manipulation of situations and stimuli that we like to work with in experimental social psychology. However, acknowledging and embracing this variability might strengthen the ecological validity of our research in ways that are needed if we want to effect lasting behaviour change. Novel methods that integrate mobile 
computing, sensing data and experience sampling to assess mental states could provide opportunities for tackling these measurement challenges.

A second way in which the grounded perspective is useful for understanding self-regulation and behaviour change processes is by offering a single, integrative framework for understanding key mechanisms of behaviour change. In particular, the notion that behaviour is motivated by reward simulations may bring useful parsimony to the study of self-regulation and behaviour change. We suggest that this basic mechanism may underlie a variety of behaviours that researchers refer to as appetitive behaviours, habits, social norms, or implementation intentions, and that this is also the mechanism that is modulated when meta-cognitive interventions like mindfulness are applied.

Future research could attempt to test this account directly, for example by examining the causal role of simulations in these behaviours. In recent work, for example, we have shown that situational cues causally affect desire through consumption and reward simulations (Papies et al., 2022), and other work shows that people often perform habitual behaviours because they are rewarding (Dutriaux, Clark, et al., 2021). Thus, it seems possible that situational cues trigger frequently performed behaviours, or habits, through reward simulations, and relatedly, that habitual behaviours can also be experienced as desires. In other words, reward expectations may play a role in at least some habits. Again, future research should test this possibility directly. Future research should then also assess whether a simulation perspective on behaviour change allows researchers to develop more effective, situated interventions.

\section{New methodological approaches for studying motivation in the context of situated conceptualisations}

Throughout the research described so far, we have worked with a variety of research methodologies to establish, interpret, manipulate, and measure the rich, idiosyncratic content and experiences of situated conceptualisations in motivated behaviour. In this process, we have worked with three methods that are likely novel to most readers and researchers in this area. The first of 
these is the feature listing task and feature coding. We have used this method extensively to establish representations of appetitive stimuli in participants' minds and in the public discourse around food. Because this method is discussed in detail in other places (Papies et al., 2021; Papies, Tatar, et al., 2020), we won't address it here. The second novel method is qualitative research. In this section, we will discuss how qualitative research has informed and enriched our research, and suggest ways in which other researchers could benefit from it, too. Finally, we will discuss a third novel research method, namely a quantitative assessment approach for motivated behaviours that attempts to capture the situated nature of behaviour.

\subsection{Qualitative research in the context of the grounded cognition perspective}

We are aware that most readers of this chapter may have a background in experimental social psychology, and may have had little exposure to qualitative research. Here, we will briefly address how, based on the research program described here, supplementing experimental research with qualitative research could potentially benefit experimental work. This may be the case particularly in the area of situated and grounded cognition, which acknowledges the richness of situations and experiences that shape cognition and behaviour, limiting the generalisability of standardised measures and manipulations.

Qualitative strategies have much to offer over purely quantitative designs. Apart from providing deeper insights into scientific inquiries, qualitative research helps generate hypotheses as well as further interpret quantitative results. Moreover, the iterative and often inductive nature of qualitative research allows researchers to gain insights they have not considered at the beginning of the research process. Qualitative research also emphasises the importance of reflexivity, the process of critical thinking about how our subjectivity as researchers and the wider context of our research impact the research process and the conclusions we draw (for a more detailed overview, see Lazard \& McAvoy, 2020; Trainor \& Bundon, 2021). This is opposed to the positivist quantitative methods 
that are constrained by deductive reasoning and removing subjectivity from the research process (Lazard \& McAvoy, 2020).

Qualitative research has been widely used in the field of health psychology and behavioural change. Within our research program, engaging in qualitative research has given us insights into how our research may be affected by our situated conceptualisations as researchers of the behaviours we study, and our situated conceptualisations of how participants will experience our study. Specifically, these can influence the research questions we ask, the methods we use, and the conclusions we draw. For example, at the beginning of our research into water drinking behaviour we held situated conceptualisations of the types of contexts people drink water in (e.g., at work), the complexity of water drinking behaviour (i.e., simplistic), as well as the rewards (e.g., long-term health benefits) and barriers (e.g., disliking the taste) people might simulate about drinking water. These situated conceptualisations were informed by our own experience with water drinking behaviour and prior theoretical knowledge in the domain of health behaviour and behaviour change. We were not always aware of the situated conceptualisations we held about water drinking behaviour, and how they influenced the research process from the offset of our studies. However, using qualitative research methods increased our awareness of our situated conceptualisations and allowed us to update them to form a more accurate representation of water drinking behaviour which may be experienced in many more ways than we had anticipated (see also Wehbe et al., 2021). Engaging in reflexive thematic analysis (Braun \& Clarke, 2006, 2019, 2021) during our qualitative research has given us an insight into the ways that our current situated conceptualisations of water drinking behaviour and our participants' experience of taking part in our studies were inaccurate and incomplete. For example, our first qualitative study (Rodger et al., 2021) on water drinking challenged our assumption that water drinking was a simple health behaviour. We explicitly noted our surprise at the prevalence of participants mentioning the effort involved in water drinking. We found that this surprise was due to our underlying situated conceptualisation of water drinking 
behaviour as including drinking from a glass or a bottle, but not the preparation behaviours (e.g., filling the glass or bottle) that need to precede this.

As another example of the benefits of reflexivity, in our recent mixed-methods experiment on using implementation intentions to increase water intake (Rodger et al., 2022) we learned that our situated conceptualisations of how participants would experience using implementation intentions during the follow up period were inaccurate. The prevalence of intervention participants struggling to remember to drink water during the situations they had planned for in the implementation intentions was uncomfortable for us to interpret at first, as this violated our assumption that implementation intentions would be salient in those situations, and that they would help participants remember their planned behaviour. This result caused us to carefully assess potential inaccuracies in our theoretical understanding of implementation intentions from previous literature and pose important new questions. This result also helped us inform our understanding of participants' experience of our intervention, which can motivate further improvements. Similar insights may also enrich the experiences of practitioners who engage with clients in the domains of eating and drinking behaviour, and who may benefit from reflexively challenging their preconceptions of what motivates clients' behaviour through qualitive research.

The insights we have gained from our qualitative research have allowed us to develop more informed research questions and study designs. These insights would not have been possible using positivist quantitative methods. Therefore, we advocate that researchers consider engaging with qualitative research or engaging in reflexivity during quantitative research to better understand what situated conceptualisations they hold, and how these influence the research process.

\subsection{The situated measurement of motivated behaviour}

We suggest that the grounded and situated cognition perspective that we have applied here to desire and motivated behaviour also has implications for the measurement of behaviour. Specifically, inspired by the construct of situated conceptualization, we have developed a new approach for 
assessing individual differences in the regulation of behaviour. Because this approach is grounded in two dimensions of situatedness — situational experience and the situated action cycle - we call it the Situated Assessment Method $\left(\mathrm{SAM}^{2}\right)$. We suggest that it has significant potential for capturing the rich content of situated conceptualizations at both the group and individual levels (Barsalou, 2019, 2020; Dutriaux, Clark, et al., 2021), which can underlie a variety of motivated behaviours as described above.

To establish individual differences for a target behaviour such as eating or drinking in a grounded manner, $\mathrm{SAM}^{2}$ assesses the behaviour on two dimensions of situatedness: (1) situational experience, (2) the situated action cycle. The superscript 2 refers to the fact that $\mathrm{SAM}^{2}$ is situated in these two manners. We next address each dimension in turn.

$\mathrm{SAM}^{2}$ assesses individual differences for in a behaviour such as eating or drinking in situational experience of it. Thus, rather than asking individuals to generalize about the behaviour across situations without explicitly taking them into account — as typical for most assessment instruments - $\mathrm{SAM}^{2}$ identifies relevant situations where the behaviour occurs and asks individuals to assess the behaviour in each separately. As an example, instead of asking individuals to generally assess how much healthy versus unhealthy food they eat, $\mathrm{SAM}^{2}$ asks individuals how much they eat specific foods in particular eating situations (e.g., How frequently do you eat a salad for dinner?).

Besides assessing a target behaviour specifically with regard to the situations where it occurs, $\mathrm{SAM}^{2}$ assesses factors from situated action that influences it, as established in the scientific literature. In the domain of eating behaviour, this includes factors such as hunger, food palatability, current emotional state, health goals, and eating identity. Typically, these influential factors are sampled from the Situated Action Cycle (see Barsalou, 2019), which includes: (1) environmental cues that trigger the target behaviour, (2) cognitive processes that establish the self-relevance of these cues related to goals, norms, values, and identity, (3) affective processes related to selfrelevance that produce motivational and emotional states in the body, (4) action that include 
executive operations in working memory, attentional responses via eye movements, and over bodily actions to achieve goals, and (5) outcomes that result from these actions that include various forms of reward and evaluation of predictive inferences made throughout the Cycle.

Once assessments of the target behaviour in relevant situations have been collected for an individual, together with assessment of situational factors that influence it, they are aggregated to establish a rich descriptive profile of the individual's behaviour across situations. We have used this approach in recent research on habits, as described above (Dutriaux, Clark, et al., 2021), to establish a variety of situated measures for the target behaviour that reflect situational experience.

Additionally, this situated measurement approach establishes factors that influence the behaviour in each individual, and also at the group level, typically explaining around $70 \%$ of the variance. Finally, Dutriaux et al. illustrate that this approach captures individual differences in personality, such as trait self-control, and explains them in terms of cognitive-affective processes from the Situated Action Cycle. In other words, this situated measurement approach can explain effects of traits through systematic patterns of how individuals implement situated action in specific situations. Similar to Whole Trait Theory (Fleeson \& Jayawickreme, 2021), SAM² captures trait-level information about individuals, together with how trait-level tendencies vary across situations.

Thus, $\mathrm{SAM}^{2}$ offers a promising approach for measuring situated conceptualizations from a grounded cognition perspective. This approach could be a useful tool to start systematically establishing the situated conceptualisations that underlie people's simulations and motivated behaviour within the rich and idiosyncratically encoded situations of interest to social psychologists.

\section{Implications for behaviour change}

In this final section, we will address the implications of the grounded cognition theory of desire and motivated behaviour for behaviour change. Throughout the chapter, we have briefly pointed to behaviour change when relevant, for example in the context of reducing meat consumption, planning as a self-regulation tool, or mindfulness reducing the effects of reward 
simulations on appetitive behaviour. Here, we will address the roles of situated conceptualisations and simulations in behaviour change more comprehensively, and with regard to several key dimensions of behaviour change. Specifically, and in line with the stages of change model (Prochaska \& Velicer, 1997), we will address the contemplation and preparation of a new behaviour, as well as action, repetition, and maintenance of a new behaviour over time. We argue that rewarding simulations of performing a new behaviour can affect behaviour change at each of these stages of change. In addition, we will separately address one-off, high-impact decision making in the face of the status quo. Throughout, we conceptualise behaviour change as overriding the reward simulations that motivate existing habits and socially normative behaviours (i.e., that favour the status quo), and as forming new situated conceptualisations to maintain behaviour change as habit change (see Figure 6 for an overview of the implications of our theory for behaviour change).

\subsection{Conceptualising behaviour change as habit change}

Our discussion here assumes that most successful behaviour change ultimately requires habit change. This can mean that new habits have to be formed, existing habits have to be disrupted, or both. Therefore, considering habits and habit formation is crucial for any attempt at behaviour change.

In most domains of health, for example eating a healthy diet, drinking water, performing physical activity, getting sufficient sleep, etc., behaviour change is only successful if the new, desired behaviour is repeated frequently over time. In many cases, it has to be repeated for the rest of a person's life. Healthy hydration, for example, is only achieved when sufficient amounts of water are consumed frequently throughout each and every day, adding up to tens of thousands of litres over a person's lifetime. While this may be an extreme case, most health behaviours rely on frequent repetition to deliver health benefits. Thus, behaviour change in such domains requires the formation and maintenance of new habits. 
In addition, most behaviours occur in a familiar context where habits for other behaviours already exist, even if these are unrelated to the new behaviour, or when they are simply the habit of "doing nothing". Behaviour change in such situations thus constitutes disrupting the status quo. The status quo can be conceptualised as continuing habitual and often socially normative behaviours (W. Samuelson \& Zeckhauser, 1988). From this perspective, even in one-off decisions, such as highimpact policy choices, habits are important: such decisions often require deviating from the habits that constitute the status quo, and substituting them with a different behaviour. Thus, behaviour change typically requires overriding the reward simulations that motivate existing habits, and often repeatedly so.

Given the pervasive role of habits in human behaviour, and the conceptualisation of the status quo as maintaining habits, we suggest that it is useful to consider any behaviour change as habit change. In other words, all else being equal, habit change is a useful starting point to conceptualise behaviour change, because it challenges researchers and intervention practitioners to consider the habits that may impede change, and which may otherwise remain unexplored. Thus, any discussion of behaviour change needs to consider both existing habits potentially preventing change, as well as forming new habits to maintain change.

We have suggested that habits can be viewed as situated conceptualisations. From that perspective, behaviour change needs to consider both existing situated conceptualisations, as well as how new situated conceptualisations can be formed to maintain change, as these will inform the action and outcome simulations that motivate behaviour. In other words, behaviour change can be conceptualised as updating situated representations of motivated behaviours in their social context. Next, we apply this perspective to examine the roles of habits and social norms in different phases of behaviour change.

\subsection{Contemplating, preparing and initiating new behaviours}


When contemplating a new behaviour, situated simulations of performing it, along with the likely outcomes, will play a key role in any decision to perform it. As an example, consider a consumer contemplating reducing their meat intake. Upon reading about the environmental impacts of meat production, they may feel that it would be good to reduce their meat consumption. Before deciding on going down that path, they may simulate relevant situations, for example being in a pub with friends, going over the menu, finding only one meat-free dish, and having to defend their choice towards their friends. Similarly, they may simulate trying to cook dinner without meat, and finding themselves making their habitual dishes with the meat "missing".

Alternatively, a consumer contemplating meat reduction may simulate sitting down with friends in a lively vegan restaurant, being overwhelmed with attractive sounding meat-free choices, and sharing a number of tasty dishes with their friends. They may also simulate choosing several attractive meat replacements in the supermarket and finding themselves keen to try them out in familiar as well as novel recipes at home.

Clearly, both the "deprivation" and the "enjoyment" scenario described here are plausible (see Wehbe et al., 2021). However, they would likely lead to very different outcomes. Simulating enjoyable and socially rewarding experiences of meat-free eating is much more likely to lead a consumer to initiate meat reduction behaviours, compared to simulations of bland food and social rejection. More generally, simulating positive and socially rewarded behavioural alternatives is much more likely to facilitate behaviour change than simulating effortful, challenging behaviours that are met with social disapproval.

More generally, how can the challenges that an individual contemplating behaviour change encounters, be understood through the grounded cognition perspective on desire, habits, and norms? When contemplating or preparing a new behaviour, upon activating a situated conceptualisation in a given situation, multiple courses of action and associated outcomes may be simulated. This includes simulations of one's habitual behaviour, and simulations of novel behaviours, along with the 
associated reward. The reward simulations can include hedonic reward (e.g., physical enjoyment), social reward (e.g., social approval), and intrinsic reward (e.g., from alignment with important values). For both habit-prone, daily-life decisions, and for one-off, high-impact decisions, a new behaviour is more likely to be initiated if simulations of performing it are more rewarding than simulations of the habitual behaviour.

Thus, when contemplating and preparing new behaviours, people may initially simulate performing their familiar, habitual, normative behaviours that lead to reward (e.g., a potential meat reducer simulating the experience of eating and enjoying meat to the approval of others). Such simulations can be triggered by external cues (e.g., the smell of bacon, meat-based dishes on a restaurant menu, the behaviour of others), and they can reduce the chances of behaviour change. When the contemplated behaviour change involves moving away from established habits within familiar contexts, it is likely that there are many cues that remind an individual of their habitual behaviours. Since habitual behaviours are typically performed with an expectation of reward (Dutriaux, Clark, et al., 2021; Kruglanski \& Szumowska, 2020; Rodger et al., 2021; Rodger \& Papies, 2021), such external cues will likely trigger reward simulations, which may create desire (Papies et al., 2021, 2022). Thus, the contemplated new behaviour must produce more appealing outcome simulations overall than the habitual behaviour, if it is to be initiated. It is for that reason that existing habits, social norms, and their interactions in producing reward simulations must be actively considered for successful behaviour change.

When preparing a new behaviour, simulations of performing it within specific situations can also help identify obstacles that need to be addressed for successful behaviour change (see also mental contrasting, e.g., Kappes et al., 2012). Again, these obstacles are likely related to existing habits. In the domain of water drinking, for example, a person wanting to drink water more frequently during the day may think about suitable situations, and how increased intake could be achieved in those situations. They may simulate sitting at their desk, and having to walk to the water 
cooler to get a glass of water; they may also anticipate that this might be perceived as effortful, given their sedentary habits, and that preparing a glass or a bottle of water in advance would increase the chances of drinking it. They may also anticipate the temptation of the soda machine in the hallway, and could devise strategies to reduce it. From a grounded cognition perspective, only if the simulations of the intended behaviour make this behaviour appear appealing and feasible during planning is it likely to be initiated later.

Future research could address how individuals motivated for behaviour change can best form situated conceptualisations that support them. In other words, which envisioning strategies can form vivid and positive situated representations of performing new behaviours, which can later be retrieved to guide simulations and behaviour in critical situations? What is the role of social reward signals and of personal values in such representations? How can the anticipated reward from one's long-term goals and values best be recruited to enhance the motivating power of these situated conceptualisations? How can individual differences in reward motivation best be captured and integrated into these efforts? What is the role of existing representations in this process (see Szpunar et al., 2007)? Situated conceptualisations of appetitive behaviours are often learned through observing others or through exposure to marketing (see also Claassen, Rusz, et al., 2022). Future research could examine how such strategies can best be used to facilitate behaviour change in the recognition of existing habits and social norms.

\subsection{Repeating and maintaining new behaviours}

Lasting behaviour change relies on the repeated initiation of a new behaviour, despite the "pull" of existing habits and often of social norms that support those habits. Once an individual has moved from the contemplation and preparation phases to the action phase of behaviour change, which challenges do they encounter in repeatedly initiating a new behaviour? How can these challenges be understood and addressed through the grounded cognition perspective? Here, we will address challenges related to remembering, reward, and effort. We argue that performing a new 
behaviour can update existing situated conceptualisations for a given situation, which makes repeated initiation more likely. This in turn will further update situated conceptualisations, establishing new habits. New habits will help to overcome challenges related to remembering, reward, and effort, and form the basis of behaviour change maintenance.

Let's first address the challenge of remembering. Given that a new behaviour, for example drinking water at one's desk, is likely to be introduced into a familiar context, it is possible that the new behaviour is simply forgotten, because the context does not trigger it. From the perspective of grounded cognition, existing situated conceptualisations of the familiar situation without the new behaviour (e.g., working at one's desk without water) may be so well entrenched that a new and competing situated conceptualisation (e.g., drinking water while working at one's desk) is not easily activated. Planning tools, such as implementation intentions, have been suggested to address this particular problem (Gollwitzer \& Sheeran, 2006; Papies, 2017; Sheeran \& Webb, 2016), although they may not be a panacea against forgetting (Rodger et al., 2022). Again, to the degree that the new behaviour is repeatedly performed in the same context, it is likely to update existing situated conceptualisations, making repeated initiation increasingly likely.

Updating situated conceptualisations will also help address the challenge of reward. A new behaviour often takes place in a context where competing habits and possibly social norms exist, and these may support behaviours that are more appealing in the short term. In other words, as described above, simulations of hedonic and social reward in response to one's habitual behaviour may make this more tempting than the new behaviour. This may affect behaviour in the contemplation, preparation, action, and maintenance phases of behaviour change, such that the new behaviour will only be initiated if it leads to more rewarding simulations than existing habits and normative behaviours. To the degree that a new behaviour has been performed more frequently and has led to rewarding outcomes that are stored in updated situated conceptualisations, the temptation of one's "old habits" may decline, as the new behaviour produces increasingly rewarding simulations. 
Finally, initially performing a new behaviour in a familiar situation could be perceived as effortful. Simulating a new, intended behaviour in a familiar situation may produce a sense of high effort and low automaticity. Even if the effort is objectively low, subjective perceptions of effort can easily derail behaviour change. In our water drinking research, for example, some participants reported finding it effortful to fill a glass of water if this interrupted their daily routines, and this perceived effort impeded their water drinking (Rodger \& Papies, 2021). To the degree that a new behaviour has been performed more frequently and updated situated conceptualisations accordingly, the perceived effort of performing it may decline, as the new behaviour produces simulations of performing the behaviour with increasing ease.

Again, future research could examine how planning and imagery can be used to construct situated conceptualisations of performing a new, intended behaviour with ease and with socially and hedonically rewarding outcomes.

\subsection{One-off decision making in the face of the status quo}

Finally, a grounded cognition perspective can inform our understanding of the processes and challenges of one-off decision making for behaviour change in the face of the status quo. As we have suggested above, the status quo can be conceptualised as the maintenance of habitual and socially normative behaviours. Although our analysis of behaviour change suggests that one-off high-impact decisions in the face of the status quo are affected by many of the same processes as more mundane, daily life decisions, we discuss them separately here because of their large societal relevance.

On the level of individual consumers, the status quo can mean, for example, sourcing electricity from energy companies rather than installing solar panels, continuing to travel in a gasoline-powered car, and keeping one's fossil-fuel heavy bank and pension fund. All of these behaviours are the results of habits, socially sanctioned, and yet harmful. They can be changed with 
one-off, high-impact decisions: installing solar panels, purchasing an electric vehicle or cargo bike, and switching one's bank and pension fund.

On the level of organisational or policy decision makers, the status quo can mean, for example, renewing contracts with external providers for meat-based school lunches, focusing city planning around individual car use, or keeping public or organisational funds invested in fossil-fuel industries. Again, all of these behaviours are the results of habits, socially sanctioned, and yet harmful. They can be changed with one-off, high-impact decisions: announcing a move toward plant-based school lunches, introducing new basic conditions for city planning, or divesting public funds from fossil fuels. What does it take for an individual citizen or a member of an organisation to engage with such high-impact decisions, and how can the challenges of doing so be understood and addressed from a grounded cognition perspective?

As described above, simulations of performing the new behaviour and of its effects will likely play a key role. And again, a behaviour is more likely to be performed if these simulations make the behaviour appear feasible and rewarding. Thus, to the degree that features of the status quo are highly rewarding to an individual personally (e.g., driving), initiating change is unlikely.

In behaviours that disrupt the socially sanctioned status quo, it is likely that outcome simulations include simulations of disapproval from others, as one threatens to deviate from social norms. In those situations, reward simulations from pursuing behaviours that align with important values (e.g., social justice) may bolster the chances of performing the behaviour despite such fears of backlash. Alternatively, reward simulations from envisioning positive futures could provide such reward, for example visions of a green, car-free, healthy city with children playing outside in spaces where highways used to be. More generally, it is possible that reward simulations can be harnessed to promote long-term thinking, and that high-impact decisions can be supported by concrete, rewarding simulations. Future research should address this, and should also examine whether situated conceptualisations that afford such reward simulations can be constructed deliberately, for 
example through envisioning exercises (see Wilson-Mendenhall et al., 2021, for an application of this idea in compassion meditation). In other words: can mental imagery create courage? This could also be a useful avenues for activism to support policy change.

It is also possible that self-regulation strategies such as mindfulness may reduce the impact of potential social disapproval. Recent research has further shown that dynamic social norms can have a strong impact on behaviour, for example the perception that other people are increasingly changing a certain behaviour (e.g., Sparkman \& Walton, 2017). Such dynamic norms can be understood as situated conceptualisations of approval by small numbers of people that represent a future majority. Possibly, such dynamic norms can be recruited to support high-impact decision making in the face of the status quo. Again, future research could examine this possibility.

\section{Conclusion}

In this chapter, we have presented recent evidence in line with the grounded cognition theory of desire and motivated behaviour, mostly from the domains of eating and drinking. Then, we have discussed how the theory can explain specific other types of motivated behaviour, most importantly habits and social norms. Across domains and types of behaviour, empirical evidence is consistent with the theme that simulations of the outcomes of one's actions play a key role in motivating and guiding behaviour.

Rich, multimodal experiences of actions, their contexts, and their outcomes are continuously encoded and updated in situated conceptualisations of motivated behaviour. We have shown how situated conceptualisations of attractive foods and drinks are dominated by simulations of consuming and enjoying them in a social context, and how these simulations shape motivation and behaviour. The expectation of reward also seems to motivate habitual behaviour, and in the domain of social norms, the expectation of social approval may be the reward simulation that motivates normative behaviour. Successful behaviour change must overcome the simulations of hedonic and social reward that will inevitably favour existing habits and behaviours, or in other words, the status quo. 
In order to move beyond the socially sanctioned, habitual behaviours that currently threaten human health and the very existence of the human species, we must understand what motivates them, and how this motivation can be harnessed for the greater good. We hope that our analysis can contribute to this. 


\section{References}

Aarts, H., \& Dijksterhuis, A. (2003). The Silence of the Library: Environment, Situational Norm, and Social Behavior. Journal of Personality and Social Psychology, 84, 18.

Adriaanse, M. A., Oettingen, G., Gollwitzer, P. M., Hennes, E. P., de Ridder, D. T. D., \& de Wit, J. B. F. (2010). When planning is not enough: Fighting unhealthy snacking habits by mental contrasting with implementation intentions (MCII). European Journal of Social Psychology, 40(7), 1277-1293. https://doi.org/10.1002/ejsp.730

Adriaanse, M. A., van Oosten, J. M. F., de Ridder, D. T. D., de Wit, J. B. F., \& Evers, C. (2011). Planning What Not to Eat: Ironic Effects of Implementation Intentions Negating Unhealthy Habits. Personality and Social Psychology Bulletin, 37(1), 69-81. https://doi.org/10.1177/0146167210390523

Alberts, H. J. E. M., Thewissen, R., \& Raes, L. (2012). Dealing with problematic eating behaviour. The effects of a mindfulness-based intervention on eating behaviour, food cravings, dichotomous thinking and body image concern. Appetite, 58(3), 847-851. https://doi.org/10.1016/j.appet.2012.01.009

Barsalou, L. W. (1999). Perceptual symbol systems. Behavioral \& Brain Sciences, 22, 577-660.

Barsalou, L. W. (2003). Situated simulation in the human conceptual system. Language and Cognitive Processes, 18, 513-562.

Barsalou, L. W. (2008). Grounded cognition. Annual Review of Psychology, 59(1), 617-645. https://doi.org/10.1146/annurev.psych.59.103006.093639

Barsalou, L. W. (2009). Simulation, situated conceptualization, and prediction. Philosophical Transactions of the Royal Society B: Biological Sciences, 364(1521), 1281-1289.

https://doi.org/10.1098/rstb.2008.0319

Barsalou, L. W. (2016a). Situated Conceptualization Offers a Theoretical Account of Social Priming. Current Opinion in Psychology, 12, 6-11.

Barsalou, L. W. (2016b). Situated Conceptualization: Theory and Application. In Foundations of embodied cognition. Psychology Press. 
Barsalou, L. W. (2019). Establishing Generalizable Mechanisms. Psychological Inquiry, 30(4), 220-230. https://doi.org/10.1080/1047840X.2019.1693857

Barsalou, L. W. (2020). Challenges and Opportunities for Grounding Cognition. Journal of Cognition, 3(1), 31. https://doi.org/10.5334/joc.116

Bartholow, B. D., \& Heinz, A. (2006). Alcohol and Aggression Without Consumption Alcohol Cues, Aggressive Thoughts, and Hostile Perception Bias. Psychological Science, 17(1), 30-37. https://doi.org/10.1111/j.1467-9280.2005.01661.x

Bauer, E. A., \& MacNamara, A. (2021). Comorbid anxiety and depression: Opposing effects on the electrocortical processing of negative imagery in a focal fear sample. Depression and Anxiety, 38(7), 690-699. https://doi.org/10.1002/da.23160

Berridge, K. C., Robinson, T. E., \& Aldridge, J. W. (2009). Dissecting components of reward: 'Liking', 'wanting', and learning. Current Opinion in Pharmacology, 9(1), 65-73. https://doi.org/10.1016/j.coph.2008.12.014

Best, M., \& Papies, E. K. (2017). Right Here, Right Now: Situated Interventions to Change Consumer Habits. Journal of the Association for Consumer Research, 2(3), 333-358. https://doi.org/10.1086/695443

Best, M., \& Papies, E. K. (2019). Lower socioeconomic status is associated with higher intended consumption from oversized portions of unhealthy food. Appetite, 140, 255-268. https://doi.org/10.1016/j.appet.2019.05.009

Birnbaum, G. E., Kanat-Maymon, Y., Mizrahi, M., Recanati, M., \& Orr, R. (2019). What Fantasies Can Do to Your Relationship: The Effects of Sexual Fantasies on Couple Interactions. Personality and Social Psychology Bulletin, 45(3), 461-476. https://doi.org/10.1177/0146167218789611

Birnbaum, G. E., Mikulincer, M., \& Gillath, O. (2011). In and Out of a Daydream: Attachment Orientations, Daily Couple Interactions, and Sexual Fantasies. Personality and Social Psychology Bulletin, 37(10), 1398-1410. https://doi.org/10.1177/0146167211410986 
Bishop, S. R., Lau, M., Shapiro, S., Carlson, L., Anderson, N. D., Carmody, J., Zindel V. Segal, Abbey, S., Speca, M., Velting, D., \& Devins, G. (2004). Mindfulness: A proposed operational definition. Clinical Psychology: Science and Practice, 11(3), 230-241. https://doi.org/10.1093/clipsy.bph077

Blake, C. E., Bisogni, C. A., Sobal, J., Devine, C. M., \& Jastran, M. (2007). Classifying foods in contexts: How adults categorize foods for different eating settings. Appetite, 49(2), 500-510. https://doi.org/10.1016/j.appet.2007.03.009

Bouton, M. E. (1994). Context, Ambiguity, and Classical Conditioning. Current Directions in Psychological Science, 3(2), 49-53. JSTOR.

Bowen, S., Witkiewitz, K., Clifasefi, S. L., \& et al. (2014). Relative efficacy of mindfulness-based relapse prevention, standard relapse prevention, and treatment as usual for substance use disorders: A randomized clinical trial. JAMA Psychiatry, 71(5), 547-556.

https://doi.org/10.1001/jamapsychiatry.2013.4546

Braun, V., \& Clarke, V. (2006). Using thematic analysis in psychology. Qualitative Research in Psychology, 3(2), 77-101. https://doi.org/10.1191/1478088706qp063oa

Braun, V., \& Clarke, V. (2019). Reflecting on reflexive thematic analysis. Qualitative Research in Sport, Exercise and Health, 11(4), 589-597. https://doi.org/10.1080/2159676X.2019.1628806

Braun, V., \& Clarke, V. (2021). Can I use TA? Should I use TA? Should I not use TA? Comparing reflexive thematic analysis and other pattern-based qualitative analytic approaches. Counselling and Psychotherapy Research, 21(3), 37-47. https://doi.org/10.1002/capr.12360

Brick, C., Bosshard, A., \& Whitmarsh, L. (2021). Motivation and climate change: A review. Current Opinion in Psychology, 42, 82-88. https://doi.org/10.1016/j.copsyc.2021.04.001

Brown, S. A., Christiansen, B. A., \& Goldman, M. S. (1987). The Alcohol Expectancy Questionnaire: An instrument for the assessment of adolescent and adult alcohol expectancies. Journal of Studies on Alcohol, 48(5), 483-491. https://doi.org/10.15288/jsa.1987.48.483 
Bruehlman-Senecal, E., \& Ayduk, O. (2015). This too shall pass: Temporal distance and the regulation of emotional distress. Journal of Personality and Social Psychology, 108(2), 356-375. https://doi.org/10.1037/a0038324

Bryant, C. J. (2019). We Can't Keep Meating Like This: Attitudes towards Vegetarian and Vegan Diets in the United Kingdom. Sustainability, 11(23), 6844. https://doi.org/10.3390/su11236844

Buckland, N. J., Er, V., Redpath, I., \& Beaulieu, K. (2018). Priming food intake with weight control cues: Systematic review with a meta-analysis. International Journal of Behavioral Nutrition and Physical Activity, 15(1), 66. https://doi.org/10.1186/s12966-018-0698-9

Buddle, E. A., Bray, H. J., \& Ankeny, R. A. (2018). Why would we believe them? Meat consumers' reactions to online farm animal welfare activism in Australia. Communication Research and Practice, 4(3), 246260. https://doi.org/10.1080/22041451.2018.1451209

Chapman, R., Keall, M., Howden-Chapman, P., Grams, M., Witten, K., Randal, E., \& Woodward, A. (2018). A Cost Benefit Analysis of an Active Travel Intervention with Health and Carbon Emission Reduction Benefits. International Journal of Environmental Research and Public Health, 15(5), 962. https://doi.org/10.3390/ijerph15050962

Chen, J., Papies, E. K., \& Barsalou, L. W. (2016). A core eating network and its modulations underlie diverse eating phenomena. Brain and Cognition, 110, 20-42. https://doi.org/10.1016/j.bandc.2016.04.004

Chiesa, A., \& Serretti, A. (2010). A systematic review of neurobiological and clinical features of mindfulness meditations. Psychological Medicine, 40(8), 1239-1252. https://doi.org/10.1017/S0033291709991747

Christensen, C. M., \& Navazesh, M. (1984). Anticipatory salivary flow to the sight of different foods. Appetite, 5(4), 307-315. https://doi.org/10.1016/S0195-6663(84)80003-3

Cialdini, R. B., Kallgren, C. A., \& Reno, R. R. (1991). A Focus Theory of Normative Conduct: A Theoretical Refinement and Reevaluation of the Role of Norms in Human Behavior. In M. P. Zanna (Ed.), Advances in Experimental Social Psychology (Vol. 24, pp. 201-234). Academic Press. https://doi.org/10.1016/S0065-2601(08)60330-5 
Cialdini, R. B., Reno, R. R., \& Kallgren, C. A. (1990). A focus theory of normative conduct: Recycling the concept of norms to reduce littering in public places. Journal of Personality and Social Psychology, 58(6), 1015-1026. https://doi.org/10.1037/0022-3514.58.6.1015

Claassen, M. A., Lomann, M., \& Papies, E. K. (2022). The influence of a Covid-19 lockdown in England on the consumption of sugar-sweetened beverages and water: A longitudinal analysis. In Preparation.

Claassen, M. A., Rusz, D., \& Papies, E. K. (2022). No evidence that consumption and reward words on labels increase the appeal of bottled water. Food Quality and Preference, 96, 104403. https://doi.org/10.1016/j.foodqual.2021.104403

Clark, M. A., Domingo, N. G. G., Colgan, K., Thakrar, S. K., Tilman, D., Lynch, J., Azevedo, I. L., \& Hill, J. D. (2020). Global food system emissions could preclude achieving the $1.5^{\circ}$ and $2^{\circ} \mathrm{C}$ climate change targets. Science, 370(6517), 705-708. https://doi.org/10.1126/science.aba7357

Clark, M. A., Springmann, M., Hill, J., \& Tilman, D. (2019). Multiple health and environmental impacts of foods. Proceedings of the National Academy of Sciences, 116(46), 23357-23362. https://doi.org/10.1073/pnas.1906908116

Cole, S., \& Balcetis, E. (2021). Chapter Three - Motivated perception for self-regulation: How visual experience serves and is served by goals. In B. Gawronski (Ed.), Advances in Experimental Social Psychology (Vol. 64, pp. 129-186). Academic Press. https://doi.org/10.1016/bs.aesp.2021.04.003

Cornil, Y., \& Chandon, P. (2016). Pleasure as a substitute for size: How multisensory imagery can make people happier with smaller food portions. Journal of Marketing Research, 53(5), 847-864. https://doi.org/10.1509/jmr.14.0299

Costa, I., Gill, P. R., Morda, R., \& Ali, L. (2019). “More than a diet”: A qualitative investigation of young vegan Women's relationship to food. Appetite, 143, 104418. https://doi.org/10.1016/j.appet.2019.104418 Crippa, M., Solazzo, E., Guizzardi, D., Monforti-Ferrario, F., Tubiello, F. N., \& Leip, A. (2021). Food systems are responsible for a third of global anthropogenic GHG emissions. Nature Food, 2(3), 198-209. https://doi.org/10.1038/s43016-021-00225-9 
Crum, A. J., Corbin, W. R., Brownell, K. D., \& Salovey, P. (2011). Mind over milkshakes: Mindsets, not just nutrients, determine ghrelin response. Health Psychology, 30(4), 424-429. https://doi.org/10.1037/a0023467

Davis, T., \& Papies, E. K. (2021a). Pleasure vs. Identity: More Eating Simulation Language in Meat Posts than Plant-based Posts on Social Media \#foodtalk. Under Review. https://osf.io/k7yhg/

Davis, T., \& Papies, E. K. (2021b). What's in a (dish) name? Diet-congruent foods are more represented through consumption simulations. In Preparation.

De Groeve, B., Bleys, B., \& Hudders, L. (2019). Okay to promote eating less meat, but don't be a cheat - The role of dietary identity, perceived inconsistency and inclusive language of an advocate in legitimizing meat reduction. Appetite, 138, 269-279. https://doi.org/10.1016/j.appet.2019.03.031

De Houwer, J., Teige-Mocigemba, S., Spruyt, A., \& Moors, A. (2009). Implicit measures: A normative analysis and review. Psychological Bulletin, 135(3), 347-368. https://psycnet.apa.org/doi/10.1037/a0014211 de Wit, S., \& Dickinson, A. (2009). Associative theories of goal-directed behaviour: A case for animal-human translational models. Psychological Research PRPF, 73(4), 463-476. https://doi.org/10.1007/s00426009-0230-6

Driskell, J. E., Copper, C., \& Moran, A. (1994). Does mental practice enhance performance? Journal of Applied Psychology, 79(4), 481-492.

Dunn, M. E., \& Goldman, M. S. (2000). Validation of multidimensional scaling-based modeling of alcohol expectancies in memory: Age and drinking-related differences in expectancies of children assessed as first associates. Alcoholism: Clinical and Experimental Research, 24(11), 1639-1646. https://doi.org/10.1111/j.1530-0277.2000.tb01965.x

Dutriaux, L., Clark, N., Papies, E. K., Scheepers, C., \& Barsalou, L. W. (2021). The Situated Assessment Method (SAM2): Establishing Individual Differences in Habitual Behavior. Under Review. https://psyarxiv.com/k3mqj/ 
Dutriaux, L., Papies, E. K., Fallon, J., Garcia-Marques, L., \& Barsalou, L. W. (2021). Incidental exposure to hedonic and healthy food features implicitly affects food preferences one day later. Cognitive Research: Principles and Implications, https://osf.io/s5u3p/.

Elder, R. S., \& Krishna, A. (2010). The effects of advertising copy on sensory thoughts and perceived taste. Journal of Consumer Research, 36(5), 748-756. https://doi.org/10.1086/605327

Elder, R. S., \& Krishna, A. (2012). The "Visual Depiction Effect" in advertising: Facilitating embodied mental simulation through product orientation. Journal of Consumer Research, 38(6), 988-1003. https://doi.org/10.1086/661531

Elwafi, H. M., Witkiewitz, K., Mallik, S., IV, T. A. T., \& Brewer, J. A. (2013). Mindfulness training for smoking cessation: Moderation of the relationship between craving and cigarette use. Drug and Alcohol Dependence, 130(1-3), 222-229. https://doi.org/10.1016/j.drugalcdep.2012.11.015

Eschen, A., Freeman, J., Dietrich, T., Martin, M., Ellis, J., Martin, E., \& Kliegel, M. (2007). Motor brain regions are involved in the encoding of delayed intentions: A fMRI study. International Journal of Psychophysiology, 64(3), 259-268.

Farrar, S., Barsalou, L. W., \& Papies, E. K. (2021). Focusing on eating experiences increases food desire through consumption and reward simulations. In Preparation.

Field, M., Schoenmakers, T., \& Wiers, R. W. (2008). Cognitive Processes in Alcohol Binges: A Review and Research Agenda. Current Drug Abuse Reviews, 1(3), 263-279.

Fillmore, M. T., Carscadden, J. L., \& Vogel-Sprott, M. (1998). Alcohol, cognitive impairment and expectancies. Journal of Studies on Alcohol, 59(2), 174-179.

Fleeson, W., \& Jayawickreme, E. (2021). Chapter Two - Whole traits: Revealing the social-cognitive mechanisms constituting personality's central variable. In B. Gawronski (Ed.), Advances in Experimental Social Psychology (Vol. 63, pp. 69-128). Academic Press. https://doi.org/10.1016/bs.aesp.2020.11.002

Foa, E. B., \& Kozak, M. J. (1986). Emotional Processing of Fear: Exposure to Corrective Information. Psychological Bulletin, 99(1), 20-35. https://doi.org/10.1037/0033-2909.99.1.20 
Fujita, K., \& Carnevale, J. J. (2012). Transcending Temptation Through Abstraction: The Role of Construal Level in Self-Control. Current Directions in Psychological Science, 21(4), 248-252. https://doi.org/10.1177/0963721412449169

Furman, C. R., Kross, E., \& Gearhardt, A. N. (2020). Distanced Self-Talk Enhances Goal Pursuit to Eat Healthier. Clinical Psychological Science, 8(2), 366-373. https://doi.org/10.1177/2167702619896366

Gardner, B. (2015). A review and analysis of the use of 'habit' in understanding, predicting and influencing health-related behaviour. Health Psychology Review, 9(3), 277-295. https://doi.org/10.1080/17437199.2013.876238

Gollwitzer, P. M. (1999). Implementation intentions: Strong effects of simple plans. American Psychologist, 54, 493-503.

Gollwitzer, P. M., \& Sheeran, P. (2006). Implementation Intentions and Goal Achievement: A Meta-analysis of Effects and Processes. In Advances in Experimental Social Psychology (Vol. 38, pp. 69-119). Academic Press. https://doi.org/10.1016/S0065-2601(06)38002-1

González, J., Barros-Loscertales, A., Pulvermüller, F., Meseguer, V., Sanjuán, A., Belloch, V., \& Ávila, C. (2006). Reading cinnamon activates olfactory brain regions. Neurolmage, 32(2), 906-912. https://doi.org/10.1016/j.neuroimage.2006.03.037

Grabenhorst, F., Rolls, E. T., \& Bilderbeck, A. (2008). How Cognition Modulates Affective Responses to Taste and Flavor: Top-down Influences on the Orbitofrontal and Pregenual Cingulate Cortices. Cerebral Cortex, 18(7), 1549-1559. https://doi.org/10.1093/cercor/bhm185

Graça, J., Godinho, C. A., \& Truninger, M. (2019). Reducing meat consumption and following plant-based diets: Current evidence and future directions to inform integrated transitions. Trends in Food Science \& Technology, 91, 380-390. https://doi.org/10.1016/j.tifs.2019.07.046

Hackel, L. M., Coppin, G., Wohl, M. J. A., \& Van Bavel, J. J. (2018). From groups to grits: Social identity shapes evaluations of food pleasantness. Journal of Experimental Social Psychology, 74, 270-280. https://doi.org/10.1016/j.jesp.2017.09.007 
Hadash, Y., Segev, N., Tanay, G., Goldstein, P., \& Bernstein, A. (2016). The Decoupling Model of Equanimity: Theory, Measurement, and Test in a Mindfulness Intervention. Mindfulness, 1-13. https://doi.org/10.1007/s12671-016-0564-2

Hawkins, R. X. D., Goodman, N. D., \& Goldstone, R. L. (2019). The Emergence of Social Norms and Conventions. Trends in Cognitive Sciences, 23(2), 158-169.

https://doi.org/10.1016/j.tics.2018.11.003

Higgs, S. (2015). Social norms and their influence on eating behaviours. Appetite, 86, 38-44. https://doi.org/10.1016/j.appet.2014.10.021

Hollands, G. J., Bignardi, G., Johnston, M., Kelly, M. P., Ogilvie, D., Petticrew, M., Prestwich, A., Shemilt, I., Sutton, S., \& Marteau, T. M. (2017). The TIPPME intervention typology for changing environments to change behaviour. Nature Human Behaviour, 1, 1-9. https://doi.org/10.1038/s41562-017-0140

Holmes, E. A., \& Mathews, A. (2010). Mental imagery in emotion and emotional disorders. Clinical Psychology Review, 30(3), 349-362. https://doi.org/10.1016/j.cpr.2010.01.001

Hölzel, B. K., Lazar, S. W., Gard, T., Schuman-Olivier, Z., Vago, D. R., \& Ott, U. (2011). How Does Mindfulness Meditation Work? Proposing Mechanisms of Action From a Conceptual and Neural Perspective. Perspectives on Psychological Science, 6(6), 537-559. https://doi.org/10.1177/1745691611419671 Hommel, B., Musseler, J., Aschersleben, G., \& Prinz, W. (2001). The Theory of Event Coding (TEC): A framework for perception and action planning. Behavioral \& Brain Sciences, 24(5), 849-878. Jacobson, R. P., Mortensen, C. R., \& Cialdini, R. B. (2011). Bodies Obliged and Unbound: Differentiated Response Tendencies for Injunctive and Descriptive Social Norms. Journal of Personality and Social Psychology, 100(3), 433-448. https://doi.org/10.1037/a0021470

Jajodia, A., \& Earleywine, M. (2003). Measuring alcohol expectancies with the implicit association test. Psychology of Addictive Behaviors: Journal of the Society of Psychologists in Addictive Behaviors, 17(2), 126-133. https://doi.org/10.1037/0893-164x.17.2.126

Jeannerod, M. (1995). Mental imagery in the motor context. Neuropsychologia, 33(11), 1419-1432. 
Jeannerod, M. (2001). Neural Simulation of Action: A Unifying Mechanism for Motor Cognition. Neurolmage, 14(1), S103-109.

Jenkins, K. T., \& Tapper, K. (2014). Resisting chocolate temptation using a brief mindfulness strategy. British Journal of Health Psychology, 19(3), 509-522. https://doi.org/10.1111/bjhp.12050

Ji, J. L., Heyes, S. B., MacLeod, C., \& Holmes, E. A. (2016). Emotional Mental Imagery as Simulation of Reality: Fear and Beyond-A Tribute to Peter Lang. Behavior Therapy, 47(5), 702-719. https://doi.org/10.1016/j.beth.2015.11.004

Johannes, N. (2020). Feature Listing App [R].

Jones, B. T., Corbin, W., \& Fromme, K. (2001). A review of expectancy theory and alcohol consumption. Addiction, 96(1), 57-72. https://doi.org/10.1046/j.1360-0443.2001.961575.x

Jordan, C. H., Wang, W., Donatoni, L., \& Meier, B. P. (2014). Mindful eating: Trait and state mindfulness predict healthier eating behavior. Personality and Individual Differences, 68, 107-111. https://doi.org/10.1016/j.paid.2014.04.013

Jouravlev, O., \& McRae, K. (2016). Thematic relatedness production norms for 100 object concepts. Behavior Research Methods, 48(4), 1349-1357. https://doi.org/10.3758/s13428-015-0679-8

Jung, Y. (2011). Understanding the Role of Sense of Presence and Perceived Autonomy in Users' Continued Use of Social Virtual Worlds. Journal of Computer-Mediated Communication, 16(4), 492-510. https://doi.org/10.1111/j.1083-6101.2011.01540.x

Kaakinen, M., Sirola, A., Savolainen, I., \& Oksanen, A. (2020). Shared identity and shared information in social media: Development and validation of the identity bubble reinforcement scale. Media Psychology, 23(1), 25-51. https://doi.org/10.1080/15213269.2018.1544910

Kahkonen, P., \& Tuorila, H. (1998). Effect of Reduced-fat Information on Expected and Actual Hedonic and Sensory Ratings of Sausage. Appetite, 30(1), 13-23. https://doi.org/10.1006/appe.1997.0104 Kappes, A., Singmann, H., \& Oettingen, G. (2012). Mental contrasting instigates goal pursuit by linking obstacles of reality with instrumental behavior. Journal of Experimental Social Psychology, 48(4), 811-818. https://doi.org/10.1016/j.jesp.2012.02.002 
Kavanagh, D. J., Andrade, J., \& May, J. (2005). Imaginary relish and exquisite torture: The elaborated intrusion theory of desire. Psychological Review, 112(2), 446-467.

Keesman, M., Aarts, H., Häfner, M., \& Papies, E. K. (2017). Mindfulness Reduces Reactivity to Food Cues: Underlying Mechanisms and Applications in Daily Life. Current Addiction Reports, 4(2), 151-157. https://doi.org/10.1007/s40429-017-0134-2

Keesman, M., Aarts, H., Hafner, M., \& Papies, E. K. (2020). The decentering component of mindfulness reduces reactions to mental imagery. Motivation Science, 61, 34-42.

Keesman, M., Aarts, H., Ostafin, B. D., Verwei, S., Häfner, M., \& Papies, E. K. (2018). Alcohol representations are socially situated: An investigation of beverage representations by using a property generation task. Appetite, 120, 654-665. https://doi.org/10.1016/j.appet.2017.10.019

Keesman, M., Aarts, H., Vermeent, S., Häfner, M., \& Papies, E. K. (2016). Consumption simulations induce salivation to food cues. PLOS ONE, 11(11), e0165449. https://doi.org/10.1371/journal.pone.0165449

Keizer, K., Lindenberg, S., \& Steg, L. (2008). The spreading of disorder. Science, 322, 1681-1685.

Keller, C., \& van der Horst, K. (2013). Dietary restraint, ambivalence toward eating, and the valence and content of spontaneous associations with eating. Appetite, 62, 150-159. https://doi.org/10.1016/j.appet.2012.11.012

Kelly, M. P., \& Barker, M. (2016). Why is changing health-related behaviour so difficult? Public Health, 136(Supplement C), 109-116. https://doi.org/10.1016/j.puhe.2016.03.030

Killgore, W. D. S., Young, A. D., Femia, L. A., Bogorodzki, P., Rogowska, J., \& Yurgelun-Todd, D. A. (2003). Cortical and limbic activation during viewing of high- versus low-calorie foods. Neurolmage, 19(4), 1381.

Knäuper, B., Roseman, M., Johnson, P. J., \& Krantz, L. H. (2009). Using Mental Imagery to Enhance the Effectiveness of Implementation Intentions. Current Psychology, 28(3), 181-186. https://doi.org/10.1007/s12144-009-9055-0

Kosslyn, S. M., Ganis, G., \& Thompson, W. L. (2001). Neural foundations of imagery. Nature Reviews Neuroscience, 2(9), 635-642. https://doi.org/10.1038/35090055 
Krishna, A., Morrin, M., \& Sayin, E. (2014). Smellizing cookies and salivating: A focus on olfactory imagery. Journal of Consumer Research, 41(1), 18-34. https://doi.org/10.1086/674664

Kruglanski, A. W., \& Szumowska, E. (2020). Habitual Behavior Is Goal-Driven. Perspectives on Psychological Science, 15(5), 1256-1271. https://doi.org/10.1177/1745691620917676

Lacaille, J., Ly, J., Zacchia, N., Bourkas, S., Glaser, E., \& Knäuper, B. (2014). The effects of three mindfulness skills on chocolate cravings. Appetite. https://doi.org/10.1016/j.appet.2014.01.072

Larson, J. S., Redden, J. P., \& Elder, R. S. (2014). Satiation from sensory simulation: Evaluating foods decreases enjoyment of similar foods. Journal of Consumer Psychology, 24(2), 188-194. https://doi.org/10.1016/j.jcps.2013.09.001

Lawrence, N. S., Hinton, E. C., Parkinson, J. A., \& Lawrence, A. D. (2012). Nucleus accumbens response to food cues predicts subsequent snack consumption in women and increased body mass index in those with reduced self-control. Neurolmage, 63(1), 415-422. https://doi.org/10.1016/j.neuroimage.2012.06.070

Lazard, L., \& McAvoy, J. (2020). Doing reflexivity in psychological research: What's the point? What's the practice? Qualitative Research in Psychology, 17(2), 159-177. https://doi.org/10.1080/14780887.2017.1400144

Lebois, L. A. M., Papies, E. K., Gopinath, K., Cabanban, R., Quigley, K. S., Krishnamurthy, V., Barrett, L. F., \& Barsalou, L. W. (2015). A shift in perspective: Decentering through mindful attention to imagined stressful events. Neuropsychologia, 75, 505-524. https://doi.org/10.1016/j.neuropsychologia.2015.05.030

Lebois, L. A. M., Wilson-Mendenhall, C. D., Simmons, W. K., Barrett, L. F., \& Barsalou, L. W. (2020). Learning situated emotions. Neuropsychologia, 145, 106637. https://doi.org/10.1016/j.neuropsychologia.2018.01.008

Levy, D. J., \& Glimcher, P. W. (2012). The root of all value: A neural common currency for choice. Current Opinion in Neurobiology, 22(6), 1027-1038. https://doi.org/10.1016/j.conb.2012.06.001 
Liem, D. G., Toraman Aydin, N., \& Zandstra, E. H. (2012). Effects of health labels on expected and actual taste perception of soup. Food Quality and Preference, 25(2), 192-197. https://doi.org/10.1016/j.foodqual.2012.02.015

Lipkus, I. M., Mays, D., Sheeran, P., Pan, W., Cameron, L. D., \& De Brigard, F. (2021). Effects of mental simulation of future waterpipe tobacco smoking on attitudes, perceived harms and intended use among young adults. Journal of Behavioral Medicine. https://doi.org/10.1007/s10865-021-00245-7

Lopez, R. B., Hofmann, W., Wagner, D. D., Kelley, W. M., \& Heatherton, T. F. (2014). Neural Predictors of Giving in to Temptation in Daily Life. Psychological Science, 25(7), 1337-1344. https://doi.org/10.1177/0956797614531492

MacNamara, A. (2018). In the mind's eye: The late positive potential to negative and neutral mental imagery and intolerance of uncertainty. Psychophysiology, 55(5), e13024. https://doi.org/10.1111/psyp.13024

Marteau, T. M. (2017). Towards environmentally sustainable human behaviour: Targeting non-conscious and conscious processes for effective and acceptable policies. Phil. Trans. R. Soc. A, 375(2095), 20160371. https://doi.org/10.1098/rsta.2016.0371

Marteau, T. M., Hollands, G. J., \& Fletcher, P. C. (2012). Changing Human Behavior to Prevent Disease: The Importance of Targeting Automatic Processes. Science, 337(6101), 1492-1495. https://doi.org/10.1126/science.1226918

Martiny-Huenger, T., Martiny, S. E., Parks-Stamm, E. J., Pfeiffer, E., \& Gollwitzer, P. M. (2017). From conscious thought to automatic action: A simulation account of action planning. Journal of Experimental Psychology: General, 146(10), 1513-1525. https://doi.org/10.1037/xge0000344

Mckay, D., \& Schare, M. L. (1999). The effects of alcohol and alcohol expectancies on subjective reports and physiological reactivity: A meta-analysis. Addictive Behaviors, 24(5), 633-647. https://doi.org/10.1016/S0306-4603(99)00021-0 
McRae, K., Cree, G. S., Seidenberg, M. S., \& Mcnorgan, C. (2005). Semantic feature production norms for a large set of living and nonliving things. Behavior Research Methods, 37(4), 547-559. https://doi.org/10.3758/BF03192726

Moors, A., \& De Houwer, J. (2006). Automaticity: A Theoretical and Conceptual Analysis. Psychological Bulletin, 132(2), 297-326. https://doi.org/10.1037/0033-2909.132.2.297

Muñoz-Vilches, N. C., van Trijp, H. C. M., \& Piqueras-Fiszman, B. (2019). The impact of instructed mental simulation on wanting and choice between vice and virtue food products. Food Quality and Preference, 73, 182-191. https://doi.org/10.1016/j.foodqual.2018.11.010

Muñoz-Vilches, N. C., van Trijp, H. C. M., \& Piqueras-Fiszman, B. (2020). Tell me what you imagine and I will tell you what you want: The effects of mental simulation on desire and food choice. Food Quality and Preference, 83, 103892. https://doi.org/10.1016/j.foodqual.2020.103892

Myrick, H., Anton, R. F., Li, X., Henderson, S., Drobes, D., Voronin, K., \& George, M. S. (2004). Differential brain activity in alcoholics and social drinkers to alcohol cues: Relationship to craving. Neuropsychopharmacology: Official Publication of the American College of Neuropsychopharmacology, 29(2), 393-402. https://doi.org/10.1038/sj.npp.1300295

Nederkoorn, C., \& Jansen, A. (2002). Cue reactivity and regulation of food intake. Eating Behaviors, 3(1), 6172.

Nederkoorn, C., Smulders, F. T. Y., \& Jansen, A. (2000). Cephalic phase responses, craving and food intake in normal subjects. Appetite, 35(1), 45-55. https://doi.org/10.1006/appe.2000.0328

Neighbors, C., Lee, C. M., Lewis, M. A., Fossos, N., \& Larimer, M. E. (2007). Are Social Norms the Best Predictor of Outcomes Among Heavy-Drinking College Students? Journal of Studies on Alcohol and Drugs, 68(4), 556-565. https://doi.org/10.15288/jsad.2007.68.556

Nielsen, K. S., Nicholas, K. A., Creutzig, F., Dietz, T., \& Stern, P. C. (2021). The role of high-socioeconomicstatus people in locking in or rapidly reducing energy-driven greenhouse gas emissions. Nature Energy, 1-6. https://doi.org/10.1038/s41560-021-00900-y 
Opriş, D., Pintea, S., García-Palacios, A., Botella, C., Szamosközi, Ş., \& David, D. (2012). Virtual reality exposure therapy in anxiety disorders: A quantitative meta-analysis. Depression and Anxiety, 29(2), 85-93. https://doi.org/10.1002/da.20910

Orvell, A., Ayduk, Ö., Moser, J. S., Gelman, S. A., \& Kross, E. (2019). Linguistic Shifts: A Relatively Effortless Route to Emotion Regulation? Current Directions in Psychological Science, 28(6), 567-573. https://doi.org/10.1177/0963721419861411

Ostafin, B. D., Bauer, C., \& Myxter, P. (2012). Mindfulness Decouples the Relation Between Automatic Alcohol Motivation and Heavy Drinking. Journal of Social \& Clinical Psychology, 31(7), 729-745. https://doi.org/10.1521/jscp.2012.31.7.729

Papies, E. K. (2013). Tempting food words activate eating simulations. Frontiers in Psychology, 4:, 838. https://doi.org/10.3389/fpsyg.2013.00838

Papies, E. K. (2016a). Health goal priming as a situated intervention tool: How to benefit from nonconscious motivational routes to health behaviour. Health Psychology Review, 10(4), 408-424. https://doi.org/10.1080/17437199.2016.1183506

Papies, E. K. (2016b). Goal priming as a situated intervention tool. Current Opinion in Psychology, 12, 12-16. https://doi.org/10.1016/j.copsyc.2016.04.008

Papies, E. K. (2017). Situating interventions to bridge the intention-behaviour gap: A framework for recruiting nonconscious processes for behaviour change. Social and Personality Psychology Compass, 11(7), 12323. https://doi.org/10.1111/spc3.12323

Papies, E. K., Aarts, H., \& de Vries, N. K. (2009). Planning is for doing: Implementation intentions go beyond the mere creation of goal-directed associations. Journal of Experimental Social Psychology, 45(5), 1148-1151.

Papies, E. K., \& Barsalou, L. W. (2015). Grounding desire and motivated behavior: A theoretical framework and review of empirical evidence. In W. Hofmann \& L. F. Nordgren (Eds.), The Psychology of Desire (pp. 36-60). Guilford Press. 
Papies, E. K., Barsalou, L. W., \& Custers, R. (2012). Mindful Attention Prevents Mindless Impulses. Social Psychological and Personality Science, 3(3), 291-299. https://doi.org/10.1177/1948550611419031

Papies, E. K., Best, M., Gelibter, E., \& Barsalou, L. W. (2017). The role of simulations in consumer experiences and behavior: Insights from the grounded cognition theory of desire. Journal of the Association for Consumer Research, 2(4), 402-418. https://doi.org/10.1086/693110

Papies, E. K., Claassen, M. A., Rusz, D., \& Best, M. (2021). Flavours of desire: Cognitive representations of appetitive stimuli and their motivational implications. Journal of Experimental Psychology: General. https://psyarxiv.com/rkn26/

Papies, E. K., Johannes, N., Daneva, T., Semyte, G., \& Kauhanen, L.-L. (2020). Using consumption and reward simulations to increase the appeal of plant-based foods. Appetite, 155, 104812. https://doi.org/10.1016/j.appet.2020.104812

Papies, E. K., Pronk, T. M., Keesman, M., \& Barsalou, L. W. (2015). The benefits of simply observing: Mindful attention modulates the link between motivation and behavior. Journal of Personality and Social Psychology, 108(1), 148-170. https://doi.org/10.1037/a0038032

Papies, E. K., Tatar, B., Johannes, N., Keesman, M., Best, M., Lindner, K., Barsalou, L. W., Rusz, D., \& Dutriaux, L. (2020). Measuring and interpreting cognitive representations of foods and drinks: A procedure for collecting and coding feature listing data. Under Review. https://doi.org/10.31219/osf.io/ufpx8

Papies, E. K., van Stekelenburg, A., Smeets, M. A. M., Zandstra, E. H., \& Dijksterhuis, G. B. (2022). Situating desire: Situational cues affect desire for food through eating simulations. Appetite, 168, 105679. https://doi.org/10.1016/j.appet.2021.105679

Patel, T., Brewin, C. R., Wheatley, J., Wells, A., Fisher, P., \& Myers, S. (2007). Intrusive images and memories in major depression. Behaviour Research and Therapy, 45(11), 2573-2580.

https://doi.org/10.1016/j.brat.2007.06.004

Paz, R., Zvielli, A., Goldstein, P., \& Bernstein, A. (2017). Brief mindfulness training de-couples the anxiogenic effects of distress intolerance on reactivity to and recovery from stress among deprived smokers. Behaviour Research and Therapy, 95, 117-127. https://doi.org/10.1016/j.brat.2017.05.017 
Perrier, E. T., Armstrong, L. E., Bottin, J. H., Clark, W. F., Dolci, A., Guelinckx, I., Iroz, A., Kavouras, S. A., Lang, F., Lieberman, H. R., Melander, O., Morin, C., Seksek, I., Stookey, J. D., Tack, I., Vanhaecke, T., Vecchio, M., \& Péronnet, F. (2021). Hydration for health hypothesis: A narrative review of supporting evidence. European Journal of Nutrition, 60(3), 1167-1180. https://doi.org/10.1007/s00394-02002296-z

Peterson, D. E., Zeger, S. L., Remington, P. L., \& Anderson, H. A. (1992). The effect of state cigarette tax increases on cigarette sales, 1955 to 1988. American Journal of Public Health, 82(1), 94-96. https://doi.org/10.2105/AJPH.82.1.94

Piazza, J., Ruby, M. B., Loughnan, S., Luong, M., Kulik, J., Watkins, H. M., \& Seigerman, M. (2015). Rationalizing meat consumption. The 4Ns. Appetite, 91, 114-128. https://doi.org/10.1016/j.appet.2015.04.011

Plassmann, H., O’Doherty, J., Shiv, B., \& Rangel, A. (2008). Marketing actions can modulate neural representations of experienced pleasantness. Proceedings of the National Academy of Sciences, 105(3), 1050-1054. https://doi.org/10.1073/pnas.0706929105

Poore, J., \& Nemecek, T. (2018). Reducing food's environmental impacts through producers and consumers. Science, 360(6392), 987-992. https://doi.org/10.1126/science.aaq0216

Prochaska, J. O., \& Velicer, W. F. (1997). The Transtheoretical Model of Health Behavior Change. American Journal of Health Promotion, 12(1), 38-48. https://doi.org/10.4278/0890-1171-12.1.38

Pross, N., Demazières, A., Girard, N., Barnouin, R., Metzger, D., Klein, A., Perrier, E., \& Guelinckx, I. (2014). Effects of Changes in Water Intake on Mood of High and Low Drinkers. PLOS ONE, 9(4), e94754. https://doi.org/10.1371/journal.pone.0094754

R Core Team. (2018). R: A language and environment for statistical computing. R Foundation for Statistical Computing. www.r-project.org/

Rauch, S. A. M., Eftekhari, A., \& Ruzek, J. I. (2012). Review of exposure therapy: A gold standard for PTSD treatment. The Journal of Rehabilitation Research and Development, 49(5), 679. https://doi.org/10.1682/JRRD.2011.08.0152 
Reich, R. R., Below, M. C., \& Goldman, M. S. (2010). Explicit and implicit measures of expectancy and related alcohol cognitions: A meta-analytic comparison. Psychology of Addictive Behaviors, 24(1), 13-25. https://doi.org/10.1037/a0016556

Riet, J. van't, Sijtsema, S. J., Dagevos, H., \& De Bruijn, G.-J. (2011). The importance of habits in eating behaviour. An overview and recommendations for future research. Appetite, 57(3), 585-596. https://doi.org/10.1016/j.appet.2011.07.010

Rodger, A., \& Papies, E. K. (2021). "I don't just drink water for the sake of it": Understanding the influence of value, reward, self-identity and early life on water drinking behaviour. PsyArXiv. https://doi.org/10.31234/osf.io/kg367

Rodger, A., Vezevicius, A., \& Papies, E. K. (2022). Can a simple plan change a complex behaviour? Implementation intentions in the context of water drinking. In Preparation.

Rodger, A., Wehbe, L. H., \& Papies, E. K. (2021). "I know it's just pouring it from the tap, but it's not easy": Motivational processes that underlie water drinking. Appetite, 164, 105249. https://doi.org/10.1016/j.appet.2021.105249

Rodríguez-Ardura, I., \& Martínez-López, F. J. (2014). Another look at 'being there' experiences in digital media: Exploring connections of telepresence with mental imagery. Computers in Human Behavior, 30, 508-518. https://doi.org/10.1016/j.chb.2013.06.016

Rogers, P. J., \& Hill, A. J. (1989). Breakdown of dietary restraint following mere exposure to food stimuli: Interrelationships between restraint, hunger, salivation, and food intake. Addictive Behaviors, 14(4), 387-397. https://doi.org/10.1016/0306-4603(89)90026-9

Rosenfeld, D. L., \& Tomiyama, A. J. (2021). Gender differences in meat consumption and openness to vegetarianism. Appetite, 166, 105475. https://doi.org/10.1016/j.appet.2021.105475

Ross, B. H., \& Murphy, G. L. (1999). Food for thought: Cross-classification and category organization in a complex real-world domain. Cognitive Psychology, 38(4), 495-553.

https://doi.org/10.1006/cogp.1998.0712 
Ruby, M. B., \& Heine, S. J. (2011). Meat, morals, and masculinity. Appetite, 56(2), 447-450. https://doi.org/10.1016/j.appet.2011.01.018

Rucker, D. D., Preacher, K. J., Tormala, Z. L., \& Petty, R. E. (2011). Mediation Analysis in Social Psychology: Current Practices and New Recommendations. Social and Personality Psychology Compass, 5(6), 359-371. https://doi.org/10.1111/j.1751-9004.2011.00355.x

Safran, J. D., \& Segal, Z. V. (1990). Interpersonal Process in Cognitive Therapy. Basic Books.

Samuelson, P. A. (1952). Probability, Utility, and the Independence Axiom. Econometrica, 20(4), 670-678. https://doi.org/10.2307/1907649

Samuelson, W., \& Zeckhauser, R. (1988). Status quo bias in decision making. Journal of Risk and Uncertainty, 1(1), 7-59. https://doi.org/10.1007/BF00055564

Santos, A., Chaigneau, S. E., Simmons, W. K., \& Barsalou, L. W. (2011). Property generation reflects word association and situated simulation. Language and Cognition, 3, 83-119. https://doi.org/10.1515/LANGCOG.2011.004

Scarborough, P., Adhikari, V., Harrington, R. A., Elhussein, A., Briggs, A., Rayner, M., Adams, J., Cummins, S., Penney, T., \& White, M. (2020). Impact of the announcement and implementation of the UK Soft Drinks Industry Levy on sugar content, price, product size and number of available soft drinks in the UK, 2015-19: A controlled interrupted time series analysis. PLOS Medicine, 17(2), e1003025. https://doi.org/10.1371/journal.pmed.1003025

Schacht, J. P., Anton, R. F., Randall, P. K., Li, X., Henderson, S., \& Myrick, H. (2011). Stability of fMRI striatal response to alcohol cues: A hierarchical linear modeling approach. Neurolmage, 56(1), 61-68. https://doi.org/10.1016/j.neuroimage.2011.02.004

Sheeran, P., \& Webb, T. L. (2016). The Intention-Behavior Gap. Social and Personality Psychology Compass, 10(9), 503-518. https://doi.org/10.1111/spc3.12265

Sheppes, G. (2020). Chapter Four - Transcending the "good \& bad" and "here \& now" in emotion regulation: Costs and benefits of strategies across regulatory stages. In B. Gawronski (Ed.), Advances in 
Experimental Social Psychology (Vol. 61, pp. 185-236). Academic Press. https://doi.org/10.1016/bs.aesp.2019.09.003

Siep, N., Roefs, A., Roebroeck, A., Havermans, R., Bonte, M. L., \& Jansen, A. (2009). Hunger is the best spice: An fMRI study of the effects of attention, hunger and calorie content on food reward processing in the amygdala and orbitofrontal cortex. Behavioural Brain Research, 198(1), 149-158. https://doi.org/10.1016/j.bbr.2008.10.035

Simmons, W. K., Martin, A., \& Barsalou, L. W. (2005). Pictures of appetizing foods activate gustatory cortices for taste and reward. Cerebral Cortex, 15(10), 1602-1608.

Simon, J. J., Skunde, M., Wu, M., Schnell, K., Herpertz, S. C., Bendszus, M., Herzog, W., \& Friederich, H.-C. (2015). Neural dissociation of food- and money-related reward processing using an abstract incentive delay task. Social Cognitive and Affective Neuroscience, 10(8), 1113-1120. https://doi.org/10.1093/scan/nsu162

Sniehotta, F. F., Schwarzer, R., Scholz, U., \& Schüz, B. (2005). Action planning and coping planning for longterm lifestyle change: Theory and assessment. European Journal of Social Psychology, 35(4), 565576. https://doi.org/10.1002/ejsp.258

Sobal, J. (2005). Men, Meat, and Marriage: Models of Masculinity. Food and Foodways, 13(1-2), 135-158. https://doi.org/10.1080/07409710590915409

Sparkman, G., \& Walton, G. M. (2017). Dynamic Norms Promote Sustainable Behavior, Even if It Is Counternormative. Psychological Science, 28(11), 1663-1674. https://doi.org/10.1177/0956797617719950

Springmann, M., Wiebe, K., Mason-D'Croz, D., Sulser, T. B., Rayner, M., \& Scarborough, P. (2018). Health and nutritional aspects of sustainable diet strategies and their association with environmental impacts: A global modelling analysis with country-level detail. The Lancet Planetary Health, 2(10), e451-e461. https://doi.org/10.1016/S2542-5196(18)30206-7

Stacy, A. W. (1997). Memory activation and expectancy as prospective predictors of alcohol and marijuana use. Journal of Abnormal Psychology, 106(1), 61-73. https://doi.org/10.1037//0021-843x.106.1.61 
Stacy, A. W., Leigh, B. C., \& Weingardt, K. R. (1994). Memory accessibility and association of alcohol use and its positive outcomes. Experimental and Clinical Psychopharmacology, 2(3), 269-282. https://doi.org/10.1037/1064-1297.2.3.269

Stawarz, K., Gardner, B., Cox, A., \& Blandford, A. (2020). What influences the selection of contextual cues when starting a new routine behaviour? An exploratory study. BMC Psychology, 8(1), 29. https://doi.org/10.1186/s40359-020-0394-9

Stein, K. D., Goldman, M. S., \& Del Boca, F. K. (2000). The influence of alcohol expectancy priming and mood manipulation on subsequent alcohol consumption. Journal of Abnormal Psychology, 109(1), 106115. https://doi.org/10.1037/0021-843X.109.1.106

Steuer, J. (1992). Defining Virtual Reality: Dimensions Determining Telepresence. Journal of Communication, 42(4), 73-93. https://doi.org/10.1111/j.1460-2466.1992.tb00812.x

Stice, E., Spoor, S., Ng, J., \& Zald, D. H. (2009). Relation of obesity to consummatory and anticipatory food reward. Physiology \& Behavior, 97(5), 551-560. https://doi.org/10.1016/j.physbeh.2009.03.020

Stice, E., Yokum, S., Burger, K. S., Epstein, L. H., \& Small, D. M. (2011). Youth at Risk for Obesity Show Greater Activation of Striatal and Somatosensory Regions to Food. The Journal of Neuroscience, 31(12), 4360-4366. https://doi.org/10.1523/JNEUROSCI.6604-10.2011

Stokes, L. C. (2020). When the Fog of Enactment Lifts: Utilities Drive Rapid Retrenchment of Ohio's Renewable Energy Laws. In Short Circuiting Policy. Oxford University Press. https://doi.org/10.1093/oso/9780190074258.003.0008

Stroebe, W., van Koningsbruggen, G. M., Papies, E. K., \& Aarts, H. (2013). Why Most Dieters Fail But Some Succeed: A Goal Conflict Model of Eating Behavior. Psychological Review, 120(1), 110-138. https://doi.org/10.1037/a0030849

Szpunar, K. K., Watson, J. M., \& McDermott, K. B. (2007). Neural substrates of envisioning the future. Proceedings of the National Academy of Sciences, 104(2), 642-647. https://doi.org/10.1073/pnas.0610082104 
Tang, D. W., Fellows, L. K., Small, D. M., \& Dagher, A. (2012). Food and drug cues activate similar brain regions: A meta-analysis of functional MRI studies. Physiology \& Behavior, 106(3), 317-324. https://doi.org/10.1016/j.physbeh.2012.03.009

Tatar, B., Pázmányová, R., \& Papies, E. K. (2021). "The thought is gonna come and the thought is gonna go": A qualitative study on how non-meditators learn and apply brief mindfulness-based instructions for food cravings. Appetite, 105482. https://doi.org/10.1016/j.appet.2021.105482

Tiffany, S. T., \& Hakenewerth, D. M. (1991). The production of smoking urges through an imagery manipulation: Psychophysiological and verbal manifestations. Addictive Behaviors, 16(6), 389-400. https://doi.org/10.1016/0306-4603(91)90047-L

Trainor, L. R., \& Bundon, A. (2021). Developing the craft: Reflexive accounts of doing reflexive thematic analysis. Qualitative Research in Sport, Exercise and Health, 13(5), 705-726. https://doi.org/10.1080/2159676X.2020.1840423

Tucker, M., \& Ellis, R. (1998). On the relations between seen objects and components of potential actions. Journal of Experimental Psychology: Human Perception and Performance, 24(3), 830-846. https://doi.org/10.1037/0096-1523.24.3.830

Turnwald, B. P., Bertoldo, J. D., Perry, M. A., Policastro, P., Timmons, M., Bosso, C., Connors, P., Valgenti, R. T., Pine, L., Challamel, G., Gardner, C. D., \& Crum, A. J. (2019). Increasing vegetable intake by emphasizing tasty and enjoyable attributes: A randomized controlled multisite intervention for taste-focused labeling. Psychological Science, 30(11), 1603-1615. https://doi.org/10.1177/0956797619872191

Turnwald, B. P., Boles, D. Z., \& Crum, A. J. (2017). Association Between Indulgent Descriptions and Vegetable Consumption: Twisted Carrots and Dynamite Beets. JAMA Internal Medicine, 177(8), 1216-1218. https://doi.org/10.1001/jamainternmed.2017.1637

Turnwald, B. P., \& Crum, A. J. (2019). Smart food policy for healthy food labeling: Leading with taste, not healthiness, to shift consumption and enjoyment of healthy foods. Preventive Medicine, 119, 7-13. https://doi.org/10.1016/j.ypmed.2018.11.021 
Turnwald, B. P., Jurafsky, D., Conner, A., \& Crum, A. J. (2017). Reading between the menu lines: Are restaurants' descriptions of "healthy" foods unappealing? Health Psychology, 36(11), 1034-1037. https://doi.org/10.1037/hea0000501

Van Bavel, J. J., \& Pereira, A. (2018). The Partisan Brain: An Identity-Based Model of Political Belief. Trends in Cognitive Sciences, 22(3), 213-224. https://doi.org/10.1016/j.tics.2018.01.004

van den Akker, K., Jansen, A., Frentz, F., \& Havermans, R. C. (2013). Impulsivity makes more susceptible to overeating after contextual appetitive conditioning. Appetite, 70, 73-80.

https://doi.org/10.1016/j.appet.2013.06.092

van der Laan, L. N., de Ridder, D. T. D., Viergever, M. A., \& Smeets, P. A. M. (2011). The first taste is always with the eyes: A meta-analysis on the neural correlates of processing visual food cues. Neurolmage, 55(1), 296-303. https://doi.org/10.1016/j.neuroimage.2010.11.055

Verplanken, B., \& Orbell, S. (2003). Reflections on past behavior: A self-report index of habit strength. Journal of Applied Social Psychology, 33(6), 1313-1330.

Versluis, I., \& Papies, E. K. (2016). The Role of Social Norms in the Portion Size Effect: Reducing normative relevance reduces the effect of portion size on consumption decisions. Frontiers in Psychology, 7, 756. https://doi.org/10.3389/fpsyg.2016.00756

Volkow, N. D., Wang, G. J., Fowler, J. S., Tomasi, D., \& Baler, R. (2012). Food and drug reward: Overlapping circuits in human obesity and addiction. In Brain imaging in behavioral neuroscience (pp. 1-24). Springer. http://link.springer.com/chapter/10.1007/7854_2011_169

Volkow, N. D., Wang, G.-J., Tomasi, D., \& Baler, R. D. (2013). Obesity and addiction: Neurobiological overlaps: Overlaps between drug and food addiction. Obesity Reviews, 14(1), 2-18. https://doi.org/10.1111/j.1467-789X.2012.01031.x

Wang, G.-J., Volkow, N. D., Telang, F., Jayne, M., Ma, J., Rao, M., Zhu, W., Wong, C. T., Pappas, N. R., Geliebter, A., \& Fowler, J. S. (2004). Exposure to appetitive food stimuli markedly activates the human brain. Neurolmage, 21(4), 1790-1797. https://doi.org/10.1016/j.neuroimage.2003.11.026 
Watanabe, S., \& Dawes, C. (1988). The effects of different foods and concentrations of citric acid on the flow rate of whole saliva in man. Archives of Oral Biology, 33(1), 1-5. https://doi.org/10.1016/00039969(88)90089-1

Wehbe, L., Banas, K., \& Papies, E. K. (2021). It's easy to maintain when the changes are small: Exploring sustainability motivated dietary changes from a self-control perspective. Under Review. https://psyarxiv.com/9y3zq

Weingarten, E., Chen, Q., McAdams, M., Yi, J., Hepler, J., \& Albarracín, D. (2016). From primed concepts to action: A meta-analysis of the behavioral effects of incidentally presented words. Psychological Bulletin, 142(5), 472-497. https://doi.org/10.1037/bul0000030

Westbrook, C., Creswell, J. D., Tabibnia, G., Julson, E., Kober, H., \& Tindle, H. A. (2013). Mindful attention reduces neural and self-reported cue-induced craving in smokers. Social Cognitive and Affective Neuroscience, 8(1), 73-84. https://doi.org/10.1093/scan/nsr076

Whitmarsh, L., Poortinga, W., \& Capstick, S. (2021). Behaviour change to address climate change. Current Opinion in Psychology, 42, 76-81. https://doi.org/10.1016/j.copsyc.2021.04.002

Wilson-Mendenhall, C. D., Dunne, J., \& Davidson, R. (2021). Visualizing compassion: Episodic simulation as contemplative practice. https://doi.org/10.31231/osf.io/zbu6k

Wood, W., \& Neal, D. T. (2007). A New Look at Habits and the Habit-Goal Interface. Psychological Review, 114(4), 843-863. https://doi.org/10.1037/0033-295X.114.4.843

Wood, W., \& Rünger, D. (2016). Psychology of Habit. Annual Review of Psychology, 67(1), 289-314. https://doi.org/10.1146/annurev-psych-122414-033417

Wooley, S. C., \& Wooley, O. W. (1973). Salivation to the Sight and Thought of Food: A New Measure of Appetite. Psychosomatic Medicine, 35(2), 136-142.

Wu, L., \& Barsalou, L. W. (2009). Perceptual simulation in conceptual combination: Evidence from property generation. Acta Psychologica, 132(2), 173-189. https://doi.org/10.1016/j.actpsy.2009.02.002 
Xie, H., Minton, E. A., \& Kahle, L. R. (2016). Cake or fruit? Influencing healthy food choice through the interaction of automatic and instructed mental simulation. Marketing Letters, 27(4), 627-644. https://doi.org/10.1007/s11002-016-9412-3

Yokum, S., Ng, J., \& Stice, E. (2011). Attentional Bias to Food Images Associated With Elevated Weight and Future Weight Gain: An fMRI Study. Obesity, 19(9), 1775-1783.

https://doi.org/10.1038/oby.2011.168 
Table 1.

Examples of Supporting Quote from Qualitative Water Drinking Studies

\begin{tabular}{|c|c|c|c|}
\hline Interpretation & Evidence & & Paper \\
\hline $\begin{array}{l}\text { Situated water } \\
\text { drinking habits. } \\
\text { Water drinking is } \\
\text { effortless in one } \\
\text { situation but } \\
\text { effortful in another. } \\
\text { Examples: } \\
\text { University versus } \\
\text { Home and } \\
\text { Mealtimes versus } \\
\text { Work }\end{array}$ & $\begin{array}{l}\text { "It's like I forget to } \\
\text { drink water. I think } \\
\text { as well at uni } \\
\text { everyone else has } \\
\text { always got a bottle } \\
\text { of water, so it's like, } \\
\text { just easier to drink } \\
\text { water than anything } \\
\text { else. And then at } \\
\text { home, I can have a } \\
\text { cup of tea, which is } \\
\text { easier to have a cup } \\
\text { of tea at home than it } \\
\text { is at uni so I'd just } \\
\text { rather have that." - } \\
\text { Jessica (lines 120- } \\
\text { 130) }\end{array}$ & $\begin{array}{l}\text { "it was drummed } \\
\text { into you that you } \\
\text { have like breakfast, } \\
\text { lunch and dinner and } \\
\text { because we work } \\
\text { right over lunchtime } \\
\text { and probably right } \\
\text { over dinner time, } \\
\text { sometimes ... it's not } \\
\text { until your body's } \\
\text { actually at the point } \\
\text { of sheer craving it. } \\
\text { 'shit I haven't had a } \\
\text { drink today, I should } \\
\text { have a drink."”-- } \\
\text { Emily (lines } 401- \\
412 \text { ) }\end{array}$ & \\
\hline $\begin{array}{l}\text { Relying on } \\
\text { infrequently } \\
\text { occurring contextual } \\
\text { cues. Example: } \\
\text { Situated water } \\
\text { drinking habit } \\
\text { during their evening } \\
\text { routine only happens } \\
\text { once during the day. }\end{array}$ & $\begin{array}{l}\text { "after I've brushed } \\
\text { my teeth at night, I } \\
\text { guzzle water like an } \\
\text { absolute Goblin } \\
\text { straight from the tap. } \\
\text { And it's really weird } \\
\text { because I don't really } \\
\text { do that at any other } \\
\text { point through the } \\
\text { day" - Sarah (lines } \\
\text { 85-88) }\end{array}$ & $\begin{array}{l}\text { "I drink a glass of } \\
\text { water and then I go } \\
\text { through and wash } \\
\text { my face and hands } \\
\text { and clean my teeth } \\
\text { before I go to bed." } \\
\text { - Joyce (lines 180- } \\
\text { 189) }\end{array}$ & Rodger et al., 2021 \\
\hline $\begin{array}{l}\text { Relying on thirst, } \\
\text { which can lack } \\
\text { salience and be } \\
\text { suppressed or } \\
\text { ignored }\end{array}$ & $\begin{array}{l}\text { "it's not till the end } \\
\text { of the day. If like } \\
\text { I've not peed all day } \\
\text { and I'm like, 'oh my } \\
\text { god I've actually not } \\
\text { drank anything } \\
\text { today,"”- Jessica } \\
\text { (lines } 156-165 \text { ) }\end{array}$ & $\begin{array}{l}\text { "sometimes I just } \\
\text { like, ignore that } \\
\text { feeling of being } \\
\text { thirsty until I'm like, } \\
\text { you know, like } \\
\text { lightheaded or } \\
\text { something." - Nelly } \\
\text { (lines 424-427) }\end{array}$ & \\
\hline $\begin{array}{l}\text { Lack of reward in } \\
\text { low water drinkers }\end{array}$ & $\begin{array}{l}\text { "I drink water } \\
\text { because I feel I } \\
\text { should for my body's } \\
\text { functioning. Very } \\
\text { occasionally when I } \\
\text { am very thirsty or it }\end{array}$ & $\begin{array}{l}\text { "It's difficult } \\
\text { because it doesn't } \\
\text { taste of much" [P7b] }\end{array}$ & $\begin{array}{c}\text { Rodger \& Papies } \\
2021\end{array}$ \\
\hline
\end{tabular}


is very hot, is

drinking water

anything other than a

chore" [P13b]

Reward in high

"I don't just drink

"I can notice a huge

water drinkers

water for the sake of

difference in my

it. I drink it because

mood and how well

I enjoy the

I operate on a day-

experience, how it to-day basis when I

makes me feel and

am properly

the overall health

hydrated versus not"

benefits I notice"

[P16a] 


\section{CORE ASSUMPTIONS OF THE GROUNDED COGNITION THEORY OF DESIRE AND MOTIVATED BEHAVIOUR}

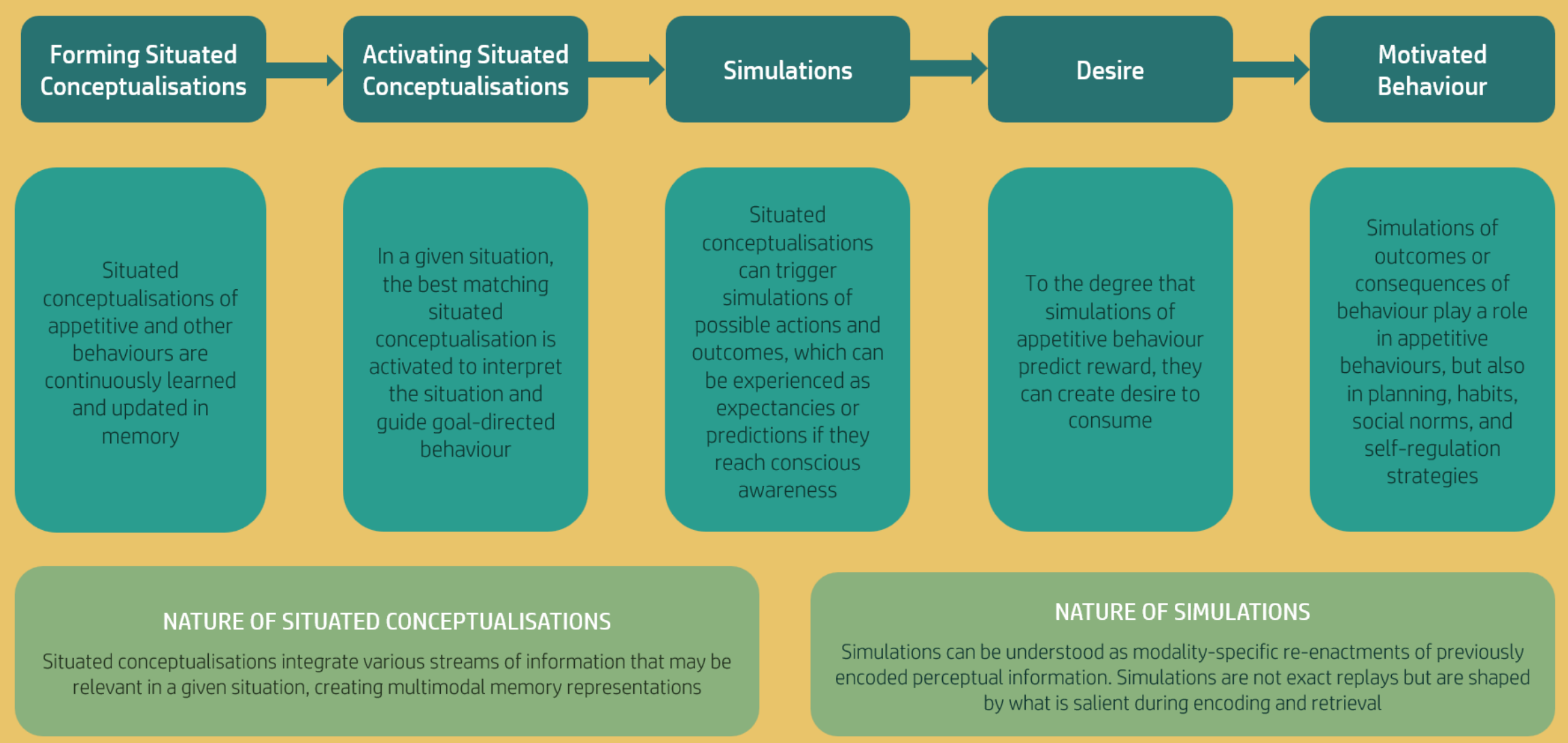

Figure 1. Core assumptions of the grounded cognition theory of desire and motivated behaviour 


\section{Percentages of features generated for each drink product}

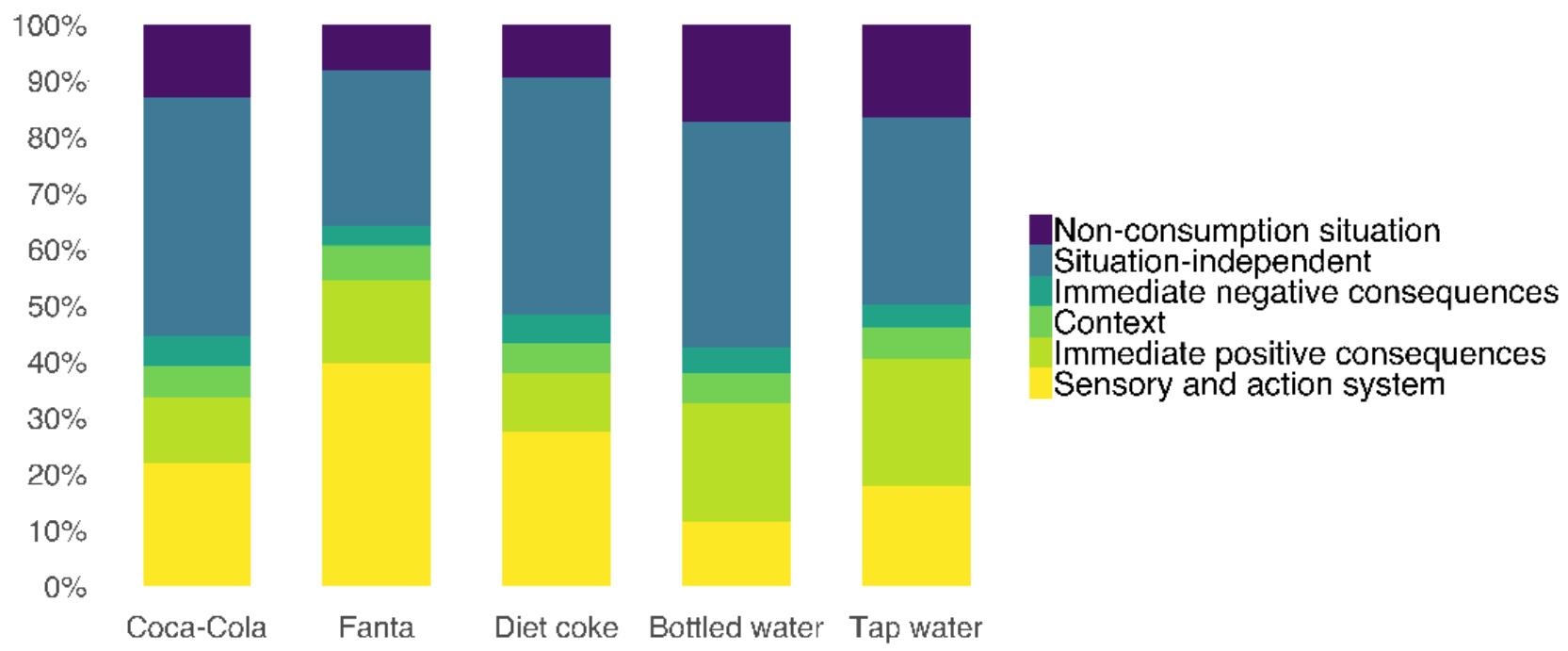

Figure 2. Percentage of features for each drink for the categories of consumption situation (containing features related to sensory and action system, immediate positive consequences, context, and immediate negative consequences), nonconsumption situation, and situation-independent features.

Reprinted from "Flavors of desire: cognitive representations of appetitive stimuli and their motivational implications," by Papies, E., et al. (2021). Journal of Experimental Psychology: General, in press. 


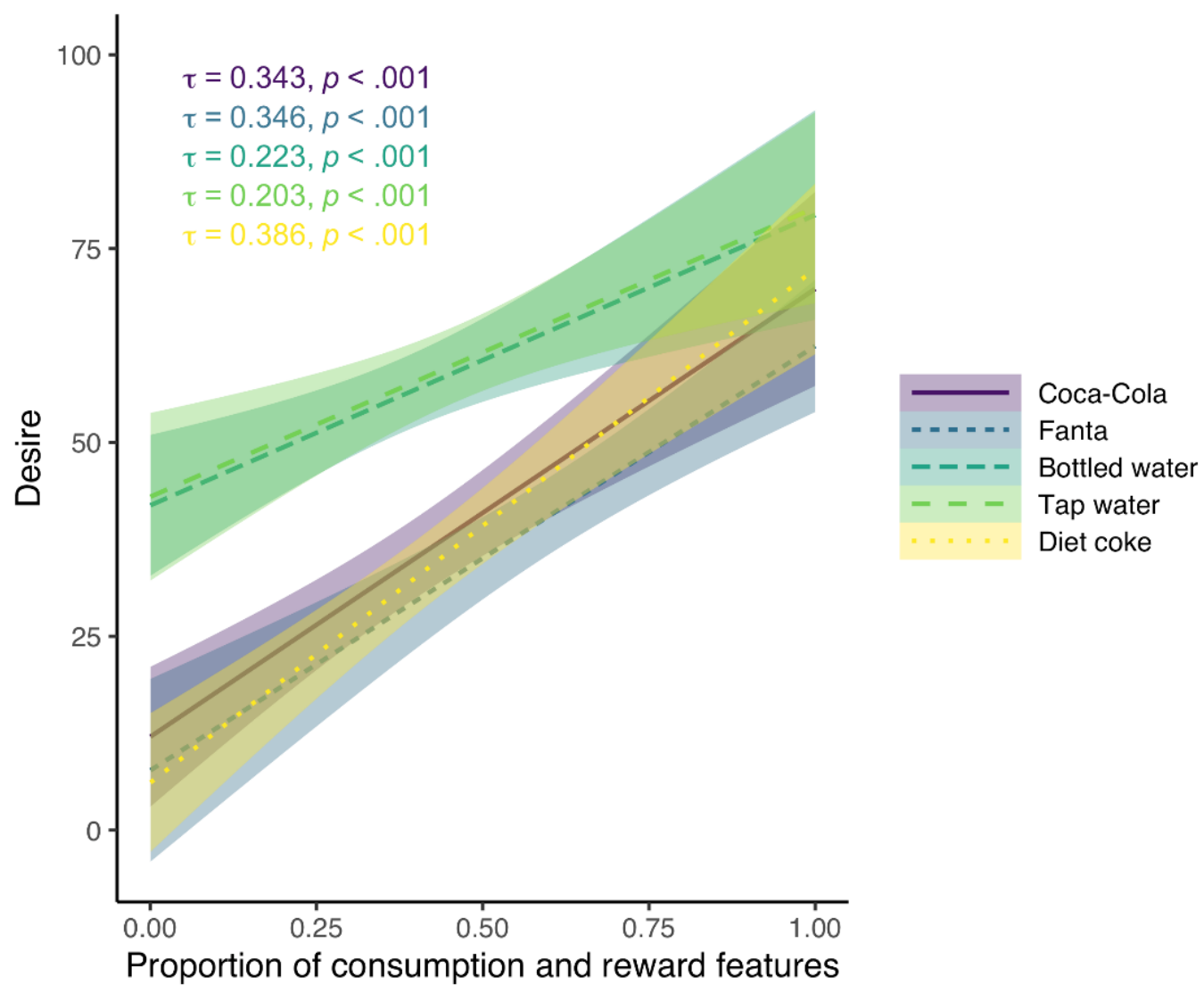

Figure 3. Regression lines (with 95\% CI) and correlation coefficients (Kendall) between desire to consume and proportion of consumption and reward features across drink categories in Experiment 2.

Reprinted from "Flavors of desire: cognitive representations of appetitive stimuli and their motivational implications," by Papies et al. (2021). Journal of Experimental Psychology: General, in press. 

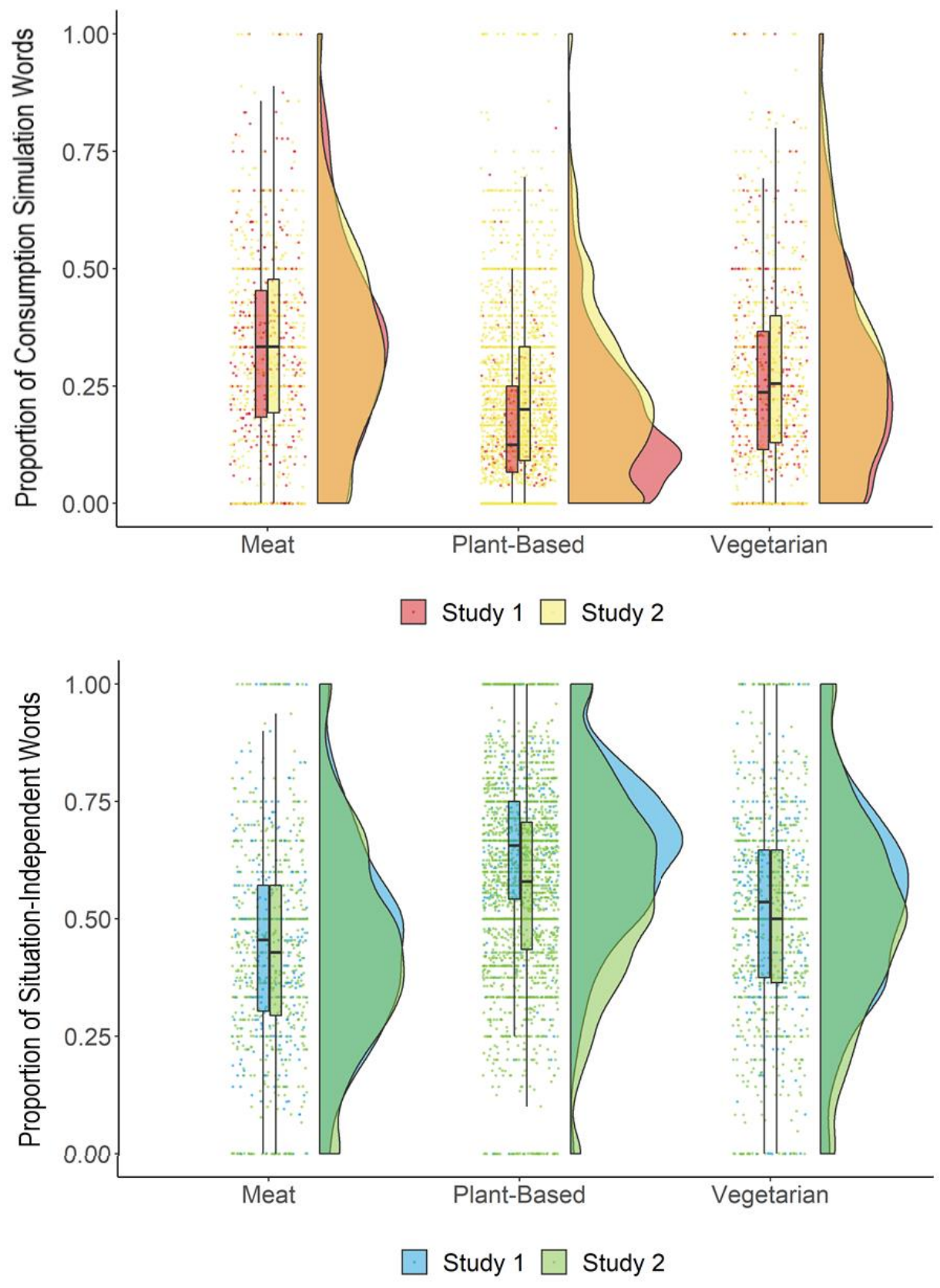

Figure 4: Raincloud plots of the consumption simulation and situation-independent category proportion means in hashtags on Instagram posts about meat foods, plant-based foods, and vegetarian foods. The boxplots represent the proportion means and the scatterplots and violin plots represent the distribution of the proportions for all observations.

Reprinted from "Pleasure vs. Identity: More Eating Simulation Language in Meat Posts than Plantbased Posts on Social Media" by Davis \& Papies (2021, September 16). OSF Preprints,

DOI:10.31219/osf.io/k7yhg. 


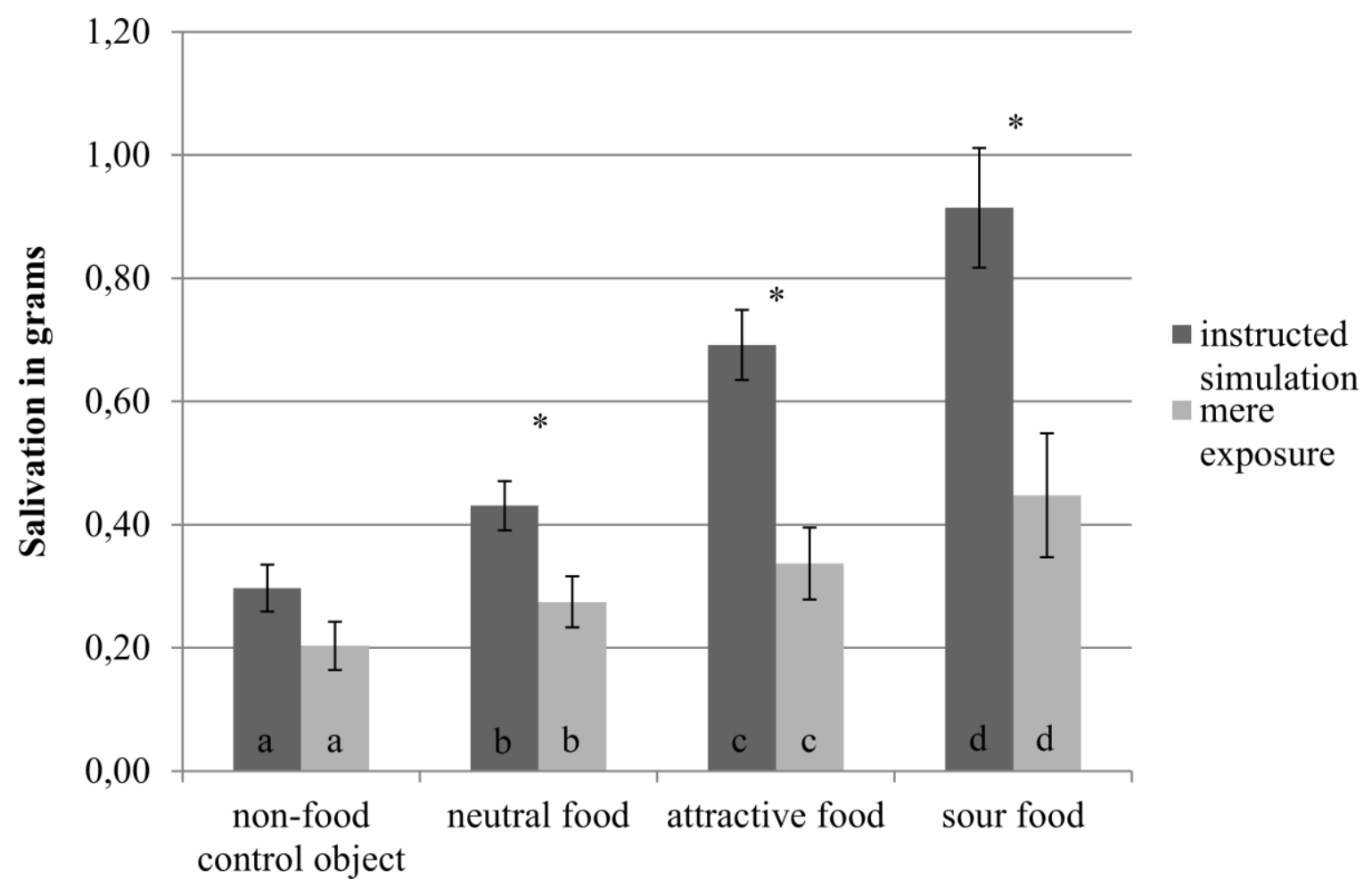

Figure 5: Salivary responses to different objects in the instructed simulation and mere exposure conditions. Different letters indicate significant differences between objects within a condition, $p$ $<.05$. Asterisks indicate significant differences between conditions for an object, $p<.05$. Error bars represent standard errors from the mean.

Adapted from Keesman, M., Aarts, H., Vermeent, S., Häfner, M., \& Papies, E. K. (2016). Consumption simulations induce salivation to food cues. PLOS ONE, 11(11), e0165449. https://doi.org/10.1371/journal.pone.0165449 


\section{IMPLICATIONS OF THE GROUNDED COGNITION THEORY OF DESIRE AND MOTIVATED BEHAVIOUR FOR BEHAVIOUR CHANGE}

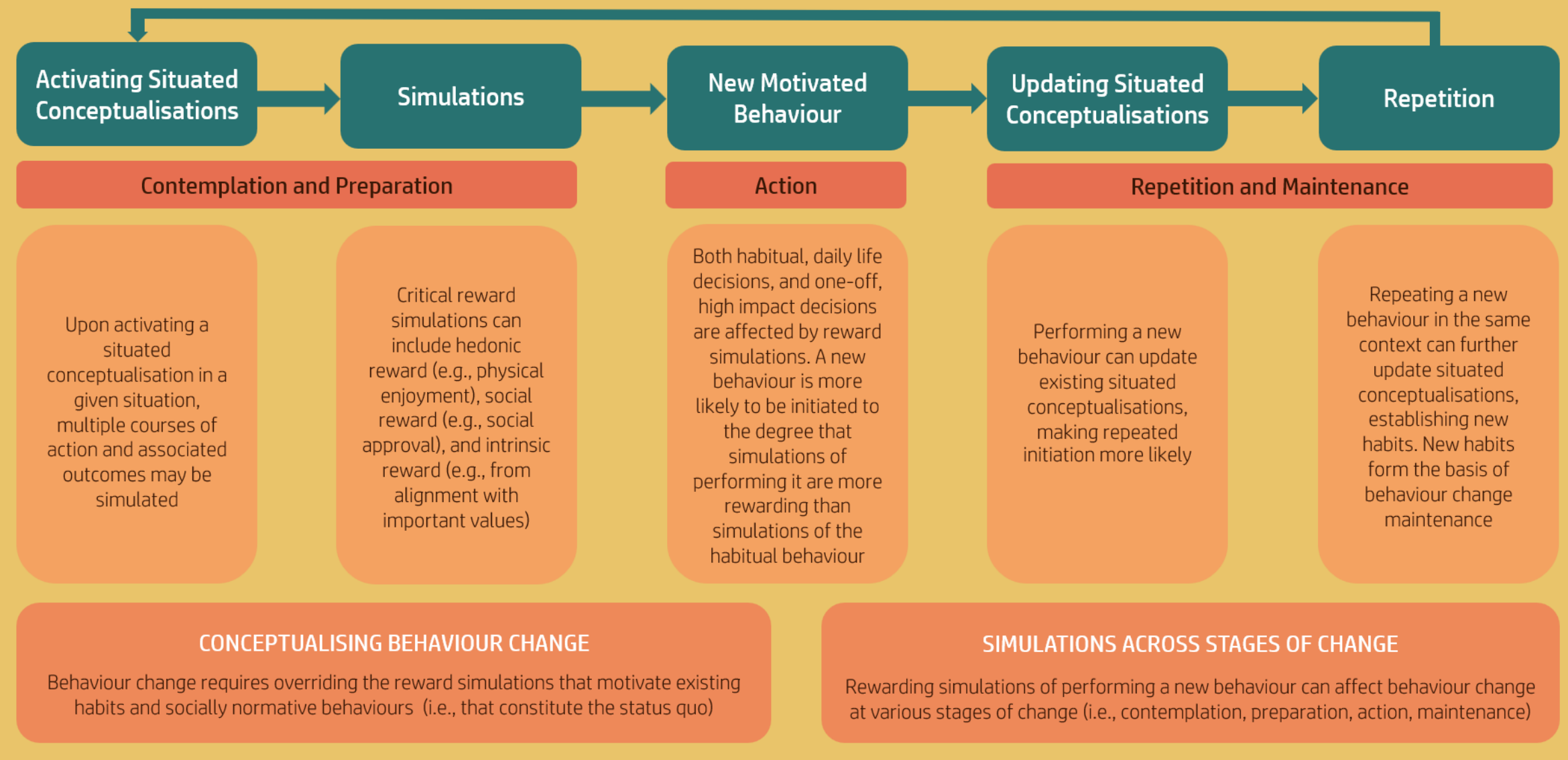

Figure 6. Implications of the grounded cognition theory of desire and motivated behaviour for behaviour change. 